DOUGLAS D'ASSUNÇÃO

CIRCUITO PIEZELÉTRICO CHAVEADO PARA CONTROLE DE VIBRAÇÕES E COLETA DE ENERGIA EM UMA SEÇÃO TÍPICA AEROELÁSTICA

SÃO CARLOS 
DOUGLAS D'ASSUNÇÃO

\section{CIRCUITO PIEZELÉTRICO CHAVEADO PARA CONTROLE DE VIBRAÇÕES E COLETA DE ENERGIA EM UMA SEÇÃO TÍPICA AEROELÁSTICA}

Dissertação apresentada à Escola de Engenharia de São Carlos, da Universidade de São Paulo, como requisito parcial para a obtenção do título de Mestre em Engenharia Mecânica.

Área de Concentração: Aeronaves

Orientador: Prof. Dr. Carlos De Marqui Júnior

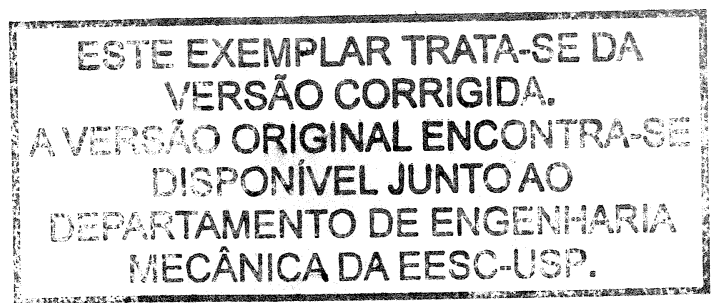

\section{SÃO CARLOS}


AUTORIZO A REPRODUÇÃO TOTAL OU PARCIAL DESTE TRABALHO, POR QUALQUER MEIO CONVENCIONAL OU ELETRÔNICO, PARA FINS DE ESTUDO E PESQUISA, DESDE QUE CITADA A FONTE.

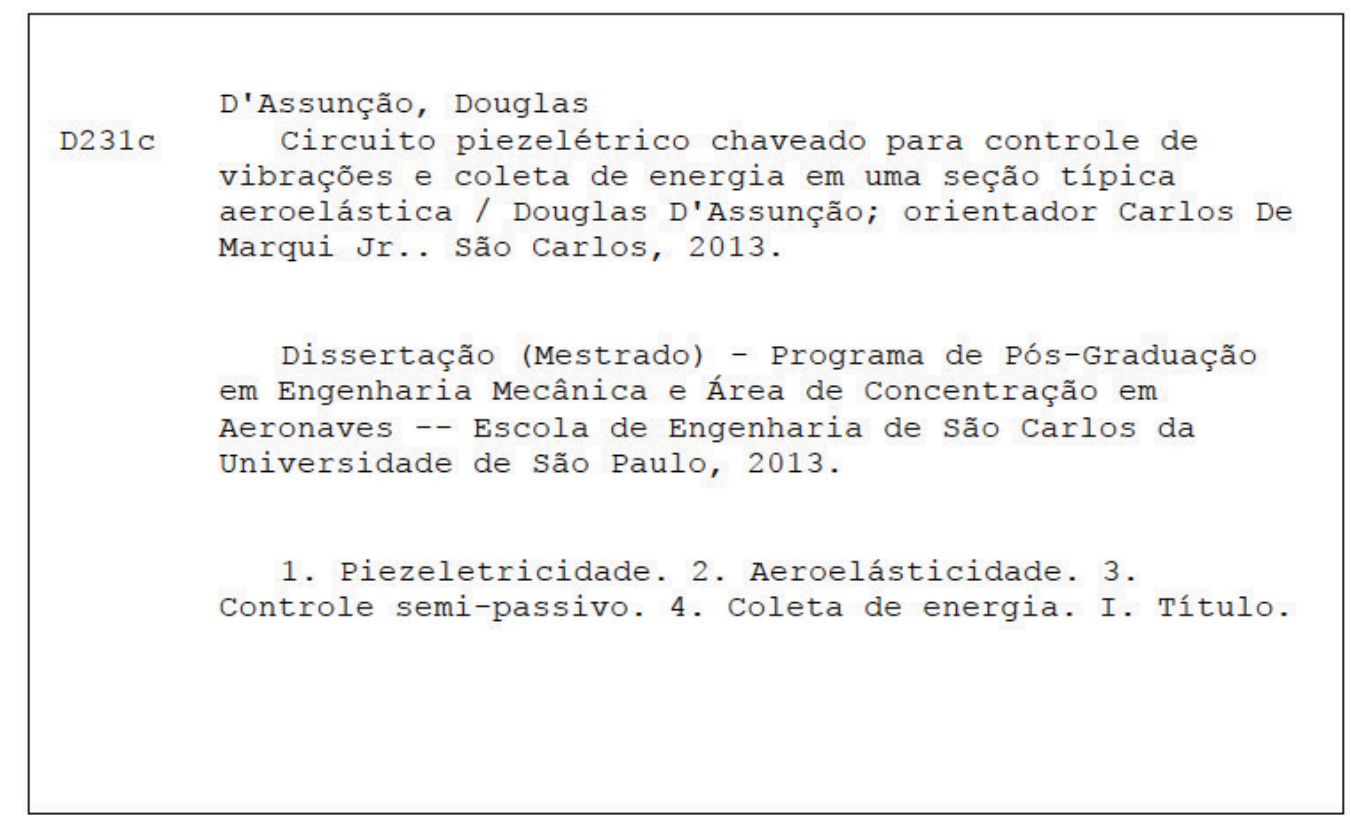




\section{FOLHA DE JULGAMENTO}

Candidato: Bacharel DOUGLAS D'ASSUNÇÃO.

Título da dissertação: "Circuito piezelétrico chaveado para controle de vibrações e coleta de energia em uma seção típica aeroelástica".

Data da defesa: 14/06/2013

Comissão Julgadora:

Prof. Dr. Carlos De Marqui Junior (Orientador)

(Escola de Engenharia de São Carlos/EESC)

Prof. Associado Marcelo Areias Trindade

(Escola de Engenharia de São Carlos/EESC)

Prof. Dr. Fred Nitzsche

(Carleton University/Canadá)

\section{Resultado:}
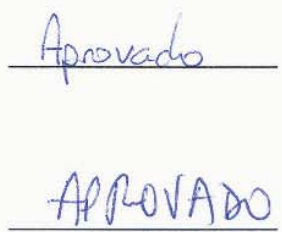

aprovado

Coordenador do Programa de Pós-Graduação em Engenheira Mecânica: Prof. Associado Marcelo Areias Trindade

Presidente da Comissão de Pós-Graduação:

Prof. Titular Denis Vinicius Coury 

A meus pais, que sempre tiveram em suas mãos cabos de enxadas, para que nas minhas houvessem canetas. 



\section{AGRADECIMENTOS}

Começo agradecendo ao meu orientador, o Prof. Dr. Carlos de Marqui Jr., que sempre esteve a disposição para transmitir seus conhecimentos e experiência, que sempre ofereceu apoio nos momentos mais difíceis desta caminhada.

Ao Prof. Dr. Flávio Marques, por conceder o uso do laboratório, onde foi executada todas as experiências e medidas deste trabalho.

Aos técnicos Cláudio, Galo e Mário, por estarem sempre a disposição na aquisição, empréstimo, confecção e manutenção de equipamento pertinentes ao trabalho. Às "meninas" da secretaria Gisele e Mazé, que sempre me ajudaram com as burocracias, impressões, cafezinhos, etc...

Ao pessoal do grupo Aerodesign, por emprestar a bomba a vácuo por muitas vezes.

Ao Ms. Vagner Candido de Sousa, que através de discussões sempre trouxe contribuição ao meu trabalho, e pelos trabalhos em conjunto. E ao Ms. Ricardo Medeiros, pela ajuda inicial no manuseio de alguns equipamentos.

Ao Conselho Nacional de Desenvolvimento Científico e Tecnológico (CNPq), pela concessão da bolsa de mestrado e pelo apoio financeiro para a pesquisa, aqui desenvolvida.

Ao Instituto Nacional de Ciência e Tecnologia (INCT - CNPq), pelo apoio financeiro.

À Escola de Engenharia de São Carlos e ao Departamento de Aeronáutica.

Gostaria também de agradecer, as pessoas que fazem parte do meu dia-a-dia, e que influenciam na minha constante formação pessoal, e que esteve ao meu lado durante todo esse trabalho.

Primeiramente, à meus pais Juscelino D'Assunção e Elzita Aguiar D'Assunção. Agradeço por serem minha base, por me ensinar a enfrentar as dificuldades com sabedoria e cabeça erguida. 
Agradeço por me darem as mãos nos momentos difíceis e comemorarem comigo nos momentos de alegria, por serem meu exemplo. À vocês que agradeço por tudo, e é por vocês que sempre sigo em frente. Obrigado!

À minhas irmãs Jussara, Iara e Fernanda, pelo apoio incondicional. Agradeço muito a vocês por fazerem parte da minha vida. Melhores irmãs não poderia ter. E também à minha princesa Letícia, que só com um sorriso me faz esquecer qualquer problema, que me cura qualquer dor.

À Moab, pela paciência por todos esses anos. Por muitas vezes ser meus braços, minhas pernas, meu coração, meu porto. À minha outra princesa Mel, por sempre me encher de carinho e afeto, por sempre me dar alegrias.

À Marcela Dias, por sempre me ajudar em tudo que estava ao seu alçance, agradeço-lhe por tudo.

Ao meu irmão Phillip Springer, pela amizade, parceria, e por que não, pelas diferenças. Amizade que levarei para sempre.

Ao Paulo Alberto, por sempre estar disposto a ajudar, e por sempre nos puxar para cima com seu alto astral, com seus ensinamentos e ideais, que nos contamina de ânimo na busca de um futuro melhor.

À todos os companheiros de pós-graduação, e em especial ao Alexandre (Comandante Simões), Marcelo e "Os colombianos", William (Cocoliso), David, Jonathan e Andres, pelas rodas de conversa regadas a café, a churrasco e cerveja, a comida do R.U., ou simplesmente um bom papo. 
"A leitura após certa idade distrai excessivamente o espírito humano das suas reflexões criadoras. Todo o homem que lê de mais e usa o cérebro de menos adquire a preguiça de pensar." 



\section{SUMÁRIO}

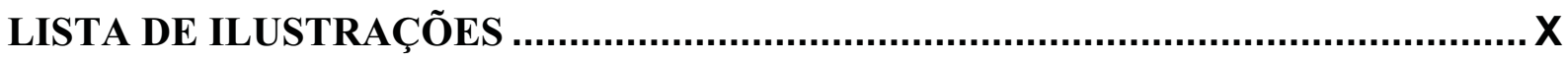

RESUMO

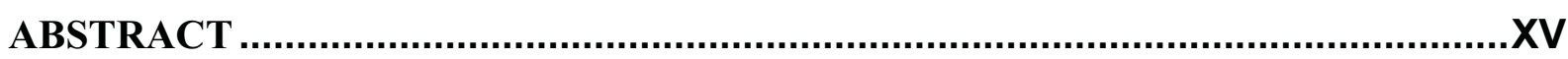

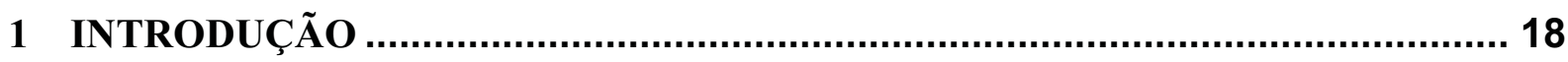

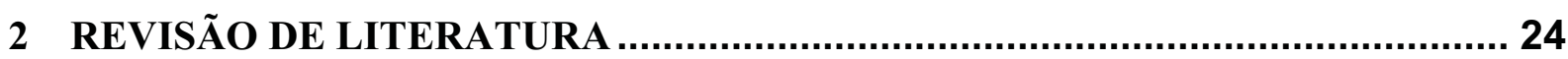

2.1 ESTRATÉGIAS DE CONTROLE UTILIZANDO MATERIAIS PIEZELÉTRICOS. 24

2.1.1 Controle Ativo Utilizando Materiais Piezelétricos....................................... 24

2.1.2 Controle Passivo Utilizando Materiais Piezelétricos ................................... 26

2.1.3 Controle Utilizando Materiais Piezelétricos e Circuitos Chaveados .............. 28

2.1.3.1 Controle Semi-Passivo Utilizando Materiais Piezelétricos......................... 29

2.1.3.2 Controle Semi-Ativo Utilizando Materiais Piezelétricos ........................... 34

2.2 CONVERSÃO PIEZELÉTRICA DE ENERGIA …............................................... 35

3 DESENVOLVIMENTO DO CIRCUITO CHAVEADOR .................................... 42

4 RESULTADOS E DISCUSSÃO ….............................................................. 50

4.1 CONTROLE SEMI-PASSIVO EM UMA VIGA ENGASTADA …....................... 50

4.2 CONTROLE SEMI-PASSIVO DE OSCILAÇÕES AEROELÁSTICAS .................... 53

4.2.1 Controle Semi-Passivo de Oscilações Aeroelásticas Lineares .................... 58

4.2.2 Controle Semi-Passivo de Oscilações Aeroelásticas Não Lineares.............. 67

4.2.3 Ciclo de Trabalho do Sistema Chaveado ................................................... 75

4.3 COLETA PIEZOAEROELÁSTICA DE ENERGIA UTILIZANDO CIRCUITO

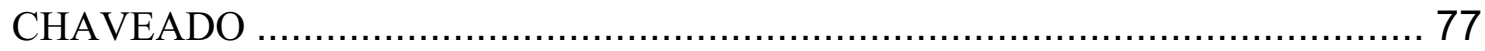

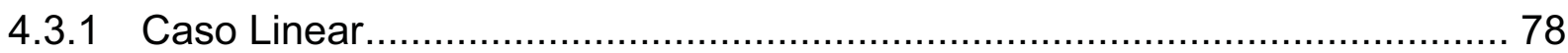

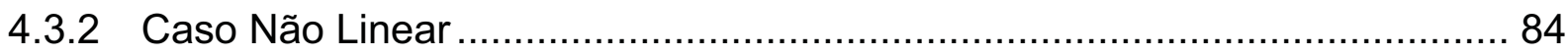

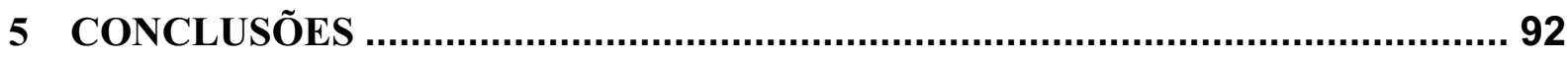

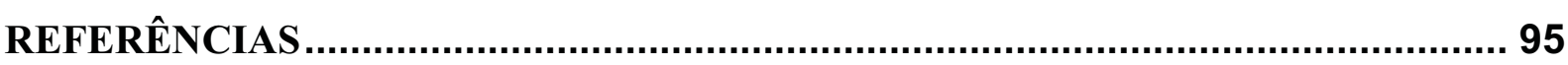




\section{LISTA DE ILUSTRAÇÕES}

FIGURA 1 - Esquema Representativo dos Circuitos Shunt passivos: (a) Shunt

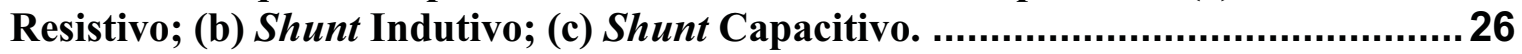

FIGURA 2 - Esquema Representativo dos Circuitos Shunt Semi-passivos: (a) State Switching; (b) SSDS; (c) SSDI.

FIGURA 3 - Comparação das tensão elétrica em um piezelétrico: (a) em Circuito Aberto; (b) com SSDS; (c) com SSDI.

FIGURA 4 - Representação do circuito shunt SSDV, proposto por Lefeuvre (2006) .. 35

FIGURA 5 - Configurações dos eletrodos das piezocerâmicas: (a) Eletrodos

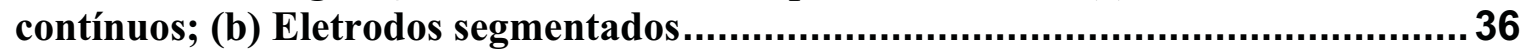

FIGURA 6 - Esquema do Circuito Chaveador Autônomo ....................................... 44

FIGURA 7 - Esquema do Circuito Chaveador Autônomo Completo ........................... 45

FIGURA 8 - Sinal de tensão elétrica viltrado pelo detector envelope, para referência

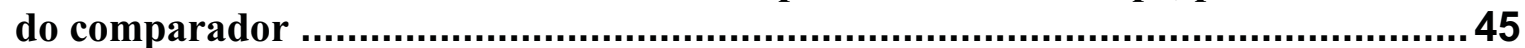

FIGURA 9 - Representação das relações elétricas de um transistor PNP................... 46

FIGURA 10 - Sinal de tensão elétrica da piezocerâmica e do detector envelope caso SSDS 47

FIGURA 11 - Circuito chaveador autônomo de onda completa adaptado para a coleta de energia

FIGURA 12 - Foto do experimento e sistema de aquisição para o teste da viga engastada 51

TABELA 1 - COMPONENTES DO CIRCUITO CHAVEADOR

GRÁFICO 1 - Efeito do uso do circuito chaveador na FRF de velocidade da placa engastada, com frequência de ressonância de $91,5 \mathrm{~Hz}$

FIGURA 13 - (a) esquema de uma seção típica; (b) esquema da seção típica considerando o acoplamento eletromecânico

FIGURA 14 - Fotos da Estrutura da Seção Típica: (a) Vigas de Flexão e Flunge; (b) Cantoneira com Fio Mola.

FIGURA 15 - Fotos da Estrutura da Seção Típica: (a) Seção Típica em posição no túnel de vento; (b) Pastilha piezocerâmica colada na Viga de Aço............................ 55

FIGURA 16 - Foto do Sistema de Aquisição de Dados utilizado no Experimento........56

TABELA 2 - COMPONENTES DO CIRCUITO CHAVEADOR UTILIZADO NA SEÇÃO TÍPICA

FIGURA 17 - Circuito chaveador com diodos D7 e D8, adaptados para o experimento com a Seção Típica.

TABELA 3 - PARÂMETROS DO SISTEMA DE 2-GDL

GRÁFICO 2 - Deslocamentos da seção típica medidos experimentalmente na velocidade de 11,7 m/s e piezocerâmicas em circuito aberto: (a) Plunge; (b) Pitch. . 59 
GRÁFICO 3 - Deslocamentos da seção típica medidos experimentalmente na velocidade de 12,0 m/s e piezocerâmicas em circuito aberto: (a) Plunge; (b) Pitch.. 59

GRÁFICO 4 - Deslocamento linear medido na velocidade de $10,0 \mathrm{~m} / \mathrm{s}$, para cálculo da razão de amortecimento: (a) Circuito Aberto; (b) SSDS; (c) SSDI.

GRÁFICO 5 - Repostas da Seção Típica, sob escoamento de 12,0 m/s, com acionamento do SSDS no tempo 10,6 s: (a) Plunge; (b) Pitch.; (c) Tensão elétrica. . 61

GRÁFICO 6 - Repostas da Seção Típica, sob escoamento de 12,0 m/s, com acionamento do SSDI no tempo 10,4 s: (a) Plunge; (b) Pitch.; (c) Tensão elétrica... 62

GRÁFICO 7 - Detalhe do sinal de tensão elétrica e processo de chaveamento: (a) SSDS; (b) SSDI.

GRÁFICO 8 - Repostas da Seção Típica, sob velocidade de 12,7 m/s, utilizando a técnica SSDS: (a) Plunge; (b) Pitch.; (c) Tensão elétrica.

GRÁFICO 9 - Repostas da Seção Típica, sob velocidade de 12,9 m/s, utilizando a técnica SSDS: (a) Plunge; (b) Pitch.; (c) Tensão elétrica.

GRÁFICO 10 - Repostas da Seção Típica, sob velocidade de 13,1 m/s, com SSDI: (a) Plunge; (b) Pitch.; (c) Tensão elétrica.................................................................... 66

GRÁFICO 11 - Repostas da Seção Típica, sob velocidade de 13,2 m/s, com SSDI: (a) Plunge; (b) Pitch.; (c) Tensão elétrica.

GRÁFICO 12 - Repostas da Seção Típica, sob velocidade de 10,3 m/s, em circuito aberto: (a) Plunge; (b) Pitch.; (c) Tensão elétrica.

GRÁFICO 13 - Repostas da Seção Típica, sob escoamento de 10,4 m/s, em circuito aberto: (a) Plunge; (b) Pitch.; (c) Tensão elétrica.

GRÁFICO 14 - Repostas da Seção Típica, sob velocidade de 10,9 m/s, em circuito aberto: (a) Plunge; (b) Pitch.; (c) Tensão elétrica.

GRÁFICO 15 - Repostas da Seção Típica, sob velocidade de 10,4 m/s, com acionamento do SSDS, após t = 40s: (a) Plunge; (b) Pitch.; (c) Tensão elétrica....... 70

GRÁFICO 16 - Repostas da Seção Típica, sob velocidade de 10,4 m/s, com acionamento do SSDI, após t $=40 \mathrm{~s}$ : (a) Plunge; (b) Pitch.; (c) Tensão elétrica.

GRÁFICO 17 - Detalhe do sinal de tensão elétrica, após acionamento do: (a) SSDS; (b) SSDI. 72

GRÁFICO 18 - Repostas da Seção Típica, sob velocidade de 11,2 m/s, com SSDS:

(a) Plunge; (b) Pitch.; (c) Tensão elétrica.

GRÁFICO 19 - Repostas da Seção Típica, sob velocidade de 11,4 m/s, em circuito aberto: (a) Plunge; (b) Pitch.; (c) Tensão elétrica.

GRÁFICO 20 - Repostas da Seção Típica, sob velocidade de 11,6 m/s, SSDI: (a) Plunge; (b) Pitch.; (c) Tensão elétrica.

GRÁFICO 21 - Repostas da Seção Típica, sob velocidade de 11,7 m/s, SSDI: (a) Plunge; (b) Pitch.; (c) Tensão elétrica.

GRÁFICO 22 - Comparação do Ciclo de Trabalho do SSDS com SSDI, para o caso linear. 76 
GRÁFICO 23 - Comparação do Ciclo de Trabalho do SSDS com SSDI, para o caso não linear. 77

GRÁFICO 24 - Tensão elétrica obtida com o Gerador Básico.

GRÁFICO 25 - Potência obtida com o gerador básico, onde a potência máxima gerada foi de $3,5 \mathrm{~mW}$, fornecida pela resistência de $700 \mathrm{k} \Omega$.

GRÁFICO 26 - Tensão elétrica gerada pelo SSHS.

GRÁFICO 27 - Potência obtida com o SSHS, onde a potência máxima gerada foi de $6,8 \mathrm{~mW}$, fornecida pela resistência de $700 \mathrm{k} \Omega$.

GRÁFICO 28 - Tensão elétrica gerada pelo SSHI.

GRÁFICO 29 - Potência obtida com o SSHI, onde a potência máxima gerada foi de $9,1 \mathrm{~mW}$, fornecida pela resistência de $700 \mathrm{k} \Omega$. .

GRÁFICO 30 - Tensão elétrica obtida com o Gerador Básico.

GRÁFICO 31 - Potência obtida com o Gerador Básico, onde a potência máxima gerada foi de $7,8 \mathrm{~mW}$, fornecida pela resistência de $700 \mathrm{k} \Omega$.

GRÁFICO 32 - Tensão elétrica gerada pelo SSHS.

GRÁFICO 33 - Potência obtida com o SSHS, onde a potência máxima gerada foi de $15,7 \mathrm{~mW}$, fornecida pela resistência de $700 \mathrm{k} \Omega$.

GRÁFICO 34 - Tensão elétrica gerada pelo SSHI.

GRÁFICO 35 - Potência obtida com o SSHI, onde a potência máxima gerada foi de $25,5 \mathrm{~mW}$, fornecida pela resistência de $700 \mathrm{k} \Omega$. 


\section{RESUMO}

D'Assunção, D. Circuito piezelétrico chaveado para controle de vibrações e coleta de energia em uma seção típica aeroelástica. 2013. Dissertação (mestrado) - Escola de Engenharia de São Carlos, Universidade de São Paulo, São Carlos, 2013.

Os materiais inteligentes têm sido utilizados em problemas de controle de vibrações e conversão de energia mecânica em energia elétrica. Apesar das diferentes opções existentes, os piezelétricos têm recebido grande atenção devido a facilidade de instalação, além de possibilidade de uso como sensores ou atuadores. Em termos de sistemas de controle utilizando materiais piezelétricos, dois grandes grupos podem ser encontrados: os controladores passivos e os ativos. Os controladores ativos utilizam o efeito piezelétrico inverso e apresentam bom desempenho na redução de vibrações. Entretanto, apresentam desvantagens relacionadas à complexidades de uma lei de controle, necessidade de equipamentos externos e, potencialmente, exigem elevada potência de atuação. Por outro lado, os controladores passivos utilizam circuitos elétricos simples, compostos somente por elementos elétricos passivos. Apesar de serem de fácil implementação prática, apresentam bom desempenho em faixas restritas de frequências. Os controladores semi-passivos, surgiram como uma alternativa aos pontos negativos dos controladores passivos e ativos. Nestes novos sistemas, o material piezelétrico instalado na estrutura a ser controlada é conectado e desconectado a um circuito shunt de forma sincronizada com as vibrações mecânicas. Em geral, a conversão eletromecânica de energia é amplificada, assim como o efeito shunt damping. Dessa forma, os circuitos chaveados têm sido utilizados tanto como controladores semi-passivos quanto em problemas de coleta piezelétrica de energia. Neste trabalho, o controle piezelétrico semi-passivo de oscilações aeroelásticas lineares e não lineares, assim como a coleta piezelétrica de energia a partir das mesmas condições, são investigados experimentalmente. Uma seção típica com dois graus de liberdade e acoplamento eletromecânico é utilizada nos experimentos. Dois tratamentos não lineares do sinal elétrico proveniente dos piezelétricos são utilizados. Primeiro, o chaveamento a partir da condição de circuito aberto para uma resistência muito baixa, próxima ao curto circuito, e posteriormente, o chaveamento da condição de circuito aberto para um indutor. Um circuito chaveador autônomo (que não depende de fontes externas de energia) é apresentado. $\mathrm{O}$ desempenho dos dois sistemas no controle de flutter, e também de oscilações em ciclo limite, são discutidos. Os resultados mostraram um aumento na velocidade de flutter de até $8,8 \% \mathrm{e}$ $11,5 \%$, com chaveamento em uma resistência e em um indutor, respectivamente. No caso de coleta de energia a partir de oscilações aeroelásticas lineares e não lineares, o desempenho dos circuitos chaveados são comparados entre si, e com o caso em que uma resistência é considerada no domínio elétrico, resultando em um aumento da potência elétrica de até $101 \%$, para chaveamentos em resistência, e $227 \%$, para chaveamentos em um indutor.

Palavras-chave: Piezeletricidade, aeroelasticidade, controle semi-passivo, coleta de energia 



\begin{abstract}
D’Assunção, D. Piezolectric switching circuit for vibration control and energy harvesting on aeroelastic typical section. 2013. Dissertation - São Carlos School of Engineering, São Paulo University, São Carlos, 2013.

Smart materials have been used in vibration control and also in energy harvesting problems. Although different materials are available, piezoelectric one has received most attention due to ease of installation and possibility of use as sensors or actuators. In general, there are two large categories of vibration control techniques using piezoelectric materials: passive and active control. In active control the reverse piezoelectric effect is used. In general, they present good performance in vibration reduction over a range of frequencies. However, active control has the disadvantages of additional complexities of a control law, additional hardware and the potentially large amount of power required. On the other hand, piezoelectric passive controllers use simple electric circuits composed by passive electrical elements. Although they are simple to implement, the performance of the controlled system is sensitive to the exciting frequency. The semi-passive controllers are a recent alternative to the drawbacks of passive and active controllers. In semi-passive systems, the piezoelectric element is switched in and out of a shunt impedance, in a synchronous way with mechanical vibrations. In general, the electromechanical energy conversion is enhanced as well as the shunt effect damping. Therefore, the switching techniques have been used both in semi-passive control problems and in piezoelectric energy harvesting problems. In this work, semi-passive techniques are experimentally investigated in aeroelastic control and piezoaeroelastic energy harvesting cases. An electromechanically coupled aeroelastic typical section is used in the experiments. Two techniques are investigated, the synchronized switching damping on short and the synchronized switching damping on inductor. An autonomous switching circuit (that does not requires external source of energy) is presented resulting in a self-powered flutter controller. The performance of the two semi-passive techniques is discussed for the linear case, flutter control, as well as limit cycle oscillations control. The linear flutter speed is increased by $8.8 \%$ and $11.5 \%$ when the SSDS and SSDI techniques are used, respectively. In the case of energy harvesting from linear and nonlinear aeroelastic oscillations, the performance of switching techniques is investigated and compared to the case of simple load resistance in the electrical domain. The power output is increased by $101 \%$ for the SSDS case and $227 \%$ for SSDI case.
\end{abstract}

Key words: Piezoelectricity, aeroelasticity, semi-passive control, energy harvesting 

1 INTRODUÇÃO 


\section{INTRODUÇÃO}

O problema de controle de vibrações estruturais tem sido amplamente investigado por diversos grupos de pesquisa. Vibrações indesejadas podem reduzir a vida de uma estrutura devido a fadiga, produzir ruído e evitar que funcionalidades da mesma sejam executadas apropriadamente. Diferentes conceitos de sistemas de controle foram propostos e estudados ao longo dos anos, como mostra os artigos de revisão (SUN et al., 1995), (HOUSNER et al., 1997), (YI; DYKE, S. J., 2000) e (YI et al., 2001).

$\mathrm{O}$ uso de materiais inteligentes em problemas de controle também tem recebido grande atenção nos últimos anos. Apesar da variedade de materiais atualmente disponíveis, os piezelétricos têm sido amplamente utilizados. Eles possuem um bom acoplamento eletromecânico e a capacidade de operar como sensor e/ou atuador, através do efeito piezelétrico direto e inverso, respectivamente. A literatura mostra diversas aplicações em diferentes áreas da engenharia, como por exemplo, na construção civil (CHEN; CHEN, 2004), em sistemas mecânicos (HASSAN et al., 2007) e estruturas aeronáuticas (SHETA et al., 2006).

As técnicas de controle utilizando materiais piezelétricos podem ser divididas em duas grandes áreas, o controle ativo e o controle passivo. No caso de controle ativo, o material piezelétrico (colado sobre a estrutura a ser controlada ou mesmo como um elemento estrutural da mesma) é utilizado como atuador (efeito piezelétrico inverso). Uma voltagem deve ser aplicada ao piezelétrico e uma saída mecânica é produzida com o intuito de reduzir vibrações indesejadas (FULLER et al., 1996). Sensores distribuídos na estrutura e também uma fonte externa de energia são requeridos. Em geral, os controladores ativos possuem um bom desempenho na atenuação de vibrações em uma ampla faixa de frequências, porém, possuem a desvantagem de necessitarem de sensores, projeto de leis de controle, além de implementação prática dependente de equipamentos como fontes de voltagem, unidades de processamento, etc.

Já no caso de controle passivo, o material piezelétrico é ligado a um circuito elétrico passivo (circuito shunt), onde a energia é dissipada. No caso, a energia mecânica (vibrações) é convertida em energia elétrica através do efeito piezelétrico direto. As primeiras aplicações do efeito shunt damping incluem o caso de um circuito resistivo (UCHINO; ISHII, 1988), um circuito resistivo indutivo em série (HAGOOD; VON FLOTOW, 1991) e resistivo indutivo em paralelo (WU, 1996). Apesar de serem de implementação prática mais simples do que os 
controladores ativos, os controladores passivos apresentam bom desempenho na redução de vibrações em faixas restritas de frequências.

No caso particular de problemas aeronáuticos, e em especial, problemas aeroelásticos, são encontrados na literatura diversos trabalhos utilizando materiais piezelétricos para o controle de vibrações. Por exemplo, o controle ativo de flutter utilizando atuadores piezelétricos apresentado por Heeg (1993), o programa da NASA "Piezoelectric Aeroelastic Response Tailoring Investigation (PARTI)" desenvolvido para controle de flutter e atenuação da resposta a rajada (MCGOWAN et al., 1998) e os trabalhos apresentados para controle ativo de buffeting utilizando materiais piezelétricos nas empenagens verticais da aeronave F/A-18 (MOSES, 1997, 1999; DÜRR, 1998; HOPKINS et al., 1998). Uma revisão bastante abrangente sobre o uso de materiais inteligentes em soluções de problemas aeroelásticos é apresentada por Giurgiutiu (2000).

Apesar da literatura apresentar estudos sobre controle ativo de problemas aeroelásticos, algumas questões persistem, como a potência requerida para a atuação, a complexidade de hardware utilizada, além da necessidade de se projetar e implementar leis de controle (MCGOWAN, 1999). Uma alternativa seria a utilização de controladores passivos para amortecer um único modo ou vários modos de vibrar de uma estrutura. No caso, uma fonte externa de energia não é necessária e circuitos elétricos simples poderiam ser utilizados. Alguns artigos reportam a investigação de controladores passivos em problemas aeroelásticos. McGowan (1999) examina numericamente o efeito de um circuito resistivo indutivo (RL) sobre a resposta aeroelástica de uma seção típica com acoplamento eletromecânico em um dos graus de liberdade. A autora conclui que circuitos piezelétricos passivos, podem ser uma boa alternativa para controle de respostas aeroelásticas subcríticas (abaixo da velocidade de flutter).

Já Agneni et al. (2003) utilizam circuitos piezelétricos passivos, RL em série, para o controle de vibrações em um modelo em escala de uma asa de um planador comercial. Eles concluem que o controle passivo tem pouco efeito na expansão do envelope de flutter da aeronave, mas atenuam sensivelmente nas oscilações provenientes de resposta a rajada.

Como usualmente as frequências envolvidas em problemas aeroelásticos são baixas (menores que $20 \mathrm{~Hz}$ ), as indutâncias requeridas no caso de controladores passivos são muito elevadas. Tal fato, leva a necessidade de utilização de indutâncias sintéticas (FLEMING et al., 2000). Entretanto, a resistência interna dos circuitos de indutância sintética, geralmente, reduz 
o desempenho de um controlador passivo resistivo-indutivo, já que a resistência resultante pode ser muito diferente da resistência ótima a ser utilizada.

Os circuitos piezelétricos chaveados, também conhecidos como SSD (Synchronized Switch Damping) (RICHARD et al., 1999), surgiram recentemente como uma alternativa aos controladores passivos e controladores ativos de vibração. A técnica SSD introduz o tratamento não linear do sinal elétrico (tensão elétrica) proveniente dos materiais piezelétricos e resulta em maior conversão de energia mecânica em energia elétrica. Nesta técnica, o material piezelétrico é conectado e desconectado a um circuito shunt de forma sincronizada com as oscilações mecânicas do sistema. Em alguns casos, energia externa pode ser necessária para o acionamento do chaveamento. Assim, estas técnicas são classificadas como semi-passivas.

A partir deste conceito, vários estudos buscaram a supressão de vibrações com circuitos semi-passivos (CLARK, 2000; RICHARD, et al., 2000; GUYOMAR, et al., 2007; LALLART et al., 2008a; DELPERO et al., 2011). Entre as diversas configurações de controladores semi-passivos, destacamos o caso de chaveamento para a condição de curto circuito - SSDS (Synchronized Switch Damping on Short) e o caso de chaveamento para um indutor - SSDI (Synchronized Switch Damping on Inductor).

No caso SSDS, o material piezelétrico é mantido na condição de circuito aberto a maior parte do tempo, exceto por um curto período de tempo, no qual a tensão elétrica é cancelada devido ao chaveamento para uma resistência baixa (condição próxima ao curto circuito). A energia elétrica é dissipada durante o cancelamento e, consequentemente, o efeito shunt damping ampliado. No caso SSDI, a tensão elétrica é invertida devido ao chaveamento para um indutor. Neste caso, além de uma pequena parte da energia sofrer dissipação, a inversão da tensão elétrica resulta em uma força mecânica dissipativa fora de fase com a velocidade, resultando em um aumento do efeito shunt damping. As técnicas SSDS e SSDI apresentam a vantagem de serem estáveis, em alguns casos, não necessitam de uma fonte externa de energia, ou precisam de pouca energia externa, somente para controlar o processo de chaveamento. No caso específico do SSDI, é eliminada a necessidade de altos valores de indutância para controle passivo de vibrações em baixas frequências.

O melhor desempenho na conversão eletromecânica de energia, obtido com as tecnicas SSD, chamou a atenção da comunidade que investiga problemas de coleta piezelétrica de energia. $\mathrm{O}$ objetivo de tais pesquisas é a conversão de energia mecânica, disponível no ambiente, em eletricidade. A coleta de energia através de materiais piezelétricos 
têm recebido grande atenção no meio acadêmico e industrial (BEEBY et al., 2006; ANTON; SODANO, 2007; COOK-CHENNAULT et al., 2008). A motivação vem do avanço no desenvolvimento de componentes elétricos e dispositivos eletrônicos de baixo consumo, que poderiam ser alimentados por sistemas de geração piezelétrica de energia. A geração piezelétrica de energia tem também grande apelo em sistemas remotamente operados e com fontes limitadas de energia, pois abre a possibilidade de uma redução, ou até mesmo, a eliminação do uso de baterias. Tal fato traz benefícios econômicos e também ambientais, que é um assunto amplamente discutidos na atualidade. A maior autonomia de dispositivos remotos implica em maiores intervalos para intervenções de manutenção e a redução do descarte de baterias, que são compostas de materiais poluentes.

Recentemente, alguns autores passaram a investigar a utilização de circuitos piezelétricos chaveados em problemas de coleta de energia (GUYOMAR et al., 2005; BADEL et al., 2006; LALLART et al., 2008b; ZHU et al., 2012; CHEN et al., 2012; LIANG; LIAO, 2012). Vale ressaltar que, em alguns casos, os mesmos circuitos dos casos SSDS e SSDI são utilizados para os problemas de coleta de energia. Entretanto, os casos de coleta de energia são encontrados na literatura como SSHS (Synchronized Switch Harvesting on Short) e SSHI (Synchronized Switch Harvesting on Inductor). Em ambos, há a ampliação da saída elétrica devido a ampliação da conversão eletromecânica, como anteriormente comentado.

No presente trabalho, uma investigação experimental sobre circuitos piezelétricos chaveados é apresentada para dois casos: 1 - controle de oscilações aeroelásticas lineares e não lineares e 2 - coleta piezelétrica de energia a partir de oscilações aeroelásticas lineares e não lineares. Os experimentos em túnel de vento são realizados com uma seção típica aeroelástica de dois graus de liberdade (2GDL), deslocamento angular e deslocamento linear. O acoplamento eletromecânico é adicionado ao GDL de deslocamento linear, através da colagem do material piezelétrico aos elementos estruturais que conferem rigidez a esse GDL. Nos casos não lineares, uma folga é adicionada ao GDL de deslocamento angular, resultando em um sistema bilinear.

As técnicas SSDS e SSDI foram utilizadas para o controle de flutter e de oscilações aeroelásticas no pós flutter com sucesso. Também, no caso aeroelástico não linear, oscilações em ciclo limite (LCOs) foram suprimidas com sucesso com as técnicas SSDS e SSDI. Especificamente no caso SSDI, um melhor desempenho no controle de vibrações foi observado e um valor aceitável e prático de indutância pôde ser utilizado. Para coleta de energia, as técnicas SSHS e SSHI foram utilizadas para a conversão piezoaeroelástica de 
energia no caso linear e não linear. Os resultados foram comparados entre si e também com o caso em que somente um resistor é considerado no domínio elétrico do problema. A maior potência elétrica foi obtida com a técnica SSDI.

O circuito chaveador apresentado por Lallart et al. (2008a) e Zhu et al. (2012) foi adaptado para o experimento aeroelástico deste trabalho e utilizado em todos os testes. Este circuito não necessita de fonte externa de energia para realizar o processo de chaveamento. Assim, o sistema de controle de flutter aqui apresentado, pode ser classificado como autônomo, ou autoalimentado. Vale destacar que, na literatura de controle aeroelástico utilizando materiais piezelétricos não se encontra a aplicação de controladores semi-passivos autoalimentados, como o apresentado neste trabalho. Além disso, usualmente, estes sistemas são utilizados em casos de vigas ou placas com acoplamento eletromecânico e excitadas a partir de uma fonte externa (shaker), ou seja, condição estável. De forma semelhante, a literatura não apresenta investigações de circuitos chaveados em problemas de coleta de energia em casos aeroelásticos. 
2 REVISÃO DE LITERATURA 


\section{REVISÃO DE LITERATURA}

\subsection{ESTRATÉGIAS DE CONTROLE UTILIZANDO MATERIAIS PIEZELÉTRICOS.}

Conforme discutido no capítulo anterior, os sistemas de controle utilizando materiais piezelétricos podem ser divididos em dois grandes grupos, ativos e passivos. Recentemente, novos sistemas surgiram sendo classificados como semi-passivos e semi-ativos. Apesar de algumas divergências encontradas na literatura sobre a nomenclatura e classificação destes sistemas, no presente trabalho a classificação será baseada no fato de energia externa estar sendo ou não aplicada diretamente ao material piezelétrico. Assim, os controladores compostos por componentes passivos, que não utilizam energia externa, são classificados como passivos. No caso de controle ativo, energia externa é aplicada nos atuadores piezelétricos. No caso semi-passivo, anteriormente discutido, energia externa pode ser necessária para a realização de chaveamento no circuito, mas não diretamente aplicada aos materiais piezelétricos. Já no caso semi-ativo, tensão elétrica é aplicada ao material piezelétrico em curtos períodos de tempo, enquanto que na maior parte do ciclo de trabalho o material piezelétrico trabalha de forma passiva.

\subsubsection{Controle Ativo Utilizando Materiais Piezelétricos}

O controle ativo utiliza o material piezelétrico (através do efeito piezelétrico inverso) como atuador. Este tipo de sistema requer, além dos atuadores, uma fonte externa de energia, sensores e leis de controle, para produzir uma tensão elétrica a ser aplicada nos atuadores com o intuito de atenuar vibrações (FULLER et al., 1996). Diversos autores tem apresentado investigações sobre a utilização de materiais piezelétricos para controle de vibrações (CRAWLEY; DE LUIS, 1987; HAGOOD et al., 1990; CRAWLEY; LAZARUS, 1991; DOSCH et al., 1992). Esta revisão focará na apresentação de alguns casos de controle ativo utilizando materiais piezelétricos em problemas aeroelásticos.

No caso específico de controle de oscilações aeroelásticas com materiais piezelétricos, os trabalhos pioneiros foram apresentados por Crawley; De Luis (1987); Lazarus et al. (1995, 1997). Além desses, a literatura apresenta diversos trabalhos utilizando materiais piezelétricos para o controle de vibrações em casos aeroelásticos. 
Heeg (1993) apresenta um estudo numérico e experimental para controle de flutter de uma seção típica com dois graus de liberdade (2GDL), deslocamento linear e deslocamento angular. O sistema foi projetado de forma que o GDL de deslocamento linear apresentasse instabilidade. O sistema experimental era composto por uma asa rígida associada a vigas elásticas que conferiam a rigidez dos GDLs. Os materiais piezelétricos foram colados nas duas faces da viga que confere rigidez ao GDL de deslocamento linear. Strain gages foram utilizados como sensores nos dois GDLs. Um sistema ativo de controle utilizando os materiais piezelétricos como atuadores possibilitou um aumento de $20 \%$ na velocidade de flutter.

O programa da NASA "Piezoelectric Aeroelastic Response Tailoring Investigation (PARTI)" foi realizado para estudos de controle de flutter e resposta a rajada utilizando atuadores piezelétricos (MCGOWAN et al.,1998). Uma asa em material compósito, com 36 pastilhas piezelétricas coladas em cada lado, foi investigada experimentalmente. As 36 pastilhas piezelétricas eram divididas em 15 grupos, que dependendo do caso estudado, tinham função de atuadores ou sensores. Um dos objetivos foi determinar a configuração ótima de atuação (posicionamento dos atuadores, ou definição dos grupos ativos) de forma a minimizar a potência exigida. Os resultados mostraram um aumento de $12 \%$ na velocidade de flutter e redução de $75 \%$ no momento de flexão devido a rajadas.

Um outro grande programa envolve pesquisas para controle ativo de buffeting utilizando materiais piezelétricos nas empenagens verticais da aeronave F/A-18 (MOSES, 1997, 1999; DÜRR, 1998; HOPKINS et al., 1998). Estes estudos apresentam testes em túnel de vento com um modelo de aeronave em escala dinâmica (MOSES, 1997), até ensaios em solo com uma aeronave real (MCGOWAN et al., 1998; HOPKINS et al. 1998; MOSES, 1999). Em todos os casos os autores reportam uma redução significativa dos níveis de vibração na deriva. Entretanto, o problema de se embarcar na aeronave todos os equipamentos necessários para a alimentação dos atuadores não foi resolvido. Uma revisão bastante abrangente sobre o uso de materiais inteligentes em soluções de problemas aeroelásticos é apresentada por Giurgiutiu (2000).

Apesar da literatura apresentar estudos sobre controle ativo de problemas aeroelásticos, algumas questões persistem, como a potência requerida para a atuação, a complexidade de equipamentos utilizada, além da necessidade de se projetar e implementar leis de controle (MCGOWAN, 1999). Alguns autores passaram a investigar formas alternativas de controle com o intuito de contornar os problemas relacionados ao controle ativo. 


\subsubsection{Controle Passivo Utilizando Materiais Piezelétricos}

Nos sistemas passivos, os eletrodos do material piezelétrico são conectados a circuitos compostos por elemento elétricos passivos. No caso, a energia de vibração mecânica é convertida em energia elétrica através do efeito piezelétrico direto. A energia elétrica é dissipada na parte resistiva do circuito elétrico (circuito shunt) em forma de calor, adicionando amortecimento a estrutura (efeito shunt damping). As primeiras aplicações do efeito shunt damping encontradas na literatura incluem a utilização de circuitos resistivo, indutivo, capacitivo e circuito resistivo-indutivo.

O caso de um circuito resistivo (Figura 1a) foi originalmente apresentado por Uchino; Ishii (1988). A energia elétrica proveniente da conversão eletromecânica é dissipada no resistor, resultando no efeito shunt damping resistivo. Quando um indutor é utilizado no circuito elétrico (FORWARD, 1979), o sistema se comporta como um equivalente elétrico de um absorvedor mecânico não amortecido. Posteriormente, Hagood e von Flotow (1991) investigaram um circuito resistivo-indutivo em série (Figura 1b), cujo comportamento é equivalente ao de um absorvedor mecânico amortecido. Wu (1996) apresentou a formulação de um sistema com um circuito resistivo-indutivo em paralelo e esclareceu alguns pontos relativos a determinação da resistência ótima do caso resistivo-indutivo em série apresentado por Hagood e von Flotow (1991). No caso, capacitivo apresentado na Figura 1c, o efeito é de modificação de rigidez do material piezelétrico e, consequentemente, da rigidez da estrutura a qual ele está colado.

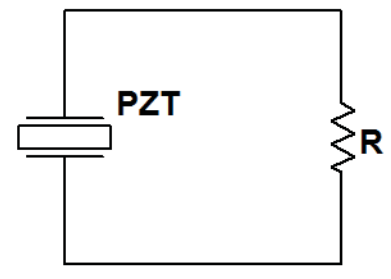

(a)

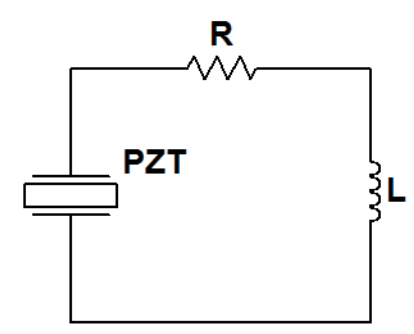

(b)

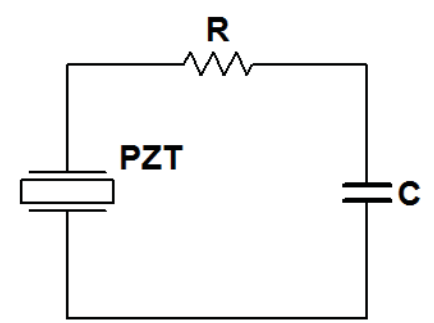

(c)

FIGURA 1 - Esquema Representativo dos Circuitos Shunt passivos: (a) Shunt Resistivo; (b) Shunt Indutivo; (c) Shunt Capacitivo.

Em geral, o controle passivo tem um bom desempenho na atenuação de vibrações, limitado a uma estreita faixa de frequências. Independentemente do tipo de circuito utilizado, 
seus elementos são ajustados segundo a frequência de interesse, normalmente a frequência de ressonância de um modo. Nos casos específicos envolvendo indutores, é importante ressaltar que a frequência de ressonância elétrica depende da própria indutância e capacitância equivalente dos materiais piezelétricos, $1 / 2 \pi \sqrt{L C}$, onde $L$ é a indutância e $C$ a capacitância equivalente. Como esta capacitância é baixa e, quando a frequência de interesse também é baixa, o resultado é a necessidade de indutores na ordem de centenas de Henries, algo pouco prático. Uma alternativa para a solução deste problema é a utilização de circuitos para indutância sintética (RIORDAN, 1967; EDBERG et al., 1992; FLEMING; MOHEIMANI, 2003). Entretanto, quanto maior os valores da indutância (baixas frequências de interesse) maior será a resistência parasita inerente ao indutor sintético (VIANA, 2005). Este fato pode reduzir o desempenho do controlador passivo, já que a resistência equivalente poderá ser muito diferente da resistência ótima para máximo amortecimento do sistema.

Alguns autores estudam a aplicação de circuitos shunt ressonantes para controle multimodal (DELL ISOLA et al., 2004). Em Zhao (2010), um circuito multimodal é apresentado para o controle de oscilações aeroelástica em uma empenagem vertical de uma aeronave. O circuito é composto por vários ramos em paralelo, onde em cada ramo há um par RL ajustado para uma frequência de interesse. Em cada ramo, também é utilizado um filtro passa banda (LC), que permite somente a passagem da frequência de interesse para o ramo e evita a interferência entre os diferentes ramos. O controle multimodal também é apresentado por Hollkamp (1994), onde indutores sintéticos são utilizados. Um circuito shunt com um indutor sintético autoajustável à frequência de ressonância da estrutura também foi estudado por Hollkamp; Starchville (1994).

No caso específico de controle de oscilações aeroelásticas, poucos autores investigaram a utilização de controladores passivos. McGowan (1999) examina numericamente o efeito de um circuito resistivo indutivo sobre a resposta aeroelástica de uma seção típica com 2GDL, deslocamento linear e deslocamento angular. O acoplamento eletromecânico foi adicionado ao GDL de deslocamento linear. O desempenho do sistema na atenuação de oscilações aerolásticas foi investigado, desde baixas velocidades, até a velocidade linear de flutter. A autora conclui que circuitos piezelétricos passivos, podem ser uma boa alternativa para controle de respostas aeroelásticas subcríticas (abaixo da velocidade de flutter), porém, apresentam pouca capacidade de alterar a fronteira de flutter do sistema.

Já Agneni et al. (2003) utilizam circuitos piezelétricos passivos (resistivo indutivo em série), para o controle da resposta aeroelástica de um modelo de uma asa de um planador 
comercial. Os autores apresentam um modelo por elementos finitos eletromecanicamente acoplado, associado a um modelo aerodinâmico não estacionário. Materiais piezelétricos foram modelados na região da raiz da asa. O controle passivo teve efeito desprezível quanto a expansão do envelope de flutter da aeronave. Entretanto, as oscilações provenientes de resposta a rajada são atenuadas. Porém, é importante ressaltar que os elevados valores de indutância requeridos, em casos aeroelásticos, torna sua aplicação pouco prática em casos experimentais ou mesmo casos de aplicações em aeronaves em escala.

Lembrando que a implementação do controle ativo exige maior complexidade, devido aos sensores e sistemas utilizados e elevada potência de atuação, os controladores passivos tem a vantagem de utilizar circuitos elétricos simples, compostos por elementos elétricos passivos (excessão é o caso de impedâncias sintéticas). Eles não dependem de uma fonte externa de energia e também não introduzem nenhuma energia ao sistema a ser controlado. Apesar da maior facilidade de projeto e implementação, os controladores passivos apresentam bom desempenho na atenuação de vibrações em uma faixa restrita de frequências. Por outro lado, os controladores ativos podem apresentar bom desempenho em faixas mais amplas de frequências (ZHAO, 2010).

Uma alternativa aos controladores ativos e passivos são os sistemas que utilizam o processamento não linear do sinal elétrico do material piezelétrico. Este processamento é realizado em diferentes técnicas, através de circuitos chaveados, e será discutido no próximo item.

\subsubsection{Controle Utilizando Materiais Piezelétricos e Circuitos Chaveados}

Conforme discutido na Introdução, os circuitos piezelétricos chaveados, também conhecidos como SSD (Synchronized Switch Damping) (RICHARD et al., 1999), são apontados como uma alternativa aos controladores passivos e controladores ativos. A técnica SSD introduz um tratamento não linear do sinal elétrico de voltagem proveniente dos materiais piezelétricos, o que resulta na maior conversão de energia mecânica em energia elétrica. Nesta técnica, o material piezelétrico é conectado e desconectado a um circuito shunt de forma sincronizada com as oscilações mecânicas do sistema. Em alguns casos, energia externa pode ser necessária para o acionamento do chaveamento ou mesmo aplicada ao material piezelétrico para o aumento da eficiência do sistema. Assim, estas técnicas podem ser 
classificadas como semi-passivas ou semi-ativas. Esta seção apresentará e discutirá estas técnicas e os trabalhos mais relevantes publicados na literatura.

\subsubsection{Controle Semi-Passivo Utilizando Materiais Piezelétricos}

Conforme o critério de classificação utilizado neste trabalho, nos controladores semipassivos, não há aplicação de energia externa diretamente no material piezelétrico. Em alguns casos, energia externa pode ser necessária somente para o chaveamento do sistema.

As técnicas de controle não lineares, utilizando circuitos semi-passivos podem ser divididas em três tipos: State Switching (SS), Synchronized Switch Damping on Short (SSDS) e Synchronized Switch Damping on Inductor (SSDI). Na Figura 2 são apresentados diagramas para cada um destes sistemas.

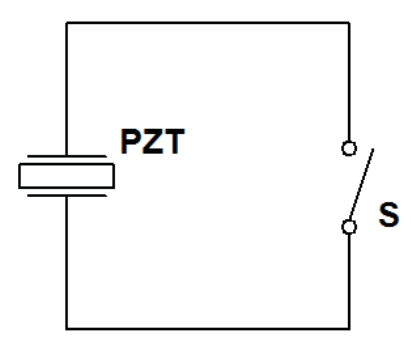

(a)

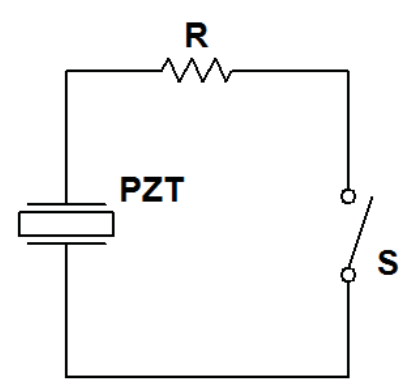

(b)

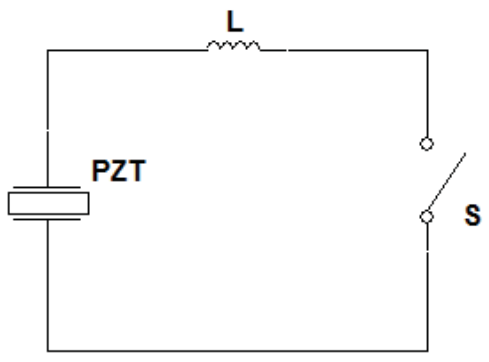

(c)

FIGURA 2 - Esquema Representativo dos Circuitos Shunt Semi-passivos: (a) State Switching; (b) SSDS; (c) SSDI.

O conceito de State Switching foi originalmente apresentado por Larson; Rogers (1994) e Larson et al. (1998) como geradores de sinais de alta amplitude e baixa frequência na aplicação de sistema de comunicação e SONAR subaquáticos. O circuito SS consiste em chaveamentos periódicos, onde o material piezelétrico é mantido em circuito aberto (condição de máxima tensão elétrica e maior rigidez do material piezelétrico) até que um máximo local de deslocamento mecânico seja atingido. É importante lembrar que, quando em circuito aberto, a saída elétrica (tensão elétrica) está em fase com o deslocamento mecânico do material piezelétrico (ERTURK; INMAN, 2011). Quando o deslocamento máximo é atingido, o circuito é chaveado para uma resistência baixa ( $R \rightarrow 0$, condição próxima ao curto circuito). Esta nova condição de contorno elétrica é mantida até que o deslocamento mecânico seja 
nulo, momento em que o sistema é novamente chaveado para a condição de circuito aberto. Assim, imaginando um movimento harmônico, o sistema é mantido em circuito aberto enquanto se afasta da condição de equilíbrio e, em curto circuito, quando se desloca para a condição de equilíbrio. Este processo de chaveamento permuta a rigidez da estrutura em dois valores discretos a cada dois quartos de período da vibração, causando dissipação de energia a partir dos pontos de máximo deslocamento e, portanto, menos energia estará presente em cada período, resultando por fim, em atenuação de vibração.

Em Clark (1999) é mostrado um estudo numérico da aplicação desta técnica para a atenuação de vibração de uma viga eletromecânica engastada. Em Clark (2000) é realizada uma comparação numérica entre o uso de um circuito passivo resistivo, um state switching e um state switching com um resistor em série. Os resultados mostraram que a técnica SS e SS com um resistor são menos sensíveis as mudanças do sistema, tendo boa performance em uma faixa mais larga de frequências e em baixas frequências. Porém, a diferença de rigidez provocada pela troca não linear da rigidez é pequena, o que leva a uma dissipação pequena de energia.

Uma técnica parecida com o SS foi apresentada em Richard et al. (1999), conforme representado na Figura 2b. Utilizando-se de transistores MOSFET e diodos, a técnica consiste no chaveamento sincronizado com o deslocamento mecânico. Neste processo de chaveamento, o material piezelétrico é mantido na condição de circuito aberto até ocorrer a máxima tensão (equivalente ao máximo deslocamento mecânico do material piezelétrico) do sistema. Atingido esse ponto, o circuito é chaveado para a condição de curto circuito por um curto período de tempo, cancelando a tensão elétrica do elemento piezelétrico. Quase instantaneamente, o circuito retorna a condição de circuito aberto, permitindo o aumento da tensão elétrica até que a próxima condição de máximo deslocamento ocorra novamente. Esta técnica é conhecida na literatura como SSDS (Synchronized Switch Damping on Short). A Figura 3a mostra o deslocamento mecânico e tensão elétrica obtida a partir do material piezelétrico em circuito aberto. A Figura 3 b exemplifica o processo SSDS, aqui discutido. Observa-se que com a sequência de chaveamentos, ocorre o aumento da amplitude do sinal elétrico, como consequência do aumento da conversão eletromecânica.

Uma terceira técnica apresentada na literatura é chamada de SSDI (Synchronized Switch Damping on Inductor) (RICHARD et al., 2000). O processo de chaveamento sincronizado com o deslocamento é o mesmo utilizado no SSDS. Entretanto, no SSDI ocorre a inversão da voltagem, ao invés do simples cancelamento obtido no SSDS, já que o material 
piezelétrico é chaveado para um indutor. O circuito ressonante formado a partir do chaveamento é composto pela capacitância interna do material piezelétrico, conectada a um circuito resistivo-indutivo. Neste caso, a frequência de ressonância elétrica deve ser muito maior que a frequência de ressonância do modo que se pretende controlar. Assim, os valores de indutância utilizados no circuito podem ser muito menores que os utilizados no caso de controladores passivos.

$\mathrm{Na}$ Figura 3c apresenta-se o comportamento do sinal elétrico proveniente do material piezelétrico sob o chaveamento no indutor. Verifica-se uma inversão desse sinal elétrico. No caso SSDI, a inversão do sinal provoca o surgimento de uma força (mecânica) dissipativa proveniente do efeito piezelétrico inverso, provocado pela inversão instantânea do sinal elétrico. Assim, o efeito shunt damping é muito mais evidente no caso SSDI do que nos casos anteriormente discutidos.

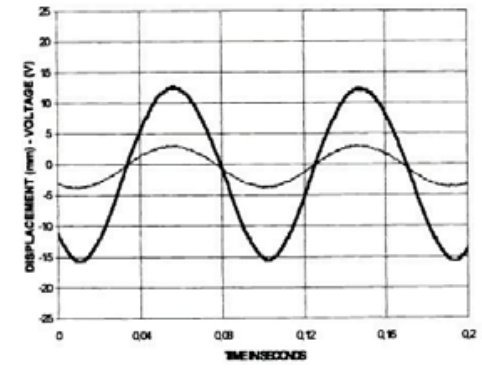

(a)

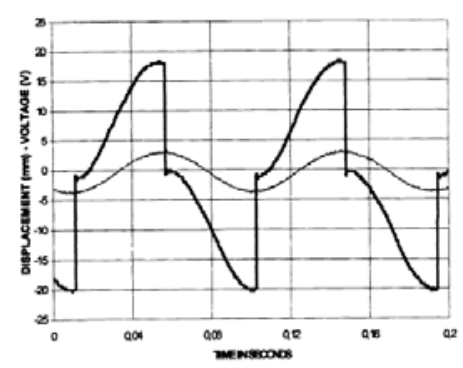

(b)

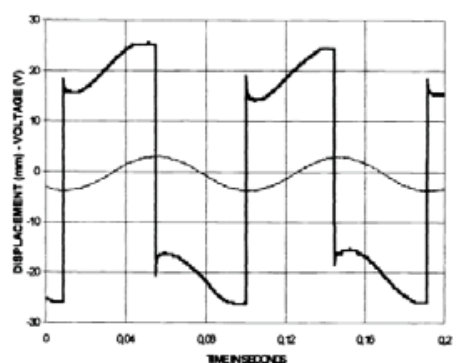

(c)

FONTE:(RICHARD et al., 2000)

FIGURA 3 - Comparação das tensão elétrica em um piezelétrico: (a) em Circuito Aberto; (b) com SSDS; (c) com SSDI.

A realização do chaveamento em pontos anteriores ou posteriores ao ponto de máxima tensão elétrica (ou deslocamento) tem grande influência no desempenho dos controladores chaveados. Assim, alguns autores investigam diferentes formas para a determinação dos pontos de máximo do sistema, com o intuito de maximizar o desempenho e evitar, por exemplo, chaveamentos em pontos inesperados, ou mesmo a não ocorrência de chaveamento. Em Guyomar et al. (2007) é realizada uma análise estatística que permite definir um critério de identificação do ponto de chaveamento de maneira precisa. Entretando, a limitação para a técnica proposta está no fato de ser necessário um prévio conhecimento do sinal, para que possa ser realizada a análise estatística. 
Uma alternativa para esse problema é apresentada em Richard et al. (2007). Os autores utilizam um circuito com componentes eletrônicos passivos para a detecção dos pontos de máximo e realização do chaveamento. O circuito proposto, por ser composto somente por elementos elétricos passivos, não depende de uma fonte de alimentação externa para a realização das tarefas de detecção do pico e do chaveamento. $\mathrm{O}$ circuito é composto por três partes: uma que detecta o envelope do sinal, outra que comparar os sinais de tensão elétrica proveniente do material piezelétrico com sinal detectado no envelope e, por fim, outra parte que realiza o chaveamento (maiores detalhes do funcionamento deste circuito são encontrados no capítulo 3). Resultados experimentais apresentados pelos autores mostraram um bom desempenho do sistema na atenuação de vibrações dos dois primeiros modos de uma viga (LALLART et al., 2008a).

Baseando-se na análise estatística para a escolha do ponto ótimo de chaveamento apresentada por Guyomar et al. (2007), Khodayari et al. (2011) propuseram um outro circuito analógico, também adaptativo. O circuito realiza, eletronicamente, cálculos básicos de estatística, a partir do sinal de tensão elétrica do material piezelétrico, aquisitado durante um curto período. E a partir desse sinal de referência, calcula-se a média temporal e o desvio padrão. Estes valores são utilizados em comparações com o sinal de referência, obtendo-se como resposta o instante do próximo chaveamento. Os autores testaram o circuito apresentado em ensaios com uma viga engastada, eletromecanicamente acoplada, e sujeita a excitação harmônica, impulsiva e também aleatória. Um bom desempenho na atenuação de vibrações foi obtido. Além disso, o circuito requer baixa potência para sua alimentação, o que poderia permitir o desenvolvimento de um sistema alimentado com energia convertida pelo próprio material piezelétrico. Porém, apresentam-se como limitações do circuito proposto, a necessidade de um conhecimento prévio do sinal, para ajuste de alguns parâmetros do circuito, e a menor sensibilidade no caso de excitações aleatórias.

Ducarne et al. (2010) fizeram um estudo com o intuito de quantificar o amortecimento e otimizar parâmetros quando utilizando as tecnicas SSDS e SSDI. Os autores verificaram, a partir de ensaios com uma estrutura com coeficiente de acoplamento modal igual à 0,2 e um fator de amortecimento de $0,1 \%$, um amortecimento adicional de 2,5\% quando a técnica SSDS foi utilizada, enquanto que com a utilização de SSDI obteve-se 10\%. Os autores também concluíram, que o único parâmetro a ser otimizado, para maximizar o amortecimento adicional, é o fator de acoplamento eletromecânico. 
Com o objetivo de melhorar o fator de qualidade elétrico de um circuito chaveador para o caso SSDI, Delpero et al. (2011), apresentaram um circuito autônomo, aperfeiçoando o circuito originalmente proposto por Niederberger; Morari (2006). O circuito proposto por Niederberger; Morari (2006), utiliza dois elementos piezelétricos, um deles como o sensor que gera o sinal para a detecção de pontos de chaveamento e outro conectado ao sistema de chaveamento, cujo sinal será tratado de forma não linear segundo o processo já descrito para o caso SSDI.

Tanto no circuito proposto por Delpero et al. (2011) como no circuito de Niederberger; Morari (2006), foi utilizado um filtro passa-baixa na detecção do ponto de máximo e de mínimo do sinal de tensão elétrica de um elemento piezelétrico sensor. A diferença do circuito proposto por Delpero está no uso de um nano amplificador operacional como comparador, transformando o sinal do filtro em uma onda quadrada que foi aplicada em MOSFETs, responsáveis pelo acionamento da chave do circuito do outro elemento piezelétrico. O nano amplificador operacional e os MOSFETs consomem apenas alguns microwatts de potência, e podem ser alimentados pelo próprio elemento piezelétrico sensor através de uma ponte retificadora e dois capacitores. Os resultados mostraram que houve aumento do desempenho na atenuação de vibrações, quando comparado com os resultados de Niederberger. O circuito proposto trouxe como vantagem um aumento no fator de qualidade do circuito chaveador e, com isso, um menor tempo de inversão da tensão elétrica.

Chen et al. (2013) apresentaram um circuito chaveador autônomo para um sistema SSDI, chamado de SP-SSDI (Self-Powered Syncronized Switch Damping on Inductor). O circuito proposto pelos autores detecta os pontos de velocidade zero do sistema mecânico, o que corresponde ao ponto de máximo deslocamento e máxima tensão elétrica do sistema eletromecânico em circuito aberto. Comparando como o SSDI convencional, que detecta os pontos de máxima tensão elétrica, o sistema apresentou maior precisão na determinação dos pontos de chaveamento. A técnica utiliza três pastilhas piezelétricas, a primeira está ligada ao circuito chaveado e sua saída elétrica será tratada de forma não linear, conforme a técnica já discutida aqui. A segunda pastilha piezelétrica, de dimensões menores, é responsável pela geração de energia que alimentará o circuito comparador. E a última opera como o sensor de velocidade, fornecendo o sinal, que é submetido à um filtro passa-baixa. Esse sinal é comparado por um nano amplificador operacional, fornecendo o onda quadrada, responsável pelo chaveamento do circuito. Os autores compararam o circuito proposto com um caso SSDI, com 3 pastilhas piezelétricas de mesmas dimensões das utilizadas no SP-SSDI, chaveado a 
partir de equipamentos externos, isto é, operado segundo um sinal fornecido por um gerador de funções e utilizando energia externa. O circuito SP-SSDI teve um eficiência de $86 \%$, onde o autor define como eficiência a diferença entre o deslocamento de uma viga sem controle e o deslocamento com o uso de SP-SSDI dividido pelo deslocamento da viga sem controle menos o deslocamento com o uso do SSDI operado a partir de sistemas externos.

No mesmo artigo, os autores também compararam o desempenho do SP-SSDI com um SSDI utilizando apenas um elemento piezelétrico e também com um controle de chaveamento ótimo externo. E obtiveram como resultado, que a eficiência do SP-SSDI chega a 95\% da eficiência SSDI convencional, agora com o denominador do equacionamento da eficiência, sendo o deslocamento da viga sem controle menos o deslocamento com o SSDI utilizando apenas um elemento piezelétrico. E concluiu que a técnica SP-SSDI é de simples implementação e degrada uma parcela ínfima do amortecimento.

\subsubsection{Controle Semi-Ativo Utilizando Materiais Piezelétricos}

O controle semi-ativo utilizando materiais piezelétricos, conhecido na literatura como SSDV (Synchronized Switch Damping on Voltage), tenta evitar as perdas na inversão existentes na técnica SSDI. As diversas técnicas e circuitos, discutidos anteriormente, para a realização de chaveamento sempre utilizam circuitos elétricos. Estes circuitos possuem uma resistência interna que provoca perdas no sistema, impedindo a inversão completa do sinal de tensão elétrica, para o caso SSDI. Assim, a técnica SSDV utiliza fontes de tensão elétrica no circuito chaveado com o intuito de garantir a inversão completa do sinal. Lefeuvre (2006) usou duas fontes de tensão elétrica, como mostrado na Figura 4. Assim, as fontes de alimentação são usadas para compensar as perdas de energia no processo de inversão do SSDI, forçando-o a inversão completa do sinal de tensão elétrica tanto nos pontos de máximo quanto de mínimo.

Alguns estudos mostraram que a energia da fonte externa, utilizada para garantir a inversão completa, pode tornar o controle SSDV instável (BADEL et al., 2006; LALLART et al., 2007). A medida que a amplitude das oscilações vai diminuindo, a utilização de fonte de alimentação constante, pode resultar na excitação da estrutura a ser controlada. Alguns autores tentaram solucionar este problema vinculando o ajuste da tensão da fonte à magnitude de tensão elétrica gerada pelo elemento piezelétrico (BADEL et al., 2006). 


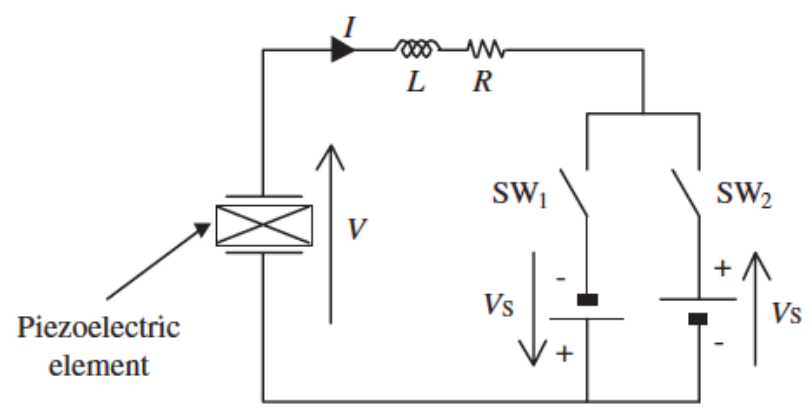

FONTE: (LEFEUVRE, 2006)

FIGURA 4 - Representação do circuito shunt SSDV, proposto por Lefeuvre (2006)

Diversos autores apresentam trabalhos baseados na técnica semi-ativa. Em geral, os resultados mostram que o desempenho dos controladores semi-ativos é sensivelmente melhor que os casos SSDS e SSDI (MARNEFFE, DE; PREUMONT, 2008; GUYOMAR et al., 2008; JI et al., 2009a; JI et al., 2009b; JI et al., 2010a; JI et al., 2010b; MOKRANI et al., 2012).

\subsection{CONVERSÃO PIEZELÉTRICA DE ENERGIA}

Os geradores piezelétricos de energia vêm sendo estudados como uma alternativa de fonte de energia para sistemas remotamente operados e de baixo consumo. A idéia é converter energia de vibração disponível no ambiente em eletricidade. Pesquisadores apresentaram nos últimos anos, modelos e investigações experimentais para o estudo do comportamento eletromecânico destes geradores piezelétricos. Os modelos apresentados variam, desde representações por parâmetros concentrados (ROUNDY et al., 2003; DUTOIT et al., 2005) a modelos aproximados de parâmetros distribuídos (LU et al., 2004; SODANO et al., 2004; CHEN et al., 2006). Alguns destes trabalhos incluem verificações experimentais e validações (DUTOIT; WARDLE, 2006; ERTURK; INMAN, 2009).

Uma forma de energia disponível na vizinhança de sensores de sistemas localizados em áreas remotas é a energia do vento. Alguns autores apresentam moinhos de vento, ou mini geradores eólicos, de modo a coletar energia fornecida pelo escoamento (PRIYA et al., 2005; MYERS et al., 2007; RANCOURT et al., 2007; XU et al., 2010). Outros autores vislumbraram a utilização de oscilações aeroelásticas para coleta de energia do escoamento de ar.

Em Erturk et al. (2008a), por exemplo, é apresentado um experimento com placas metálicas arqueadas e cobertas por fibras piezocerâmicas em compósito (MFC - Macro Fiber 
Composite), simulando um aerofólio fino. Estas vigas apresentam oscilações induzidas pelo escoamento de ar que são convertidas em eletricidade através do efeito piezelétrico direto. No referido artigo, uma carga resistiva é considerada no circuito elétrico do sistema com o intuito de se estimar a potência elétrica gerada. Em De Marqui et al. (2010), um modelo por elementos finitos eletromecanicamente acoplado foi associado a um modelo aerodinâmico não estacionário de malha de vórtices. Uma carga resistiva é utilizada para representar o domínio elétrico. As piezocerâmicas são ligadas em série a carga resistiva do circuito elétrico gerador e duas configurações de eletrodos são testadas, como mostrado na Figura 5. As simulações no domínio do tempo mostraram que a condição crítica de flutter é a mais interessante para a conversão piezelétrica de energia. Outro aspecto interessante é a segmentação de eletrodos apresentada, evitando-se o cancelamento da saída elétrica obtida a partir de movimentos de torção. Como as oscilações na condição de flutter resultam do acoplamento de modos de flexão com modos de torção, tal configuração resultou em um melhor acoplamento eletromecânico.

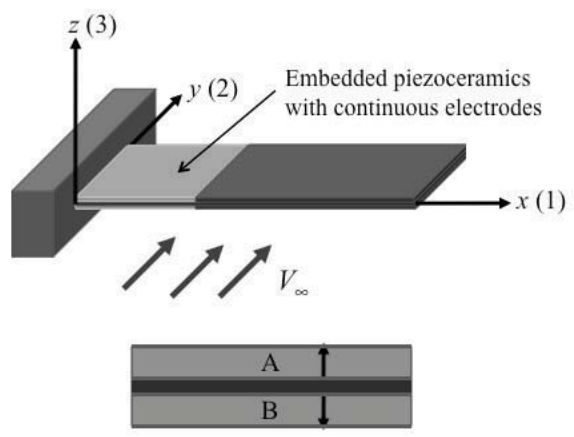

(a) Eletrodos contínuos

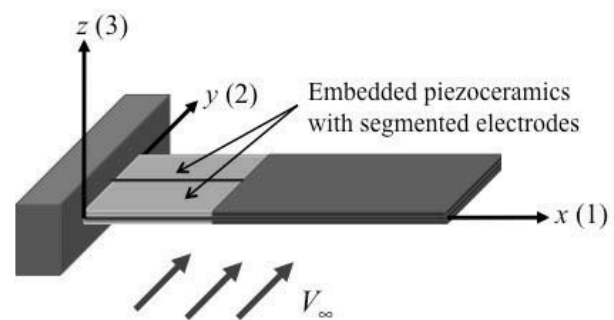

$\mathrm{A} 1 \uparrow \mid \mathrm{TA} 2$

$\mathrm{B} 1 \downarrow \square \mathrm{B} 2$

(b) Eletrodos segmentados

FONTE: (DE MARQUI et al., 2010)

FIGURA 5 - Configurações dos eletrodos das piezocerâmicas: (a) Eletrodos contínuos; (b) Eletrodos segmentados

Já em De Marqui et al. (2011), foi apresentada a formulação piezoaeroelástica no domínio da frequência. O modelo em elementos finitos eletromecanicamente acoplado foi associado ao método de malha de dipolos. Funções de resposta em frequência (FRF) piezoaeroelásticas foram definidas associando-se o problema de excitação de base com excitação aerodinâmica. Um método prático para a determinação de elementos ótimos do circuito gerador também foi apresentado. Os estudos de caso incluem no domínio elétrico um resistor e um circuito resistivo-indutivo em série. 
Em Bryant; Garcia (2011) uma seção típica com dois GDL piezoaeroelasticamente acoplada é utilizada para a conversão de energia do escoamento em energia elétrica. Os autores utilizam a teoria de Peters (1985) para a determinação do carregamento aerodinâmico não estacionário. Um esquema de chaveamento no domínio elétrico do problema é apresentado, com o intuito de maximizar a energia gerada.

Em Erturk et al. (2010) um modelo por parâmetros concentrados de uma seção típica com dois GDL é validado experimentalmente. O modelo aerodinâmico de Theodorsen (1935) é utilizado na formulação apresentada. A conversão de energia na fronteira de flutter e também a variação do comportamento aeroelástico do sistema (velocidade linear de flutter) devido a conversão piezelétrica de energia são discutidos.

Alternativas às configurações baseadas em aerofólios e placas sujeitas ao escoamento também são encontradas na literatura. Bibo et al. (2011) se basearam no princípio de funcionamento de órgãos musicais, que gera diferentes tons a partir de oscilações de hastes submetidas ao escoamento de ar, para projetar um micro gerador piezelétrico. Oscilações autoexcitadas induzidas pelo escoamento em uma viga piezelétrica engastada em uma cavidade são utilizadas para a conversão de energia.

Em Akaydin et al. (2010), uma viga eletromecanicamente acoplada, composta de uma subestrutura de Mylar coberta por uma camada de PVDF, é posicionada na esteira de um cilindro. A coincidência entre a frequência predominante no escoamento pós cilindro e a frequência de ressonância do primeiro modo de vibrar da viga geradora maximiza a saída elétrica. As dimensões da viga e seu posicionamento na esteira do cilindro também são investigadas para a maximização da potência elétrica. Outros autores, (SCHMIDT, 1992; TAYLOR et al., 2001; ALLEN; SMITS, 2001; POBERING; SCHWESINGER, 2004), exploram conceitos similares para a geração piezelétrica de energia.

Tang et al. (2009) realizam um estudo com vigas engastadas sujeitas a escoamento axial. Uma análise da energia transferida do fluido para a estrutura, quando na condição de oscilações autossustentadas, é apresentada. A conversão de energia de oscilações em ciclo limite (LCO - Limit Cycle Oscillation) de vigas eletromecânicas engastadas sujeitas ao escoamento axial, também é discutida e investigada experimentalmente por Dunnmon et al. (2011).

Kwon (2010) propõe como gerador elétrico uma viga em $\mathrm{T}$, com pastilhas piezelétricas coladas na região do engaste, submetida a um escoamento axial. Um protótipo $\left(100 \times 60 \times 30 \mathrm{~mm}^{3}\right)$ foi testado em um túnel de vento, apresentando oscilações persistentes a 
partir de $4 \mathrm{~m} / \mathrm{s}$. Algumas das vantagens do dispositivo apresentado são a simplicidade construtiva, baixo custo e a possibilidade de investigação de geradores em escalada reduzida.

Sirohi; Mahadik (2011) baseiam-se no fenômeno galloping para o projeto de um gerador piezelétrico de energia. Um corpo de seção transversal triangular é vinculado a uma viga elástica engastada. Sobre a viga são colados pastilhas piezocerâmicas para a conversão de oscilações mecânicas em energia elétrica. Um modelo eletroaeroelástico numérico é apresentado, onde a aerodinâmica é representada por um modelo quase-estático, apesar da natureza não-estacionário do problema.

Algumas pesquisas discutem os benefícios da inclusão de não-linearidades em sistemas aeroelásticos (DOWELL et al., 2003), para a conversão piezelétrica de energia. A ocorrência de grandes oscilações (em alguns casos) é a principal motivação. A ocorrência de oscilações persistentes em faixas de velocidades do escoamento permite a conversão de energia, não somente em uma velocidade específica (como nos casos piezoaeroelásticos lineares), aumentando a possibilidade de implementação prática do sistema.

Dunnmon et al. (2011) modelaram e apresentaram um protótipo experimental de um gerador piezoaeroelástico de energia não linear. Uma viga elástica engastada, com pastilhas piezocerâmicas coladas na região da raiz, é submetida ao escoamento axial. Um modelo eletroelástico não linear é apresentado e associado ao método de malha de vórtices, para a determinação do carregamento aerodinâmico não estacionário. Métricas para o cálculo da eficiência e caracterização de sistemas piezoaeroelásticos são apresentadas.

No gerador piezoaeroelástico apresentado por Bryant; Garcia (2011), um aerofólio é vinculado a extremidade livre de uma viga elástica engastada, com um GDL de rotação em torno do seu bordo de ataque. Pastilhas piezocerâmicas foram coladas na região da raiz da viga para a conversão de energia do escoamento em eletricidade. Um modelo semiempírico não linear, que leva em conta o estol dinâmico no flape, quando sujeito a grandes deflexões, foi apresentado. Ensaios em túnel de vento foram realizados, e os resultados experimentais foram utilizados para a determinação de parâmetros empíricos do modelo aerodinâmico. A potência elétrica gerada e a frequência de flutter foram investigadas em função do ângulo de incidência do escoamento.

Sousa; De Marqui (2011) apresentam um modelo não linear por parâmetros concentrados de uma seção típica eletroaeroelástica com três GDLs. Os parâmetros aeroelásticos apresentados em Tang et al. (1998) são utilizados. A velocidade linear de flutter é $24 \mathrm{~m} / \mathrm{s}$ (para a condição de curto-circuito). Ao se introduzir uma folga na superfície de 
controle, LCOs com amplitudes aceitáveis foram identificados para velocidades entre $18 \%$ e 94\% da velocidade linear flutter. Assim, há uma ampla faixa de velocidades na qual ocorre geração de energia a partir de oscilações persistentes. Fica clara a relação entre a potência elétrica gerada e o GDL que apresenta instabilidade. Como o acoplamento eletromecânico foi inserido no GDL de deslocamento linear (plunge) a saída elétrica é maximizada quando o mesmo apresenta instabilidades e consequentemente maiores amplitudes de oscilação.

Abdelkefi et al. (2011) investigaram a influência de não linearidades estruturais e aerodinâmicas no comportamento de uma seção típica piezoaeroelástica com dois GDLs. Não linearidades concentradas são consideradas nos dois GDL e o acoplamento piezelétrico, no GDL de deslocamento linear. As simulações numéricas são realizadas com o objetivo de determinar o efeito da variação da carga resistiva do domínio elétrico e das não linearidades sobre o comportamento do sistema. Os resultados mostram que o efeito da resistência elétrica sobre a velocidade de flutter é desprezível, enquanto que o efeito dos coeficientes das molas não lineares sobre o comportamento piezoaeroelástico é evidente, em conformidade com outros estudos prévios (ERTURK et al., 2010).

Em Sousa et al. (2011) foi apresentado um modelo e resultados experimentais de uma seção típica piezoaeroelástica com dois GDL. O acoplamento eletromecânico foi inserido no GDL de deslocamento linear (plunge). Foram investigados os casos linear e não linear, onde a não linearidade é introduzida no deslocamento angular (pitch). Os resultados mostraram que a presença de não linearidade favoreceram as oscilações em LCO em velocidades mais baixas que a velocidade linear de flutter, favorecendo também a geração de energia.

Uma nova técnica para geração de energia, a SSH (Synchronized Switch Harvesting), foi desenvolvida em Guyomar et al. (2005) com base na técnica de controle não linear SSD, já apresentada na seção 2.1.3.1. Nos últimos anos, pode-se encontrar na literatura vários estudos voltados a geração de energia, baseados no processamento não linear do sinal elétrico (BADEL et al., 2006; LALLART et al., 2008b; ZHU et al., 2012; CHEN et al., 2012; LIANG; LIAO, 2012). Entretanto, como pode ser observado nesta revisão, até o presente momento não há estudos com aplicação da técnica SSH para geração de energia em problemas piezoaerolásticos.

A revisão aqui apresentada, tanto para o tópico de controle de vibrações utilizando materiais piezelétricos, quanto para o tópico de conversão piezelétrica de energia mostra que a utilização de circuitos chaveados em casos aeroelásticos ainda é pouco explorada. Estas 
técnicas podem viabilizar a utilização de material piezelétrico para o controle aeroelástico, além de melhorar o desempenho de geradores piezoaeroelásticos de energia. Assim, o desenvolvimento de um circuito chaveador, utilizando materiais piezelétricos, para a investigação experimental de técnicas de controle semi-passivo a fim de atenuar a resposta aeroelástica e também para casos de coleta de energia é pertinente e pode representar uma contribuição para a área de aeroelasticidade e materiais inteligentes. 
3 DESENVOLVIMENTO DO CIRCUITO CHAVEADOR 


\section{DESENVOLVIMENTO DO CIRCUITO CHAVEADOR}

O circuito chaveador autônomo utilizado nos experimentos deste trabalho é baseado no circuito proposto por Richard et al. (2007). Há variações deste circuito apresentadas na literatura para controle multimodal (LALLART et al., 2008a) e também aplicação em caso de geração piezelétrica de energia (ZHU, et al., 2012), que serão posteriormente discutidas.

Conforme a discussão anteriormente apresentada na revisão da literatura, nos sistemas SSDS, ou SSDI, para controle de vibrações e nos casos SSHS, ou SSHI, para coleta de energia, o princípio de funcionamento do sistema consiste na detecção de deslocamentos máximos e a realização de um chaveamento. Nos casos em que o chaveamento é realizado para a condição de curto circuito, ele deve persistir até o cancelamento da tensão elétrica proveniente dos materiais piezelétricos, ou até a inversão do sinal de tensão elétrica no casos de chaveamento em um indutor. $\mathrm{O}$ circuito e as condições a serem atendidas para o processo de detecção de máximos e mínimos e realização de chaveamento serão apresentados inicialmente para o caso de chaveamento para um indutor. Posterioremente será mostrado que os casos de chaveamento para a condição de curto circuito é uma particularidade do caso anterior.

O desempenho de um sistema SSDI (ou SSHI) está diretamente relacionado com a capacidade de inversão da tensão elétrica durante o chaveamento. Esta capacidade é quantificada pelo o coeficiente de inversão $(\gamma)$. Assim, quando o coeficiente de inversão é igual a um, a tensão elétrica no final do processo de chaveamento é igual ao valor absoluto da tensão elétrica no início do chaveamento. Durante o intervalo em que ocorre o chaveamento e, consequentemente a inversão da tensão elétrica, o indutor $(L)$ e a capacitância do elemento piezelétrico $\left(C_{p}\right)$ formam um circuito ressonante. A frequência natural $\left(\omega_{n}\right)$ do circuito é representada por:

$$
\omega_{n}=\frac{1}{\sqrt{L C_{p}}}
$$

O tempo de inversão $\left(\Delta t_{i}\right)$, intervalo no qual o sistema permanece chaveado, corresponde a meio período do circuito ressonante, e pode ser obtido a partir da equação (1) como:

$$
\Delta t_{i}=\left(2 f_{n}\right)^{-1}=\pi\left(C_{p} L\right)^{1 / 2}
$$


Portanto, o tempo de inversão é diretamente proporcional à indutância utilizada no sistema ressonante. Assim, como o período de chaveamento é quase instantâneo, o uso de grandes valores de indutância não é necessário, diferentemente dos casos passivos anteriormente discutidos. Em princípio, qualquer valor de indutância poderia ser utilizado. Na prática, a indutância deve ser escolhida de forma que a frequência ressonante do circuito $\left(f_{n}\right)$, seja de 10 à 50 vezes maior que a frequência natural da estrutura a qual os materiais piezelétricos estão colados (MOHAMMADI, 2008).

Conforme discutido no capítulo anterior (figura 3c), o valor absoluto da tensão elétrica depois do chaveamento é sempre menor que o inicial e, portanto, a inversão da tensão elétrica não é completa. Na prática, portanto, o fator de inversão nunca é igual a um, porque parte da energia do sistema é dissipada no circuito chaveador (devido a resistência interna do circuito) e na resistência interna do indutor. Essas perdas podem ser melhor entendidas levando em consideração o fator de qualidade elétrico $Q$ (ou fator de mérito).

Sabe-se que o fator de qualidade pode ser representado pela razão das energias armazenada e dissipada:

$$
Q=2 \pi \frac{\text { energia armazenada }}{\text { energia dissipada por ciclo }} \Rightarrow \frac{\omega_{n} L}{R_{i}}=\frac{1}{R_{i}} \sqrt{\frac{L}{C_{p}}}
$$

onde $R_{i}$ representa a resistência interna equivalente proveniente do indutor e do circuito chaveador, $L$ é o valor da indutância, $C_{p}$ a capacitância do material piezelétrico e $\omega_{n}$ a frenquência natural do circuito ressonante.

O coeficiente de inversão da tensão elétrica $\gamma$, é expresso pela relação da tensão antes do chaveamento e depois do chaveamento:

$$
V_{\text {depois }}=-\gamma V_{\text {antes }}=-V_{\text {antes }} \exp \left(-\frac{\pi}{2 Q}\right)
$$

Das equações (3) e (4), é possível notar que quanto maiores as resistências parasitas do sistema (resistência interna), menor será o coeficiente de inversão. No caso particular da técnica SSDS a tensão elétrica não é invertida, mas sim cancelada. Logo, o caso SSDS corresponde a condição em que o coeficiente de inversão é zero, sendo considerado uma particularidade do caso SSDI, na qual o fator de qualidade elétrico é nulo.

O circuito proposto por Richard et al. (2007) é apresentado na Figura 6. Ele é composto por componentes eletrônicos passivos, e consiste, basicamente, em um detector envelope (R1, C1 e D1), um comparador (R2, D2 e Q1) e um chaveador (D3, R3 e Q2), onde 
$\mathrm{R}$ representa um resistor, $\mathrm{C}$ um capacitor, $\mathrm{D}$ um diodo e $\mathrm{Q}$ um transistor. A figura 6 mostra a parte do circuito responsável pelo chaveamento no ponto de máximo (positivo). O circuito completo, que realiza o chaveamento na região positiva e negativa do sinal, será posteriormente apresentado. Na figura 6, a tensão elétrica proveniente do material piezelétrico é comparada com a tensão do detector de envelope medida no capacitor $\mathrm{C} 1$. O detector é um filtro passa-baixa cuja saída deve ter amplitude muito próxima a do sinal original e um pequeno atraso em relação ao sinal original. O comparador do circuito (R2, D2 e Q1) utiliza o sinal filtrado, e o sinal originalmente obtido do material piezelétrico para estabelecer as condições para a realização do chaveamento. Assim, quando a amplitude da tensão elétrica do envelope do sinal detectado é menor que a do elemento piezelétrico, o transistor Q1 está bloqueado. Quando a tensão do envelope for maior que a tensão do material piezelétrico e maior que o threshold do transistor Q1, este estará conduzindo. Nesta condição o transistor Q2 será chaveado iniciando o tratamento não linear do sinal proveniente do material piezelétrico.

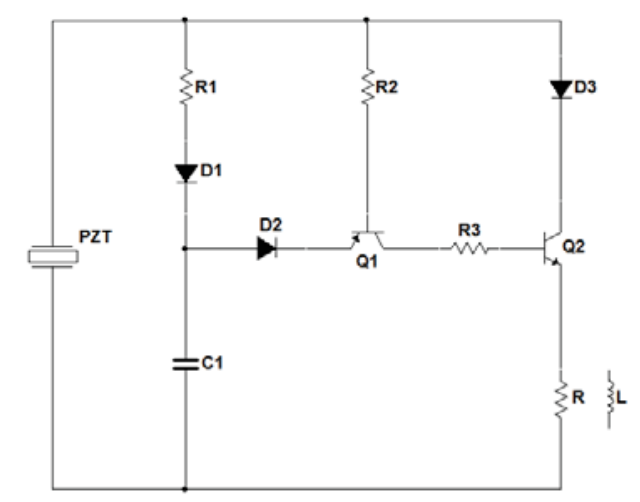

FIGURA 6 - Esquema do Circuito Chaveador Autônomo

O circuito completo, com a função de detectar máximos e mínimos, além de realizar o chaveamento, é apresentado na figura 7. O lado esquerdo do circuito, responsável pelo chaveamento nos pontos de máximo, funciona de forma equivalente ao lado direito, responsável pelo chaveamento nos mínimos. Em cada momento que um máximo, ou mínimo, é detectado os transistores Q1, ou Q4, estará conduzindo e, consequentemente Q2， ou Q3, estará conduzindo, conectando o sinal elétrico do material piezelétrico na indutância $L$ ou na resistência R, de acordo com o caso que se deseja estudar (SSDS ou SSDI). 


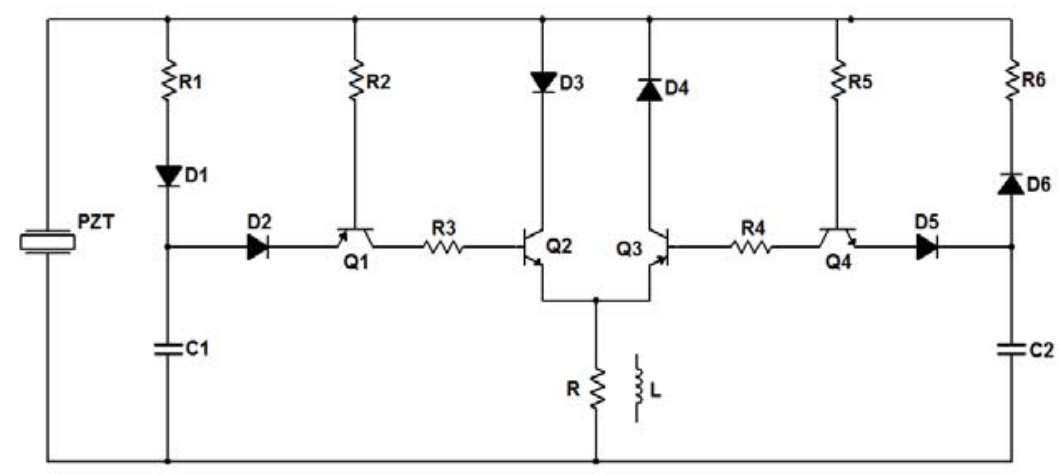

FIGURA 7 - Esquema do Circuito Chaveador Autônomo Completo

O processo de chaveamento pode ser discutido com mais detalhes a partir da análise apresentada por Zhu et al., (2012). Os autores mostram que a amplitude da tensão elétrica do envelope é sempre menor que a da tensão proveniente do material piezelétrico e também apresenta um atraso de fase. A figura 8 mostra exemplos dos sinais filtrados medidos em $\mathrm{C} 1 \mathrm{e}$ C2, assim como o sinal medido no material piezelétrico.

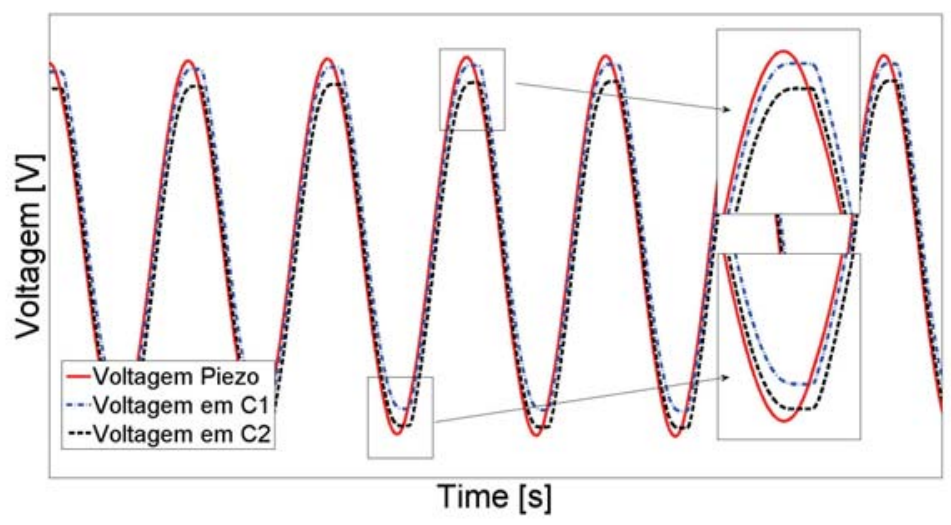

FIGURA 8 - Sinal de tensão elétrica viltrado pelo detector envelope, para referência do comparador

O sinal do envelope é comparado com a tensão elétrica da piezocerâmica nos transistores Q1 e Q4. Os transistores utilizados são, respectivamente, PNP (transistor bipolar com uma camada semicondutora com dopagem tipo n, doadoras, entre duas camadas tipo $\mathrm{p}$, receptoras) e $N P N$ (transistor bipolar com camada tipo p entre duas camada tipo n). Aplicando a lei de Kirchhoff nos terminais em um transistor qualquer (figura 9), temos:

$$
\begin{array}{r}
I_{E}=I_{B}+I_{C} \\
V_{E C}=V_{E B}+V_{B C}
\end{array}
$$


onde $I_{E}, I_{B}$ e $I_{C}$ são, respectivamente, a corrente do emissor, base e coletor, e $V_{E C}, V_{E B}, V_{B C}$ são a diferença de potencial entre a junção emissor-coletor, emissor-base e base-coletor, respectivamente.

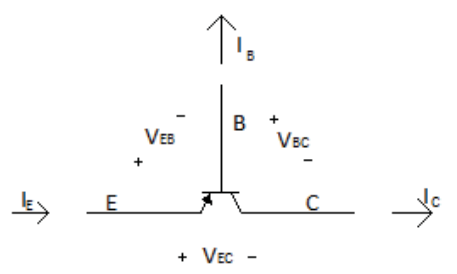

FIGURA 9 - Representação das relações elétricas de um transistor PNP

Adaptando a equação $5 \mathrm{~b}$ aos parâmetros do circuito chaveador da figura 7, em que o transistor encontra-se em um configuração $C C$ (coletor-comum), chegamos à relação:

$$
V_{E B(\text { Sat })}=V_{C_{1}}-V_{p}
$$

onde $V_{E B(\text { Sat) }}$ é a tensão de saturação da junção emissor-base, ou threshold do transistor, $V_{C I}$ é a tensão do capacitor $C_{1}$ e $V_{p}$ a tensão elétrica do material piezelétrico. A equação 6 indica que, enquanto a tensão elétrica no capacitor $C_{1}$ do envelope $\left(V_{C l}\right)$ for menor que a tensão da pastilha piezocerâmica $V_{p}$, o transistor $Q_{1}(P N P)$ estará operando na região ativa, onde a junção $B C$ (Base-Coletor) é inversamente polarizada, ou seja, ele não está conduzindo. Quando $V_{C l}$ for maior que $V_{p}$, e a diferença entre $V_{C l}$ e $V_{p}$ for maior que a tensão de saturação $\left(V_{B E(s a t)}\right)$ do transistor $Q_{1}$, ele passará a operar na região de saturação, com as junções $B C$ e $E C$ (Emissor-Coletor) diretamente polarizadas e, então, conduzirá. Essa condição, permite a passagem da corrente do coletor do $Q_{1}$ à base do transistor $Q_{2}(N P N)$, com a configuração $E C$ (Emissor-Comum). Desde modo, quando a condição $V_{C l}>V_{p}$ e $\left|V_{C l}-V_{p}\right|>V_{C E(s a t)}$ em $Q_{2}$ é respeitada, o mesmo estará na região de saturação, chaveando assim, eletronicamente, para um indutor ou um resistor. Vale ressaltar que a diferença de fase entre os sinais do material piezelétrico e do envelope, apresentada nos detalhes da figura 8, garante a ocorrência das condições aqui descritas e, assim, o chaveamento do sistema.

Após esse processo, a tensão elétrica da piezocerâmica e do filtro é descarregada (ou invertida no caso SSDI), até o momento em que uma das condições, que colocam os transistores na região de saturação, seja desrespeitada $\left(V_{C l}>V_{p}\right)$, colocando o material piezelétrico na condição de circuito aberto novamente. O comportamento desse sinal, pode ser observado, de modo ilustrativo, na Figura 10 para o caso SSDS. 


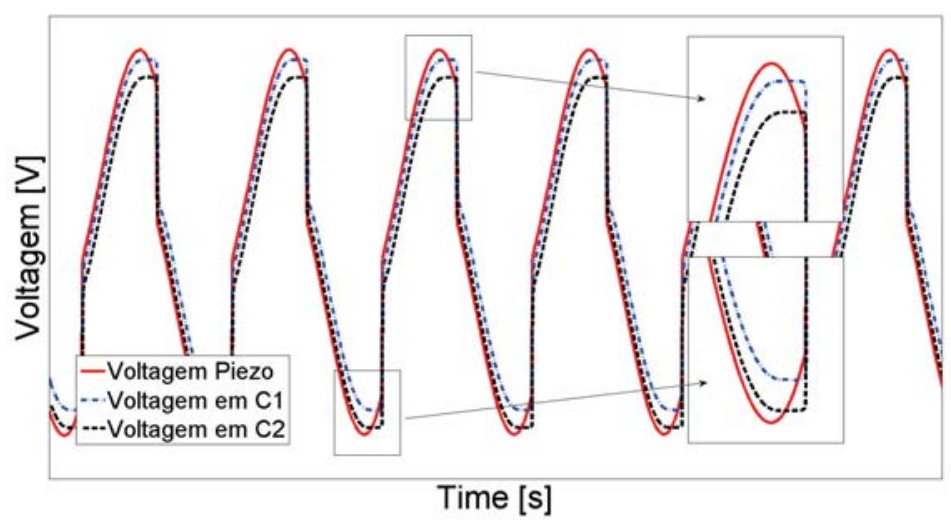

FIGURA 10 - Sinal de tensão elétrica da piezocerâmica e do detector envelope - caso SSDS

A identificação e chaveamento no pontos de mínima tensão elétrica também é executado pelo mesmo processo. Porém, ele é feito com o transistor $N P N$, na configuração $C C$, como comparador e o $P N P$, na configuração $E C$, como chaveador.

Para a identificação e chaveamento de máximo e mínimo de uma onda completa, as duas configurações do circuito chaveador são ligadas em paralelo, formando um circuito espelhado, como mostra a Figura 7.

Os diodos $D_{1}$ à $D_{6}$, têm o papel de garantir a detecção e o chaveamento de maneira independente do ponto de máxima e de mínima tensão elétrica da pastilha piezocerâmica. Sendo assim, a parte esquerda do circuito da Figura 7, identifica o ponto de máximo e a parte direita identifica o ponto de mínimo. Temos ainda, os resistores $R_{2}, R_{3}, R_{4}$ e $R_{5}$ que são utilizados para a proteção dos transistores. Na mesma figura, podemos observar a presença de uma resistência $R$, que no caso SSDS será pequena o suficiente para configurar a condição próxima ao curto circuito. Substituindo-se a resistência por um indutor $L$, obtem-se o caso SSDI.

Para casos de geração piezelétrica de energia utilizando circuitos chaveados (SSHS e SSHI), a mesma configuração de circuito é utilizada. Porém foi acrescentado, ao circuito, uma ponte retificadora de onda completa, formada por diodos, como mostra a Figura 11. Na saída da ponte, temos um capacitor $C_{f}$ filtrando o sinal de tensão elétrica, fornecendo uma tensão de corrente contínua $\left(V_{C C}\right)$. Esse valor de capacitância é escolhido de modo a diminuir o ripple na tensão de saída, sem aumentar muito o tempo de carregamento do mesmo. E em paralelo com $C_{f}$, temos a carga resistiva $\mathrm{R}_{\mathrm{L}}$, utilizada para estimar potência elétrica gerada pelo sistema. 


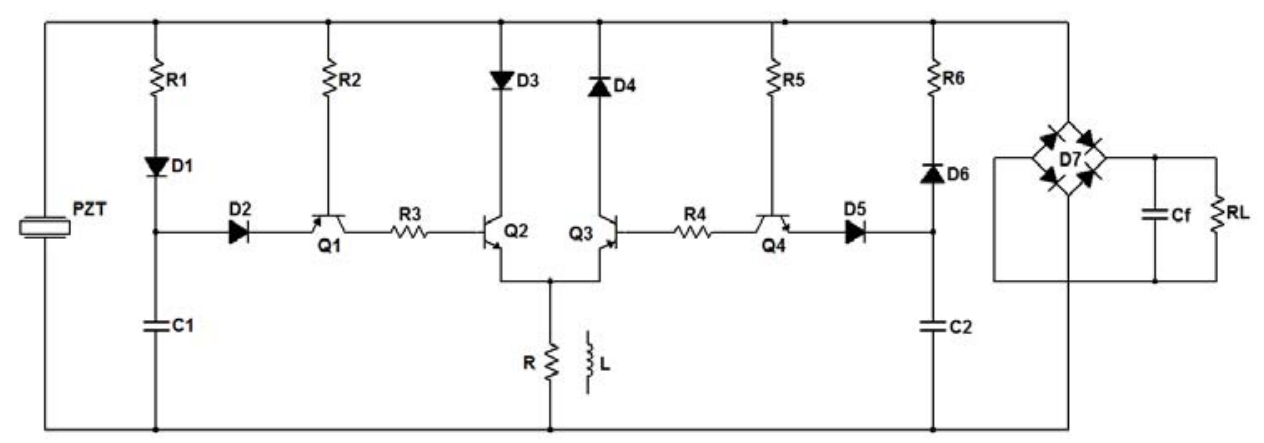

FIGURA 11 - Circuito chaveador autônomo de onda completa adaptado para a coleta de energia 


\section{RESULTADOS E DISCUSSÃO}

Os circuitos apresentados no capítulo anterior (Fig. 7 e Fig. 11) são aqui aplicados para casos de controle semi-passivo de vibrações e para geração piezelétrica de energia. Inicialmente é apresentado um estudo de caso, onde o circuito chaveador é utilizado para controle de vibrações em uma viga eletromecanicamente acoplada. Esta viga é excitada harmonicamente em sua base engastada e as técnicas SSDS e SSDI utilizadas. Este estudo foi realizado para a verificação inicial do circuito desenvolvido. Posteriormente, no segundo caso investigado neste trabalho, o circuito é utilizado para controle de vibrações aeroelásticas e também para coleta eletroaeroelástica de energia, em experimentos separados. Inicialmente, o circuito é utilizado em experimentos para controle de oscilações aeroelásticas um uma seção típica com 2GDLs no caso linear e também em um caso não linear. Em seguida, o problema de coleta de energia é apresentado para os mesmos casos aeroelásticos (linear e não linear).

\subsection{CONTROLE SEMI-PASSIVO EM UMA VIGA ENGASTADA}

Ensaios de controle semi-passivo de vibrações utilizando a configuração de circuito proposta, no capítulo anterior, foram realizados. Foi utilizada uma viga eletromecanicamente acoplada e mecanicamente engastada (T226-A4-503X da empresa PiezoSystems), composta por uma subestrutura metálica completamente coberta por duas camadas de piezocerâmica (PZT 5A), nas faces superior e inferior. A placa foi excitada a partir de sua base engastada. As dimensões originais da viga são $63,5 \times 31,8 \times 0,66 \mathrm{~mm}^{3}$. Como parte dela foi engastada, o comprimento livre da placa é de 49,65 mm. Uma massa de 2,32 gramas, composta por 4 pequenos imãs de 0,58 gramas, foi adicionada na extremidade livre da viga.

Para excitação da base foi utilizado um mini-shaker Brüel \& Kjaer 4810 e um amplificador Brüel \& Kjaer 2706. A aceleração da base foi medida com um acelerômetro 35C22 da PCB Piezotronics. A velocidade da extremidade livre da placa foi medida com um vibrômetro PDV-100 da Polytec. Os sinais de entrada e saída, bem como a função resposta em frequência (FRF de velocidade) do sistema, foram obtidos com um sistema PHOTON II LDS DACTRON. A Figura 12 mostra a visão geral do experimento. 


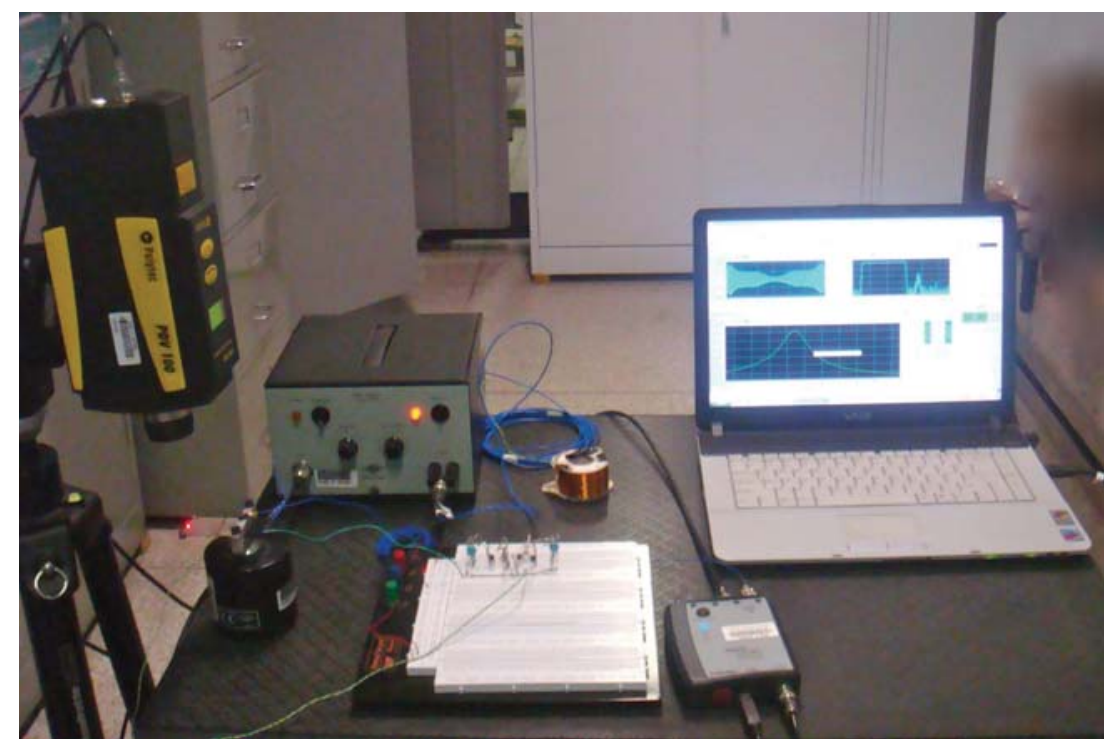

FIGURA 12 - Foto do experimento e sistema de aquisição para o teste da viga engastada

Os valores e especificações dos elementos do circuito chaveador (Figura 7) são mostrados na Tabela 1 .

TABELA 1 - COMPONENTES DO CIRCUITO CHAVEADOR

\begin{tabular}{c|l}
\hline D1 à D6 & Diodos de recuperação rápida $-\mathrm{BYW} 95 \mathrm{C}$ \\
\hline Q1 e Q3 & Transistor bipolar PNP $-2 \mathrm{~N} 2906 \mathrm{~A}-\mathrm{V}_{\text {máx }} 60 \mathrm{~V}, \mathrm{~V}_{\mathrm{EB}(\text { sat }} 1.3 \mathrm{~V}, \mathrm{~V}_{\mathrm{CE}(\text { sat) }} 1.6 \mathrm{~V}$ \\
\hline $\mathrm{Q} 2$ e Q4 & Transistor bipolar $\mathrm{NPN}-2 \mathrm{~N} 2219-\mathrm{V}_{\text {máx }} 60 \mathrm{~V}, \mathrm{~V}_{\mathrm{EB}(\text { sat })} 0.6 \mathrm{~V}, \mathrm{~V}_{\mathrm{CE}(\text { (sat) }} 0.4 \mathrm{~V}$ \\
\hline $\mathrm{C} 1$ e C6 & Capacitor cerâmico $-8,2 \mathrm{nF}$ \\
\hline R1 e R6 & Resistor $-1 \mathrm{k} \Omega$ \\
\hline R2 à R5 & Resistor $-10 \mathrm{k} \Omega$ \\
\hline
\end{tabular}

Os resistores $\mathrm{R} 2$ à $\mathrm{R} 5$, de $10 \mathrm{k} \Omega$, são utilizados para a proteção do transistores. Os valores dos resistores R1 e R6 e dos capacitores C1 e C6 foram escolhidos de forma a ajustar o sinal filtrado, a ser comparado com o sinal gerado pelo material piezelétrico, de modo que associados aos baixos valores de tensão de saturação dos transistores Q1 à Q4, proporcionem um chaveamento próximo ao valor máximo da tensão elétrica do material piezelétrico. Os diodos de recuperação rápida foram escolhidos por apresentarem resposta rápida, quando é realizada a mudança do estado de condução para não condução. 
Nos ensaios três configurações foram utilizadas no domínio elétrico do problema. Foi medida a FRF mecânica (velocidade na extremidade livre por aceleração de base) para o caso circuito aberto, posteriormente utilizando o sistema SSDS e SSDI. Para o caso SSDS a resistência para a qual o sistema foi chaveado é de $100 \Omega$, condição já mostrada na literatura como próxima a curto circuito. Para o circuito SSDI foi utilizado um indutor de $428 \mathrm{mH}$, com uma resistência interna de $175 \Omega$. Esse valor de indutância foi escolhido baseado na condição, mencionada na seção 3, em que a frequência do circuito ressonante, deve ser de 10 à 50 vezes a frenquência da estrutura mecânica.

O gráfico 1 mostra a FRF mecânica medida para as três condições. Verifica-se que a frequência de ressonância de circuito aberto do sistema é de 91,5 Hz. Esta frequência foi utilizada como referência para a determinação do valor da indutância utilizada no circuito chaveador. Verifica-se também no gráfico 1, que uma atenuação significativa foi obtida com os controladores semi-passivos. Nota-se também, como esperado, que a maior atenuação foi obtida com o sistema SSDI, evidenciando que a inversão da tensão elétrica durante o processo de chaveamento induz a um maior efeito shunt damping. Uma redução de $60 \%$ foi observada para o caso SSDS e $80 \%$ para o caso SSDI.

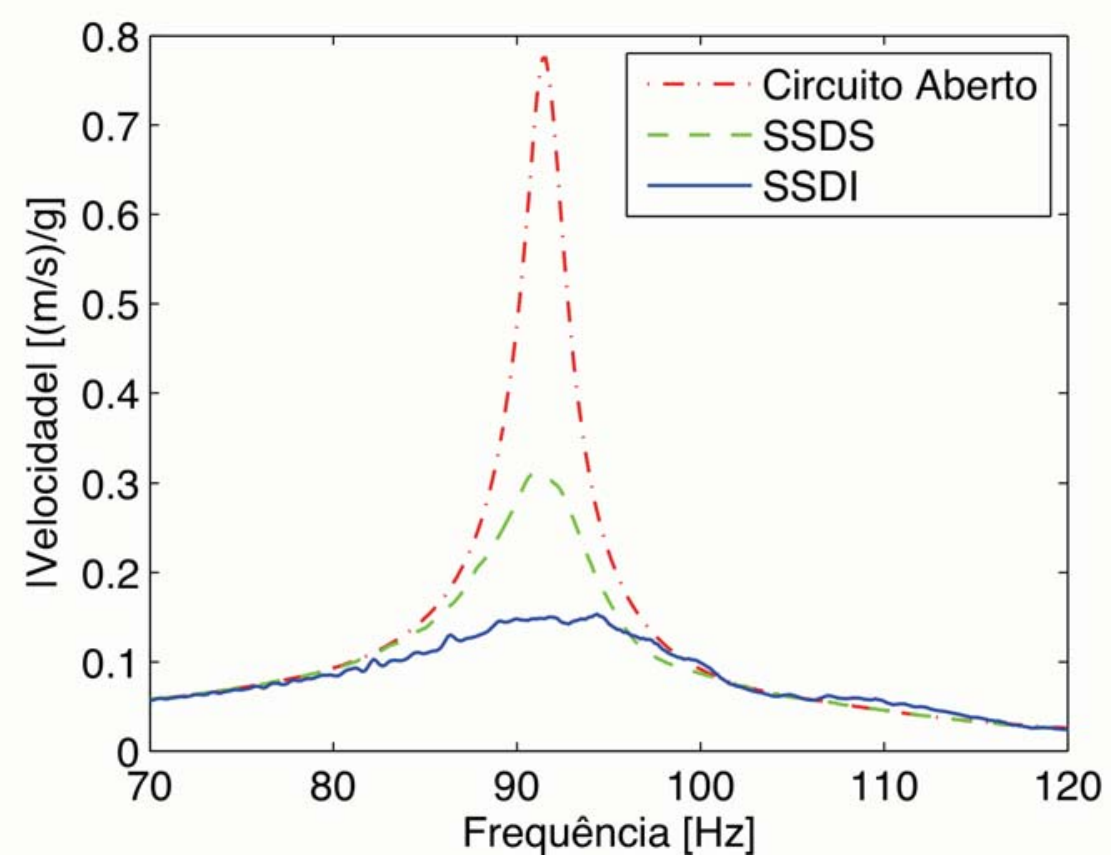

GRÁFICO 1 - Efeito do uso do circuito chaveador na FRF de velocidade da placa engastada, com frequência de ressonância de $91,5 \mathrm{~Hz}$ 


\subsection{CONTROLE SEMI-PASSIVO DE OSCILAÇÕES AEROELÁSTICAS}

Nesta seção, os experimentos em túnel de vento para controle semi-passivo (SSDS e SSDI) de oscilações aeroelásticas são descritos e os resultados apresentados e discutidos. Uma seção típica com 2-GDL, com deslocamento linear $h$ (plunge) e deslocamento angular $\alpha$ (pitch) é utilizada. Acoplamento eletromecânico é incluído no GDL de deslocamento linear através da colagem de piezocerâmicas nos elementos que conferem rigidez a este GDL. Um esquema de seção típica com 2GDL é apresentado na Figura 13a e um esquema simplificado da seção típica com acoplamento eletromecânico é apresentado na Figura 13b. O caso linear é inicialmente apresentado para controle semi-passivo de flutter. Posteriormente, uma não linearidade concentrada é adicionada ao GDL de deslocamento angular e os casos de controle semi-passivo de oscilações em ciclo limite são discutidos.

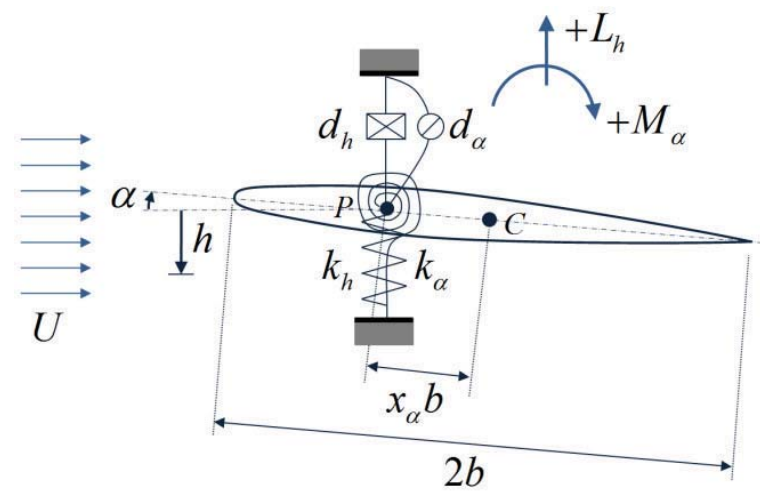

(a)

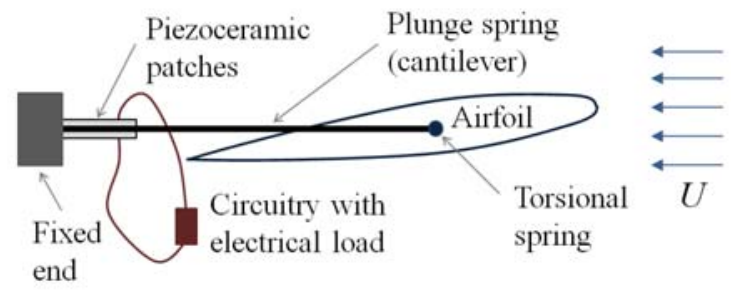

(b)

FIGURA 13 - (a) esquema de uma seção típica; (b) esquema da seção típica considerando o acoplamento eletromecânico

A Figura 14 apresenta alguns detalhes do sistema experimental utilizado neste trabalho. O modelo experimental utiliza uma asa rígida suportada por elementos elásticos que conferem rigidez aos dois GDLs do problema. No ponto localizado à $1 / 4$ da corda do aerofólio há um eixo de alumínio atravessando toda a envergadura (correspondente ao ponto $\mathrm{P}$ na Fig. 13a). Este eixo é vinculado a duas placas de aço em suas extremidades por rolamentos e flanges, como mostra a foto da Figura 14a. Na Figura 14a, verifica-se também que duas vigas de aço mola são engastadas na placa inferior e, apesar de não mostrado, mais duas vigas são vinculadas a uma placa superior. As extremidades das quatro vigas são engastadas em uma referência fixa. As quatro vigas fornecem a rigidez $\left(k_{h}\right)$ ao GDL de deslocamento linear. 
Já a rigidez do GDL de rotação $\left(k_{\alpha}\right)$ é obtida por um fio mola engastado ao eixo da asa e apoiado em uma cantoneira instalada na placa de aço superior (Figura 14b). No caso linear, o diâmetro do furo da cantoneira é igual ao diâmetro do fio mola. Já no caso não linear, um oblongo é feito na cantoneira, introduzindo uma folga (free play), e consequentemente, uma descontinuidade na rigidez do GDL de deslocamento angular (bilinear).

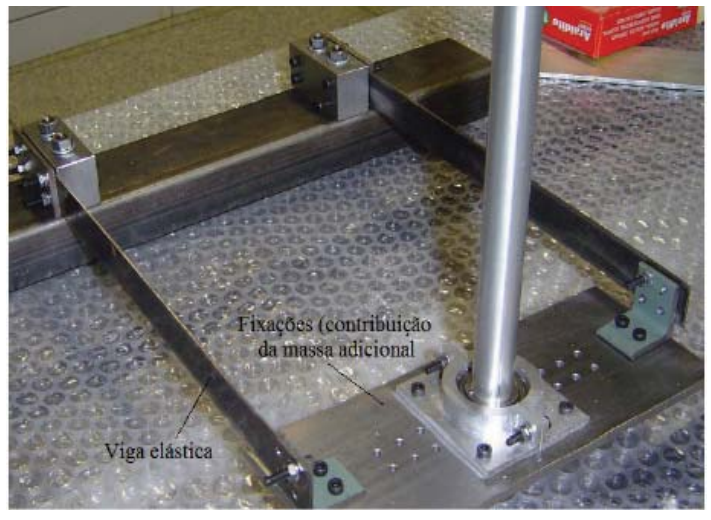

(a)

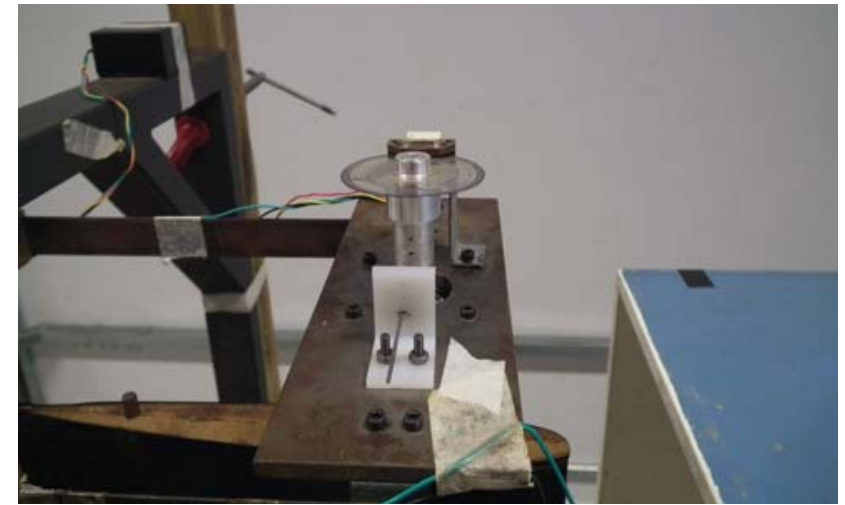

(b)

FIGURA 14 - Fotos da Estrutura da Seção Típica: (a) Vigas de Flexão e Flunge; (b) Cantoneira com Fio Mola.

O acoplamento eletromecânico $(\theta)$ é inserido no sistema através da colagem de duas cerâmicas piezelétricas (QP-10N - Mide Technology Corp.) de forma simétrica no sistema experimental. Ou seja, um material piezelétrico colado em uma viga superior e outro na viga inferior. As cerâmicas piezelétricas são coladas na região da raiz (região engastada na referência fixa) de cada viga, de forma que as mesmas também fiquem engastadas, maximizando a deformação e garantindo uma maior conversão de energia. Esses elementos piezocerâmicos são ligados em paralelo entre si, e seus eletrodos aos terminais do circuito chaveador eletrônico. A foto da Figura 15a mostra o sistema experimental no túnel de vento e a Figura 15b, o detalhe do elemento piezocerâmico colado em uma das vigas. 


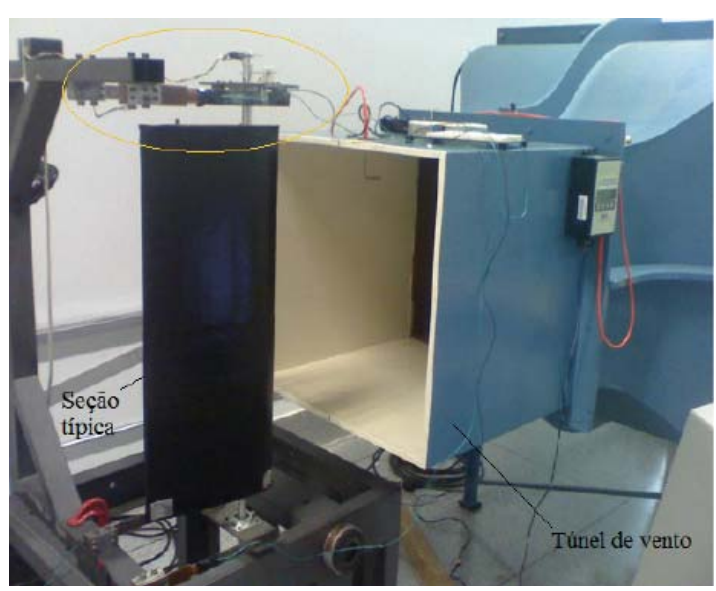

(a)

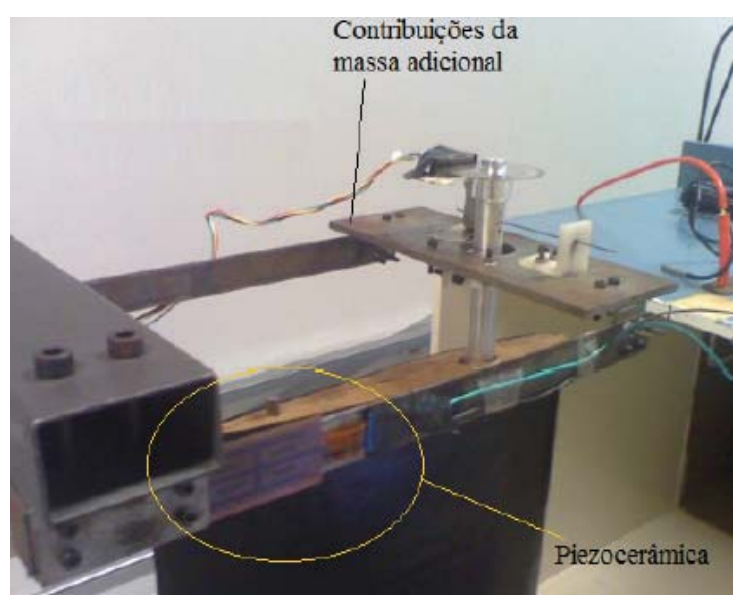

(b)

FIGURA 15 - Fotos da Estrutura da Seção Típica: (a) Seção Típica em posição no túnel de vento; (b) Pastilha piezocerâmica colada na Viga de Aço.

Para as aquisições dos dados experimentais, utilizou-se um sistema dSPACE ${ }^{\circledR}$ DS1104. A coleta dos dados de deslocamento linear $(h)$ foram feitas utilizado-se de um strain gage colado em uma das vigas de aço do GDL de deslocamento linear, e calibrado para fornecer o deslocamento. Uma configuração de $1 / 4$ de ponte foi utilizado em um sistema HBM MGC Plus ${ }^{\circledR}$. O deslocamento angular do sistema foi medido por meio de um encoder US Digital modelo HEDS-9000-T00, instalado no eixo da asa, como pode ser observado na Figura 14b. A velocidade do escoamento de ar no túnel de vento foi medida através de um medidor de vazão de ar Vectus ${ }^{\circledR}$. A Figura 16 mostra uma visão geral do sistema de aquisição. 


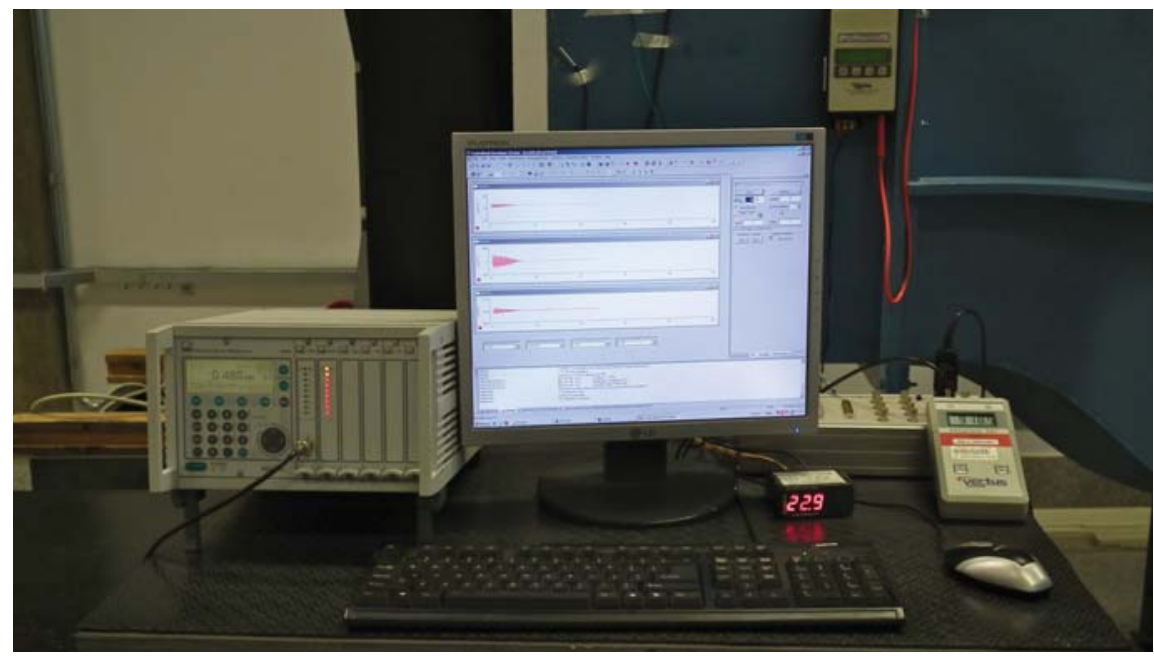

FIGURA 16 - Foto do Sistema de Aquisição de Dados utilizado no Experimento

As medidas de tensão elétrica proveniente dos materiais piezelétricos foram realizadas de maneiras distintas nos casos de controle de vibração e de geração de energia. Nos casos de controle (casos SSDS e SSDI), os dados foram coletados na dSPACE ${ }^{\circledR}$ através de uma ponta de provas com um fator de escala 100:1, conectada aos terminais resultantes da combinação das piezocerâmicas. No caso de geração de energia, a ponta de prova foi conectada aos terminais de resistores utilizados para estimar a potência elétrica gerada.

Nos ensaios em túnel de vento realizados neste trabalho, as cerâmicas piezelétricas estavam sujeitas a deformações maiores que as verificadas no caso da viga eletromecanicamente acoplada, anteriormente estudada, consequentemente, uma maior tensão elétrica foi medida na saída. Portanto, para os estudos de controle de vibração aeroelástica, alguns componentes do circuito foram modificados, como pode ser observado na tabela 2 . Os transistores utilizados possuem uma maior tensão de ruptura $\left(\mathrm{V}_{\text {máx }}\right)$, e seus respectivos threshold ( $\left.\mathrm{V}_{\mathrm{EB}(\mathrm{sat})}, \mathrm{V}_{\mathrm{CE}(\mathrm{sat})}\right)$ são menores, o que aumenta a velocidade de chaveamento. Os capacitores $\mathrm{C} 1$ e $\mathrm{C} 2$, foram substituídos por capacitores de maior tensão de ruptura e de menor capacitância $(6,8 \mathrm{nF})$, ajustando a condição de filtragem para a frequência e amplitude do sinal aeroelástico.

Um outro ponto importante foi verificado já nos primeiros ensaios em túnel de vento. Como a tensão de saída é mais elevada (se comparada com o caso de vigas), ocorria a saturação do transistor Q3 quando se estabeleciam as condições para a condução no transistor Q2 e vice-versa. Esse comportamento causava o malfuncionamento do circuito chaveador, já 
que os dois transistores conduziam ao mesmo tempo. Para evitar esse fenômeno, foi adicionado dois diodos (D7 e D8), para garantir o funcionamento independente dos dois transistores (Figura 17). Lembrando que essa adaptação, também é utilizada para o circuito de coleta de energia.

TABELA 2 - COMPONENTES DO CIRCUITO CHAVEADOR UTILIZADO NA SEÇÃO TÍPICA

\begin{tabular}{l|l}
\hline $\mathrm{D} 1$ à D8 & Diodos de recuperação rápida - BYW95C \\
\hline Q1 e Q3 & Transistor bipolar PNP - MPSA92 - $\mathrm{V}_{\text {máx }} 300 \mathrm{~V}, \mathrm{~V}_{\mathrm{EB} \text { (sat) }} 0.9 \mathrm{~V}, \mathrm{~V}_{\mathrm{CE}(\text { sat }} 0.5 \mathrm{~V}$ \\
\hline Q2 e Q4 & Transistor bipolar NPN - MPSA42 - $\mathrm{V}_{\text {máx }} 300 \mathrm{~V}, \mathrm{~V}_{\mathrm{EB} \text { (sat) }} 0.9 \mathrm{~V}, \mathrm{~V}_{\mathrm{CE}(\text { sat) }} 0.5 \mathrm{~V}$ \\
\hline $\mathrm{C} 1$ e C6 & Capacitor cerâmico $-6,8 \mathrm{nF}$ \\
\hline R1 e R6 & Resistor $-1 \mathrm{k} \Omega$ \\
\hline R2 à R5 & Resistor $-10 \mathrm{k} \Omega$ \\
\hline
\end{tabular}

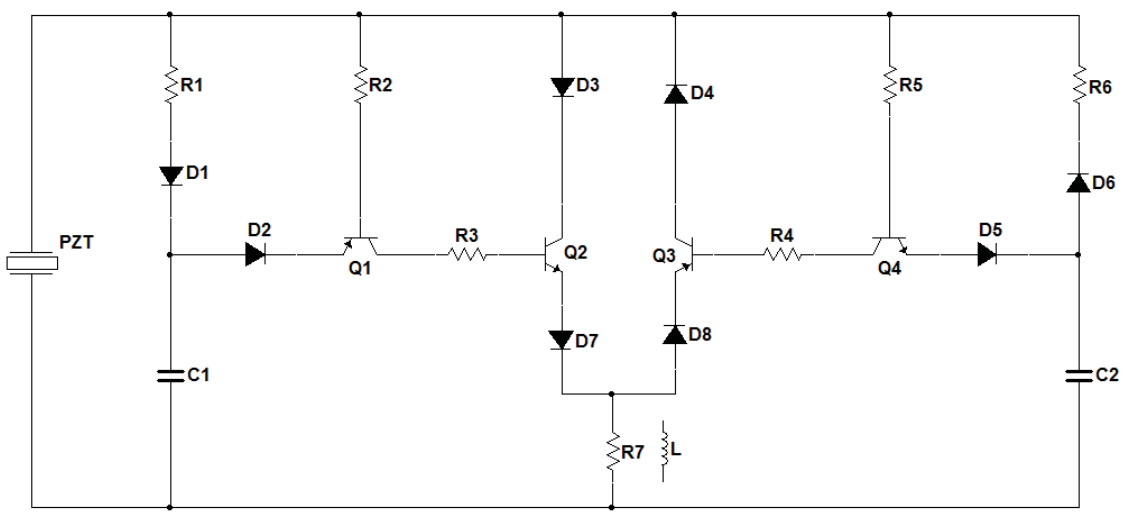

FIGURA 17 - Circuito chaveador com diodos D7 e D8, adaptados para o experimento com a Seção Típica

Os parâmetros aeroelásticos e elétricos do sistema experimental são apresentados na Tabela 3. Todos os parâmetros foram determinados experimentalmente, exceto o acoplamento eletromecânico que foi calculado utilizando o modelo de Erturk e Inman, (2008b).

TABELA 3 - PARÂMETROS DO SISTEMA DE 2-GDL

\begin{tabular}{c|c|c}
\hline Parâmetros & Valor & Unidade \\
\hline$b$ & $1.25 \times 10^{-1}$ & $\mathrm{~m}$ \\
\hline$x_{\alpha} b$ & $3.2 \times 10^{-1}$ & $\mathrm{~m}$ \\
\hline
\end{tabular}




\begin{tabular}{c|c|c}
\hline$m$ & 1.542 & $\mathrm{~kg} / \mathrm{m}$ \\
\hline$m_{e}$ & 2.548 & $\mathrm{~kg} / \mathrm{m}$ \\
\hline$I_{\alpha}$ & $7.2 \times 10^{-3}$ & $\mathrm{~kg} . \mathrm{m}$ \\
\hline$k_{\alpha}$ & 5.08 & $\mathrm{~N} / \mathrm{rad}$ \\
\hline$k_{h}$ & $4.2 \times 10^{3}$ & $\mathrm{~N} / \mathrm{m}^{2}$ \\
\hline$d_{\alpha}$ & $6.35 \times 10^{-2}$ & $\mathrm{~N} . \mathrm{s} / \mathrm{rad}$ \\
\hline$d_{h}$ & 1.8146 & $\mathrm{~N} . \mathrm{s} / \mathrm{rad}^{2}$ \\
\hline$\theta$ & $1.55 \times 10^{-3}$ & $\mathrm{~N} / \mathrm{V}$ \\
\hline$C_{p}{ }^{e q}$ & $85 \times 10^{-9}$ & $\mathrm{~F}$ \\
\hline
\end{tabular}

\subsubsection{Controle Semi-Passivo de Oscilações Aeroelásticas Lineares}

Nesta seção, são apresentados e discutidos os casos experimentais de controle de flutter (caso linear) utilizando as técnicas SSDS e SSDI. Inicialmente, as pastilhas piezocerâmicas foram mantidas na condição de circuito aberto para a determinação da velocidade linear de flutter do sistema. A velocidade foi estimada testando-se o sistema em diversas velocidades. Uma condição inicial foi aplicada ao GDL de deslocamento linear (plunge) e a resposta livre do sistema medida. Observa-se no Gráfico 2, através das respostas dos dois GDLs, que o sistema ainda é estável na velocidade de $11,7 \mathrm{~m} / \mathrm{s}$. O sistema passa a apresentar oscilações autossustentadas e de amplitudes crescentes a partir da velocidade 12 $\mathrm{m} / \mathrm{s}$ (Gráfico 3). A velocidade de $12 \mathrm{~m} / \mathrm{s}$ foi adotada como a velocidade linear de flutter do sistema. 


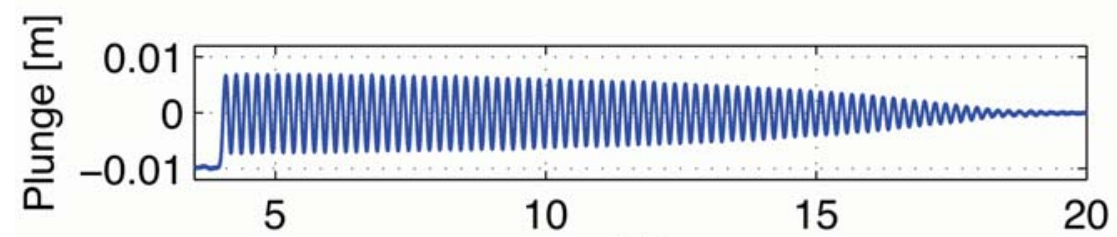

(a)

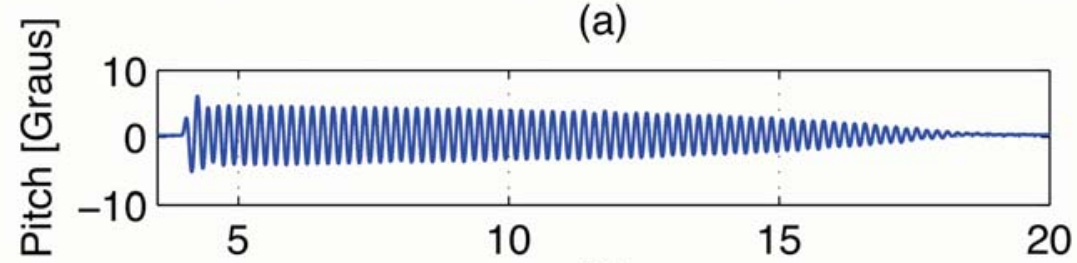

(b)

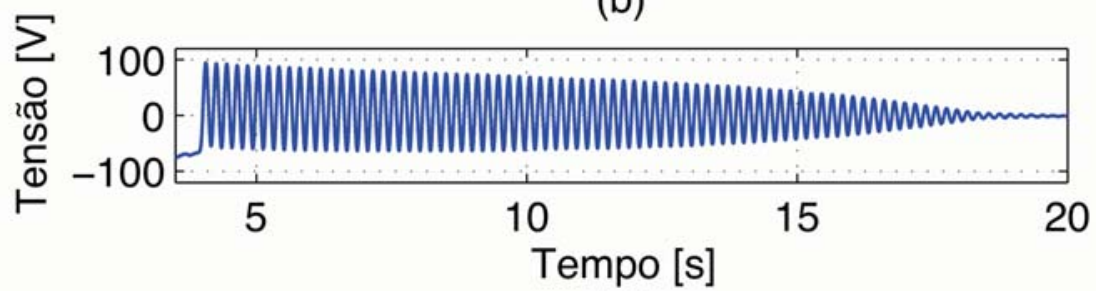

(c)

GRÁFICO 2 - Deslocamentos da seção típica medidos experimentalmente na velocidade de 11,7 m/s e piezocerâmicas em circuito aberto: (a) Plunge; (b) Pitch.

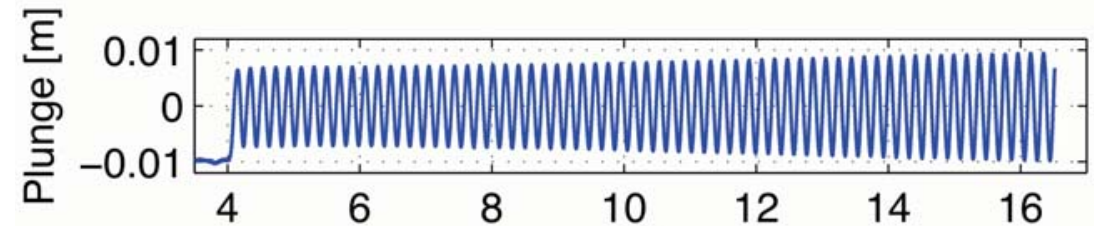

(a)

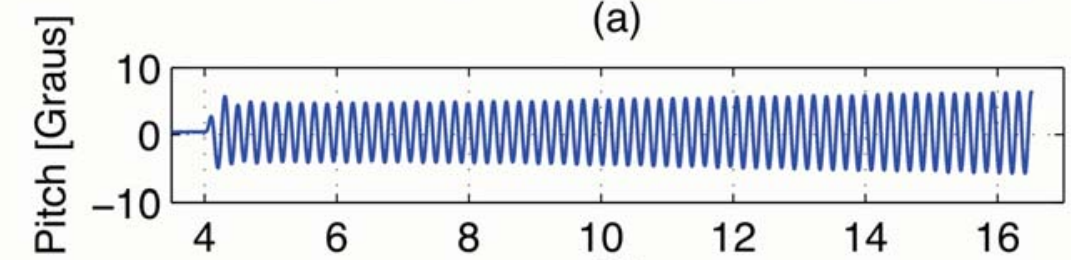

(b)

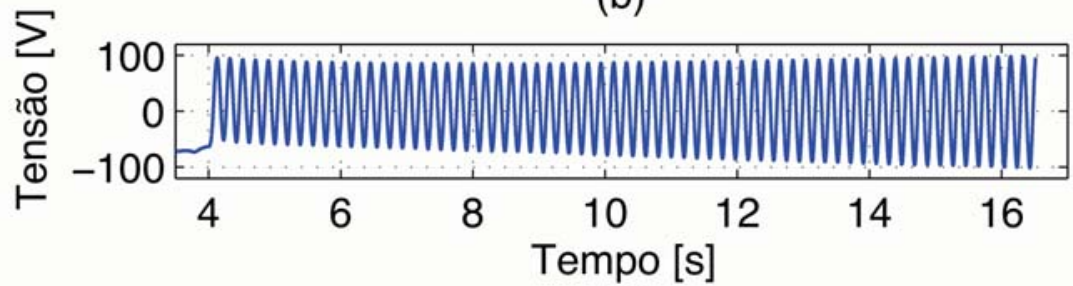

(c)

GRÁFICO 3 - Deslocamentos da seção típica medidos experimentalmente na velocidade de $12,0 \mathrm{~m} / \mathrm{s}$ e piezocerâmicas em circuito aberto: (a) Plunge; (b) Pitch. 
Determinada a velocidade linear de flutter, uma estimativa do desempenho das técnicas SSDS e SSDI foi realizada. Para isso, o fator de amortecimento foi calculada com base no decaimento das amplitudes (OGATA, 2004) do sinal de deslocamento linear da seção típica obtido na condição de circuito aberto, com a utilização da técnica SSDS e também com a utilização da técnica SSDI. Para tal estimativa, submeteu-se as três configurações às mesmas condições de escoamento, com velocidade de escoamento foi de 10,0 m/s, e também condição incial $(0,01 \mathrm{~m}$ de deslocamento linear).

O fator de amortecimendo para o GDL de deslocamento linear na condição de circuito aberto foi calculada como $1,2 \times 10^{-3}$. Para o caso SSDS, estimou-se uma razão de amortecimento cerca de duas vezes maior, $2,5 \times 10^{-3}$. Já quando a técnica SSDI foi utilizada, a razão de amortecimento obtida foi de $3,0 \times 10^{-3}$. O Gráfico 4 mostra o deslocamento linear que foi utilizado para o cálculo da razão de amortecimento para cada caso.

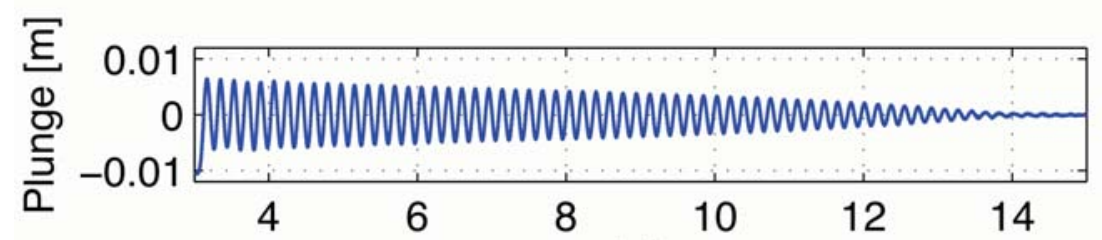

(a)

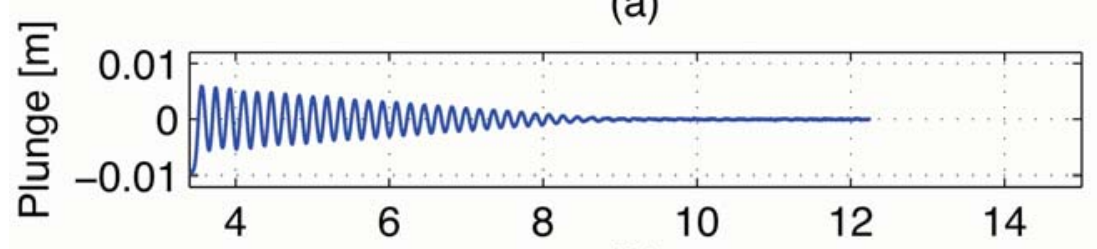

(b)

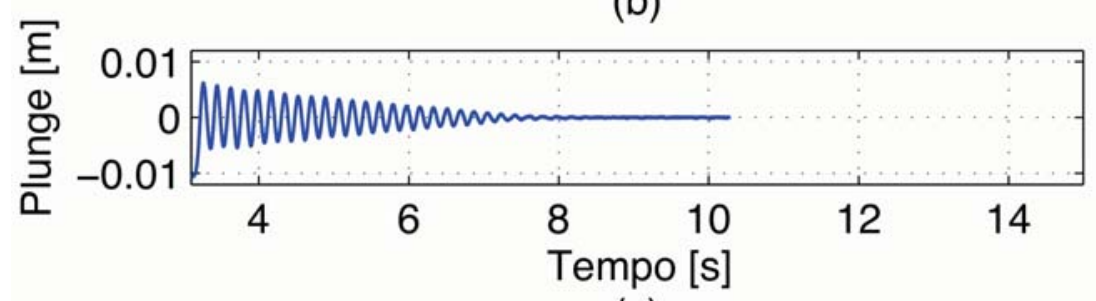

(c)

GRÁFICO 4 - Deslocamento linear medido na velocidade de $10,0 \mathrm{~m} / \mathrm{s}$, para cálculo da razão de amortecimento: (a) Circuito Aberto; (b) SSDS; (c) SSDI.

Após a avaliação do desempenho das técnicas de controle passivo em uma condição pré flutter, comparou-se o desempenho das técnicas SSDS e SSDI quanto a supressão de flutter. Nos ensaios experimentais, o túnel de vento foi mantido na velocidade linear de 
flutter, $12 \mathrm{~m} / \mathrm{s}$, e um deslocamento inicial de 0,01 metros foi aplicado no GDL de deslocamento linear. Em todos os casos, as pastilhas piezocerâmicas foram mantidas na condição de circuito aberto até, aproximadamente, o tempo de 10,6 segundos, quando foram conectadas aos circuito chaveador autônomo.

O Gráfico 5 mostra os sinais de deslocamento linear (plunge), deslocamento de angular (pitch) e tensão elétrica medidos quando a técnica SSDS foi utilizada para o controle de flutter. Observa-se que a partir do tempo 18 segundos as oscilações foram suprimidas pelo sistema autônomo. Vale ressaltar que nenhuma energia externa foi utilizada para a realização da técnica aqui apresentada. O Gráfico 5c mostra que a amplitude do sinal de tensão elétrica é inicialmente amplificada de 85 Volts para aproximadamente 110 Volts quando o processo de chaveamento é iniciado.

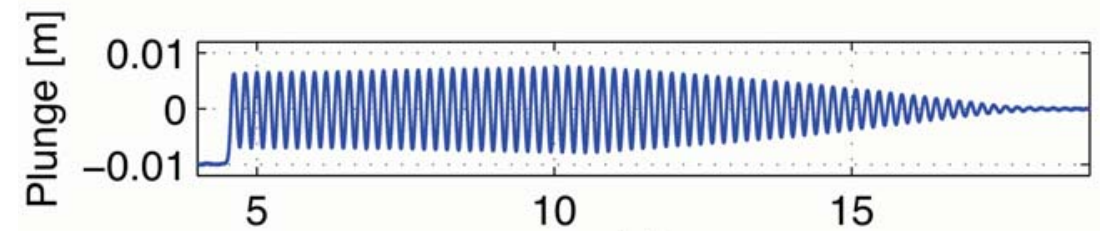

(a)

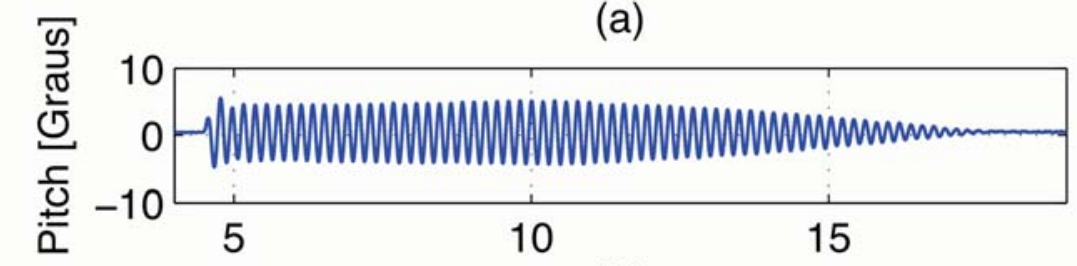

(b)

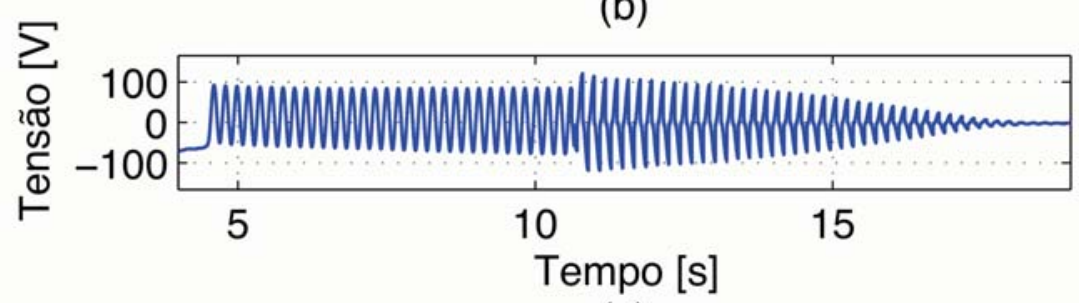

(c)

GRÁFICO 5 - Repostas da Seção Típica, sob escoamento de 12,0 m/s, com acionamento do SSDS no tempo 10,6 s: (a) Plunge; (b) Pitch.; (c) Tensão elétrica.

O Gráfico 6 mostra os sinais de deslocamento linear, deslocamento angular e tensão elétrica medidos quando a técnica SSDI foi utilizada para o controle de flutter. O ensaio foi realizado na velocidade de $12 \mathrm{~m} / \mathrm{s}$, velocidade linear de flutter do sistema, e os materiais piezelétricos conectados ao circuito chaveados em torno do tempo 11 segundos. Observa-se que a partir do tempo 16 segundos as oscilações foram suprimidas pelo sistema autônomo. 
Novamente, nenhuma energia externa foi utilizada para a realização da técnica SSDI. O Gráfico 6 c mostra que a amplitude do sinal de tensão elétrica é inicialmente amplificada de 85 Volts para aproximadamente 120 Volts.
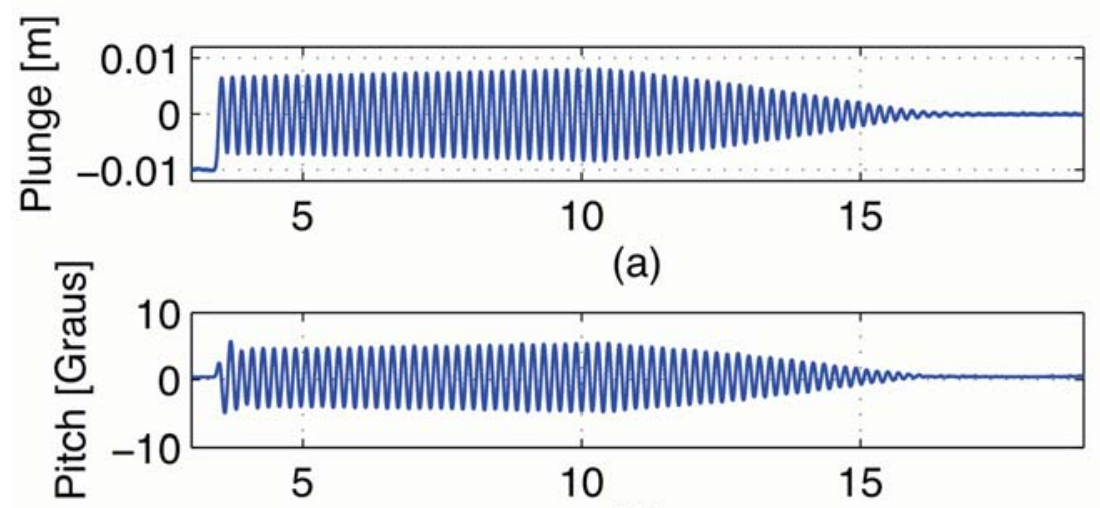

(b)

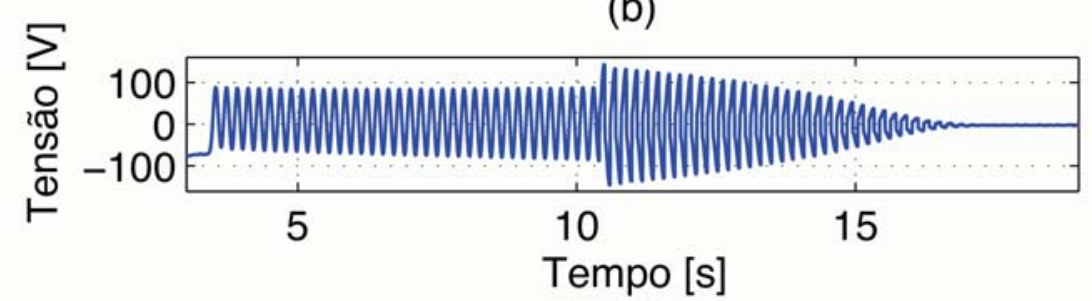

(c)

GRÁFICO 6 - Repostas da Seção Típica, sob escoamento de 12,0 m/s, com acionamento do SSDI no tempo 10,4 s: (a) Plunge; (b) Pitch.; (c) Tensão elétrica.

O Gráfico 7 mostra um detalhe do processo de chaveamento na velocidade de flutter para os dois casos aqui apresentados. No caso SSDS, Gráfico 7a, os materiais piezelétricos são mantidos em circuito aberto até que um deslocamento linear máximo (ou tensão elétrica) seja detectado. Nesse ponto, o sistema é chaveado para uma resistência de $100 \Omega$, condição muito próxima ao curto circuito, e as piezocerâmicas são, instantaneamente, descarregados. $\mathrm{O}$ sistema é novamente chaveado, para a condição de circuito aberto e quando um novo deslocamento máximo é detectado o processo se repete. Vale ressaltar que o circuito utilizado e as condições para o chaveamento são as discutidas no capítulo anterior. O Gráfico $7 \mathrm{~b}$ mostra o detalhe do processo de chaveamento do caso SSDI. Os materiais piezelétricos são mantidos em circuito aberto, até que um deslocamento linear máximo (ou máxima tensão elétrica) é detectado. Nesse ponto, o sistema é chaveado para um indutor de 8 Henries. A força dissipadora obtida proveniente da inversão do sinal de tensão elétrica naquele instante de tempo, implica no melhor desempenho na atenuação de vibrações do sistema SSDI, quando 
comparado com o SSDS. Depois de realizado o processo de inversão, o sistema é novamente chaveado para a condição de circuito aberto, até que um novo deslocamento máximo seja detectado e o processo se repete (condições para o chaveamento foram apresentadas no capítulo anterior).

O cálculo desta indutância foi realizado segundo as Eqs. (1) e (2) apresentadas no Capítulo 3, levando em consideração os limites em que a frequência ressonante deve estar entre 10 à 50 vezes a frequência de oscilação da seção típica. Uma bobina de um transformador foi utilizada para fornecer a indutância de $8 \mathrm{H}$, e apresentou uma resistência interna de $505 \Omega$.

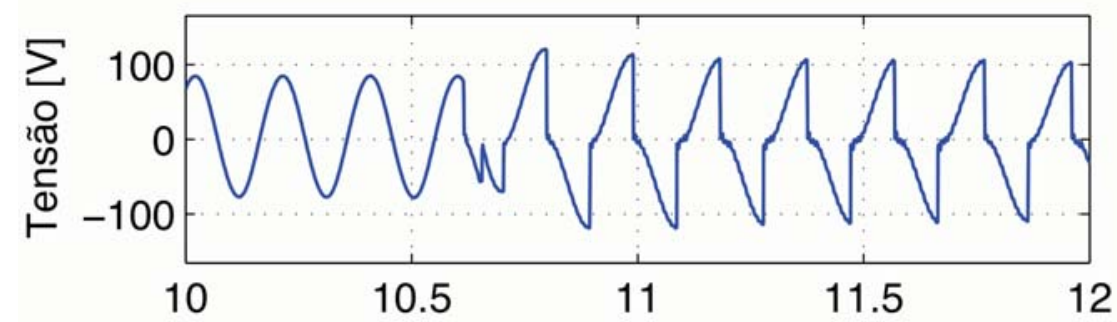

(a)

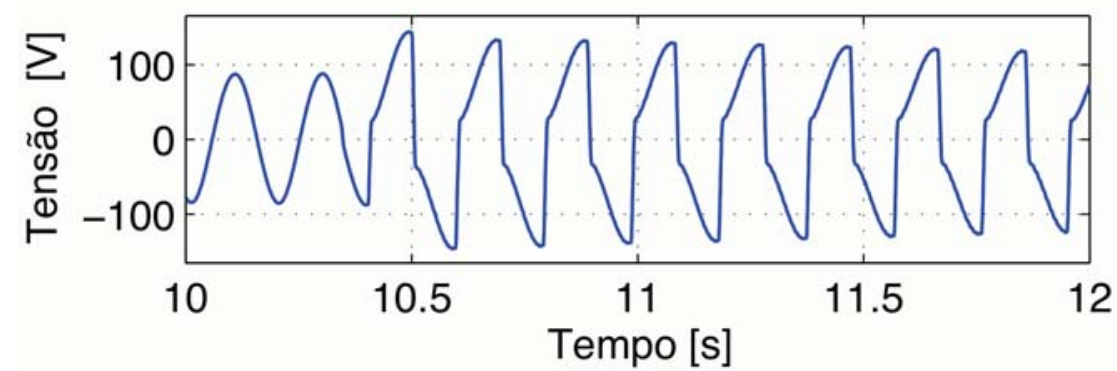

(b)

GRÁFICO 7 - Detalhe do sinal de tensão elétrica e processo de chaveamento: (a) SSDS; (b) SSDI.

O coeficiente de inversão $\gamma$, obtido a partir da resposta de tensão elétrica medida para o caso SSDI, foi de aproximadamente 0,25. Esse cálculo foi realizado utilizando-se a Equação (4). Também através da Equação (4) foi possível calcular o fator de qualidade Q=1,13. Sabendo que a capacitância medida das piezocerâmicas associadas em paralelo foi de aproximadamente $85 \mathrm{nF}$, aplicando a equação (3) obtemos a resistência interna de aproximadamente $8,59 \mathrm{k} \Omega$. Subtraindo a resistência interna do indutor, temos que a resistência interna referente ao circuito chaveador foi de aproximadamente $8,09 \mathrm{k} \Omega$. Portanto, 
a deficiência na inversão se dá devido a resistência interna do sistema, sendo a resistência interna do circuito chaveador a resistência mais significativa.

Em um outro experimento em túnel de vento, verificou-se o desempenho dos dois sistemas semi-passivos na condição de pós flutter, ou seja, em velocidades maiores que a velocidade linear de flutter. Em ambos os casos (SSDS e SSDI), os materiais piezelétricos foram mantidos conectados ao circuito chaveador e os testes foram realizados desde a velocidade linear de flutter $(12 \mathrm{~m} / \mathrm{s})$ até a velocidade em que alguma instabilidade fosse encontrada.

No caso SSDS, o sistema semi-passivo conseguiu manter o sistema estável até, aproximadamente, a velocidade de $12,8 \mathrm{~m} / \mathrm{s}$. Comparada com a velocidade crítica estimada da seção típica na condição de circuito aberto, esse valor representa um aumento de aproximadamente $8,5 \%$, na velocidade crítica de flutter. No Gráfico 8 , é possível ver o comportamento do sistema (deslocamento linear, angular e tensão elétrica) na velocidade de $12,7 \mathrm{~m} / \mathrm{s}$. No Gráfico 9, são apresentados os sinais medidos na velocidade $12,9 \mathrm{~m} / \mathrm{s}$, onde se observa a instabilidade do sistema.
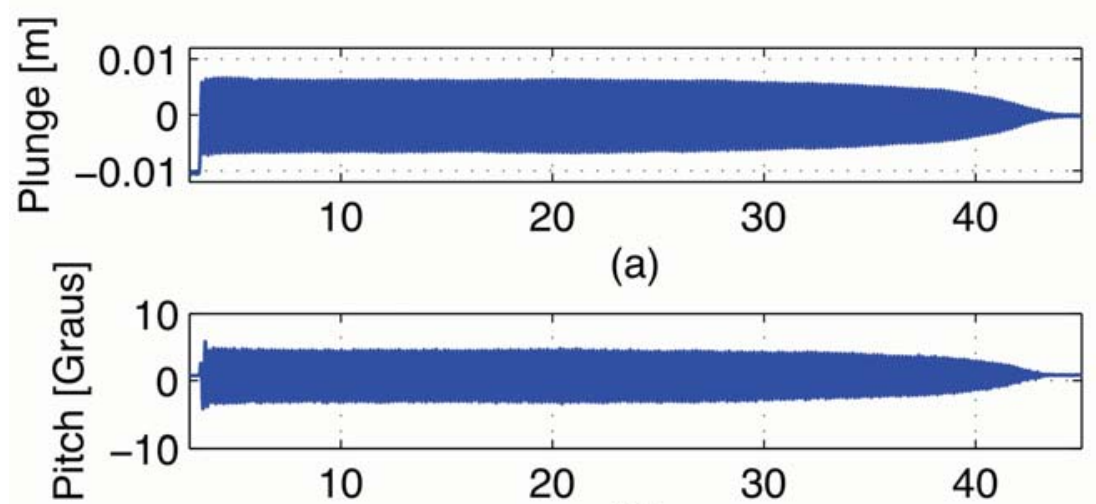

(b)

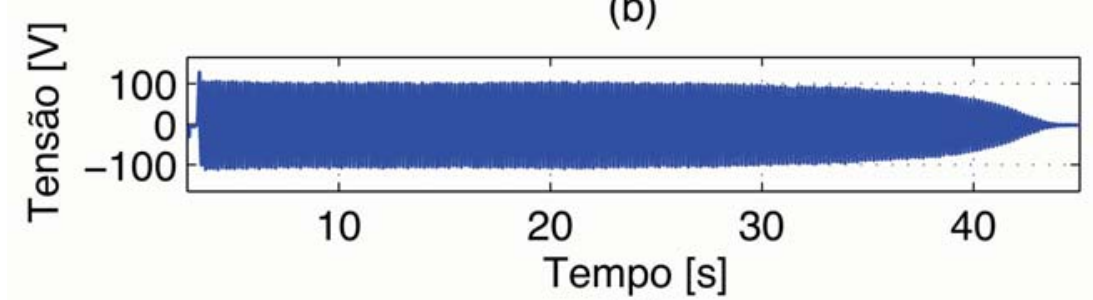

(c)

GRÁFICO 8 - Repostas da Seção Típica, sob velocidade de 12,7 m/s, utilizando a técnica SSDS: (a) Plunge; (b) Pitch.; (c) Tensão elétrica. 

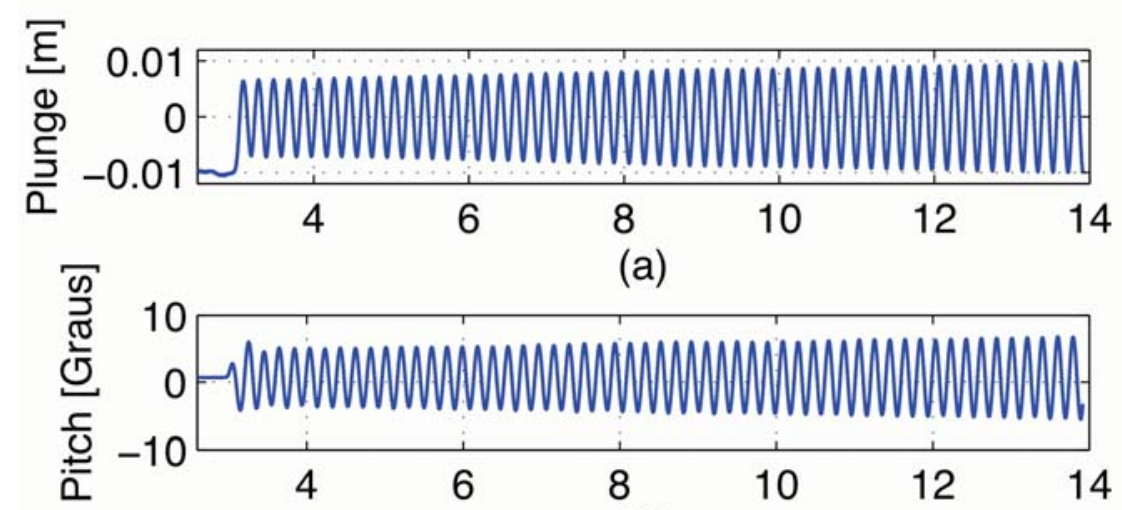

(b)

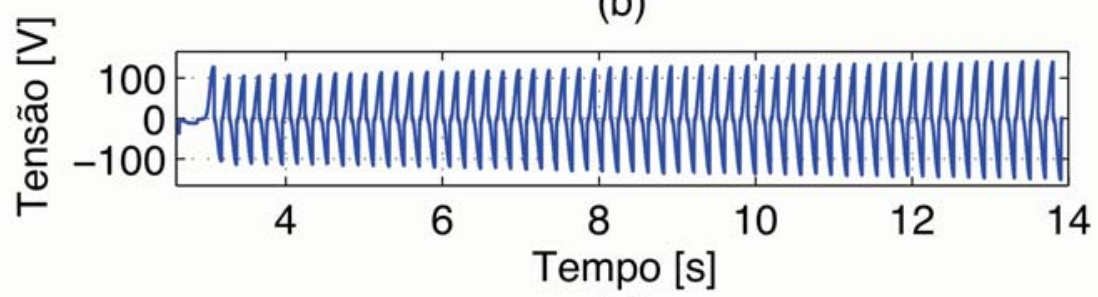

(c)

GRÁFICO 9 - Repostas da Seção Típica, sob velocidade de 12,9 m/s, utilizando a técnica SSDS: (a) Plunge; (b) Pitch.; (c) Tensão elétrica.

O mesmo ensaio foi realizado com o sistema SSDI. Neste segundo caso, o controlador semi-passivo utilizando o indutor mostrou ser mais eficiente que o caso SSDS. A nova velocidade crítica de flutter foi estimada entre $13,1 \mathrm{~m} / \mathrm{s}$ e $13,2 \mathrm{~m} / \mathrm{s}$. Esses valores representaram um aumento de aproximadamente 11,4\%, em relação a velocidade linear de flutter em circuito aberto. Os Gráficos 10 e 11, mostram os deslocamentos linear, angular e a tensão elétrica medidos na condição estável e instável, respectivamente. 


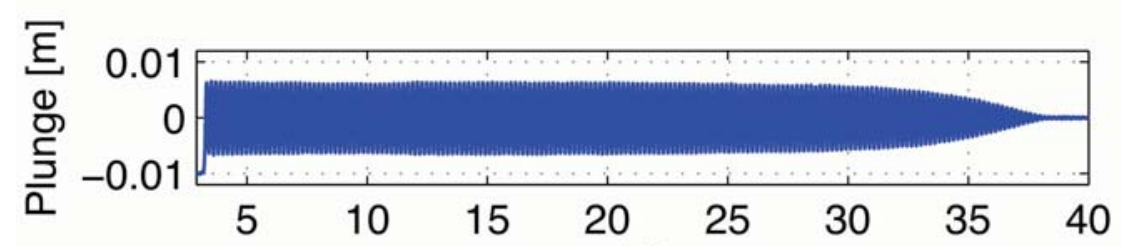

(a)

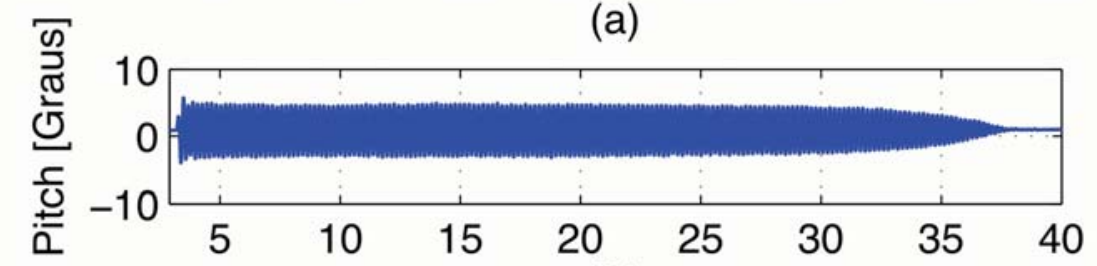

(b)

(c)

GRÁFICO 10 - Repostas da Seção Típica, sob velocidade de 13,1 m/s, com SSDI: (a) Plunge; (b) Pitch.; (c) Tensão elétrica.

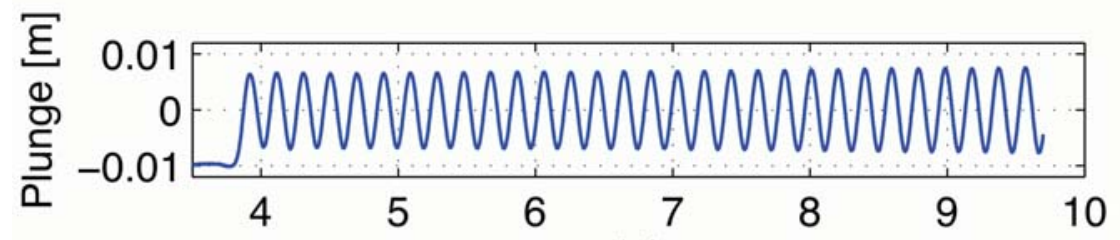

(a)

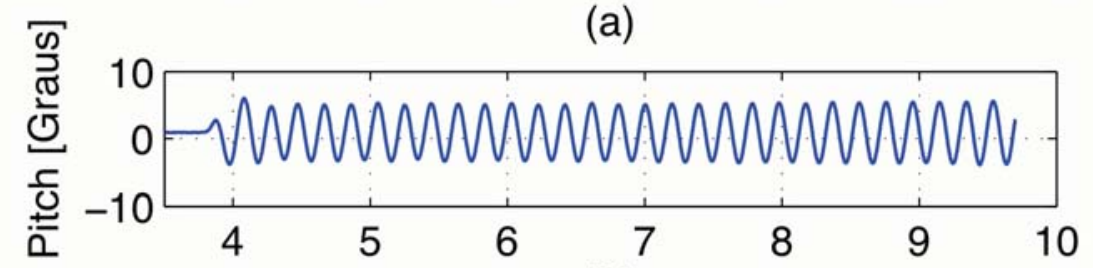

(b)

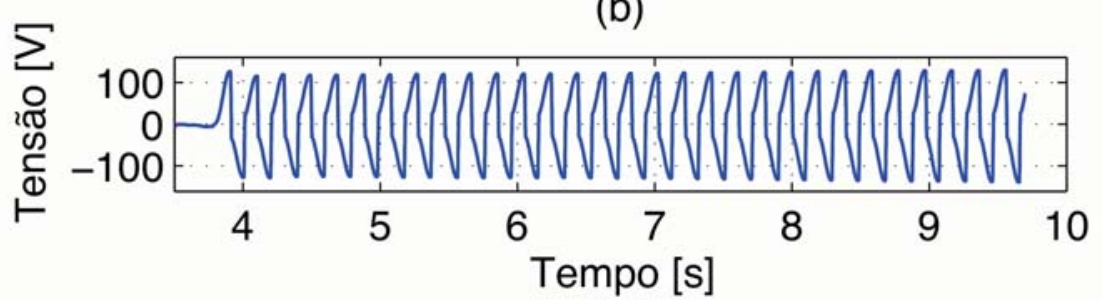

(c)

GRÁFICO 11 - Repostas da Seção Típica, sob velocidade de 13,2 m/s, com SSDI: (a) Plunge; (b) Pitch.; (c) Tensão elétrica. 
Os resultados aqui apresentados parecem ser os primeiros a surgir na literatura de um controlador autônomo energeticamente (que não depende de uma fonte externa de energia) utilizando materiais piezelétricos para o controle de flutter. Como discutido no capítulo de Revisão da Literatura, alguns autores investigaram previamente a utilização de controladores passivos para supressão de flutter (HEEG, 1993; AGNENI et al., 2003). Entretanto, concluíram que sistemas passivos são pouco efetivos e, no caso de sistemas que utilizam indutores, os valores exigidos não eram práticos, devido as baixas frequências envolvidas. As técnicas chaveadas aqui apresentadas, baseadas no circuito proposto por Richard et al. (2007), se mostram como alternativas efetivas para o controle de flutter e também evitam os altos valores de indutância.

\subsubsection{Controle Semi-Passivo de Oscilações Aeroelásticas Não Lineares}

No segundo estudo realizado neste trabalho, as técnicas SSDS e SSDI foram utilizadas para o controle de oscilações aeroelásticas não lineares. Uma não linearidade concentrada do tipo free play foi adicionada ao GDL de deslocamento angular. Para isso, a cantoneira que suportava o fio mola no caso linear foi substituída por outra cantoneira com um furo tipo oblongo, introduzindo assim uma região com rigidez nula no sistema. A presença dessa bilinearidade no sistema aerolástico, tende a reduzir a velocidade em que oscilações persistentes (oscilações em ciclo limite - LCOs) são detectadas (SOUSA et al., 2011). O sistema utilizado permitiu uma faixa de 3 graus com rigidez nula. A partir desse ponto, a rigidez obtida é a mesma do caso linear.

O primeiro teste realizado visou a determinação da velocidade em que LCOs surgiam no sistema experimental. O sistema foi mantido na condição de circuito aberto e as primeiras oscilações persistentes foram medidas na velocidade de 10,4m/s. É importante destacar que, conforme já havia sido observado em trabalhos anteriores com o mesmo sistema experimental (SOUSA et al., 2011), oscilações com amplitudes crescentes (instáveis) são detectadas em velocidades superiores a 10,4 m/s. Ou seja, apesar de diminuir a velocidade em que oscilações persistentes são detectadas, a presença de um free play não garante oscilações persistentes e com amplitudes aceitáveis em uma faixa de velocidades.

As respostas de deslocamento linear (plunge), angular (pitch) e tensão elétrica são mostradas nos Gráficos 12, 13 e 14, para as velocidades de 10,3 m/s, 10,4 m/s e 10,9 m/s, respectivamente. Na primeira velocidade as oscilações são amortecidas com o passar do 
tempo, na segunda verifica-se a presença de um LCO e na terceira as amplitudes aumentam para valores não aceitáveis e o teste foi paralisado. Nos Gráficos 12b, 13b e 14b, é apresentado o deslocamento angular para as respectivas velocidades. O deslocamento do eixo de simetria em relação ao tempo, foi devido à adição do free play ao GDL angular. Definindo, portanto, um ângulo inicial de aproximadamente 3 graus.

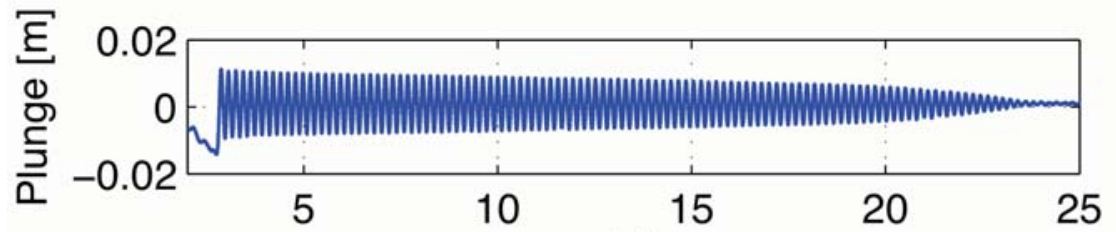

(a)

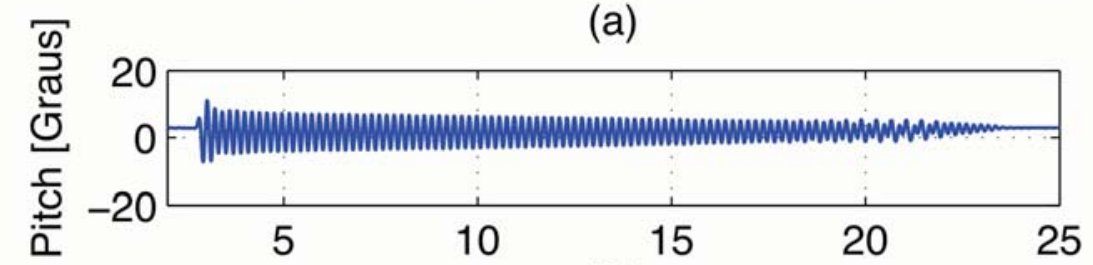

(b)

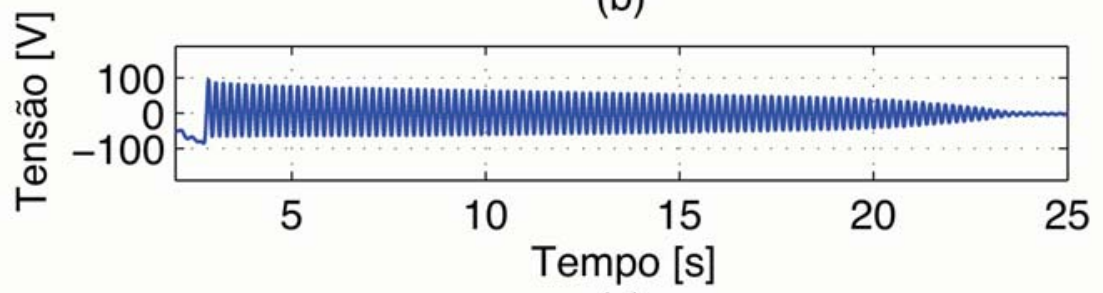

(c)

GRÁFICO 12 - Repostas da Seção Típica, sob velocidade de 10,3 m/s, em circuito aberto: (a) Plunge; (b) Pitch.; (c) Tensão elétrica. 


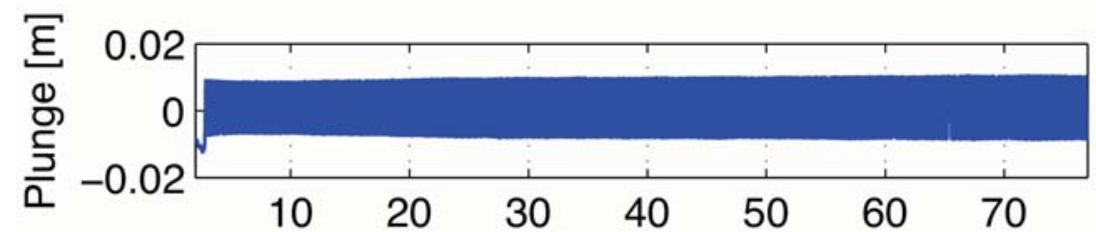

(a)

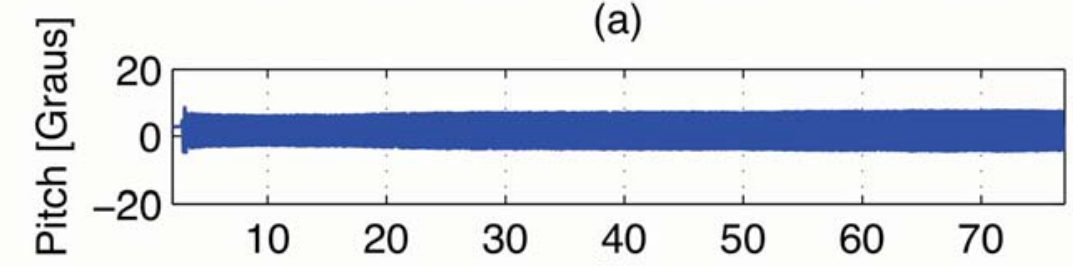

(b)

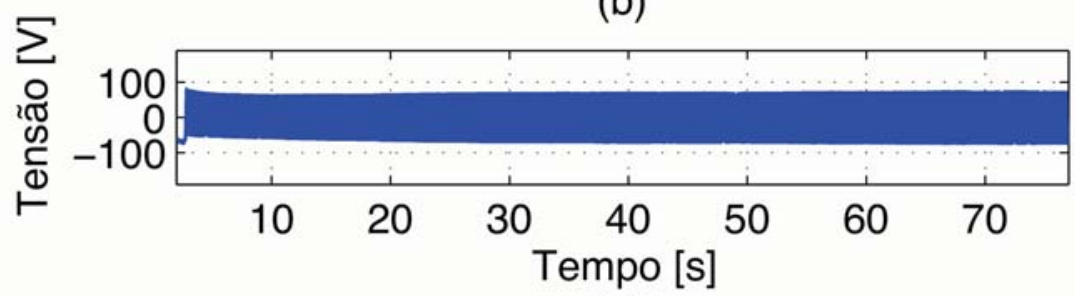

(c)

GRÁFICO 13 - Repostas da Seção Típica, sob escoamento de 10,4 m/s, em circuito aberto: (a) Plunge; (b) Pitch.; (c) Tensão elétrica.

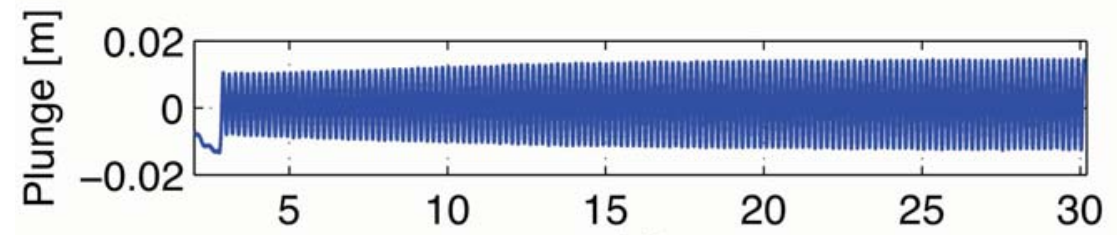

(a)

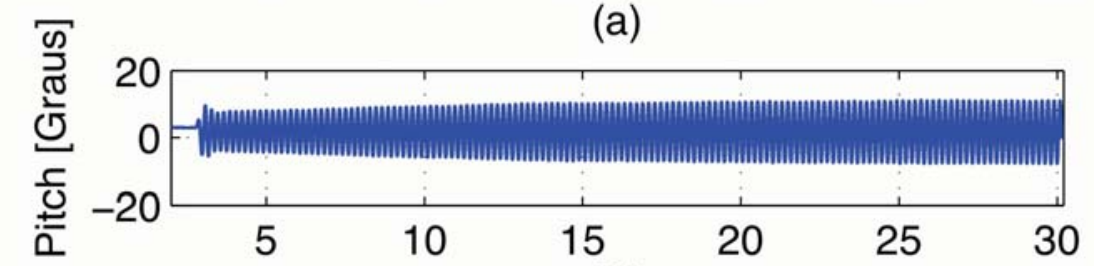

(b)

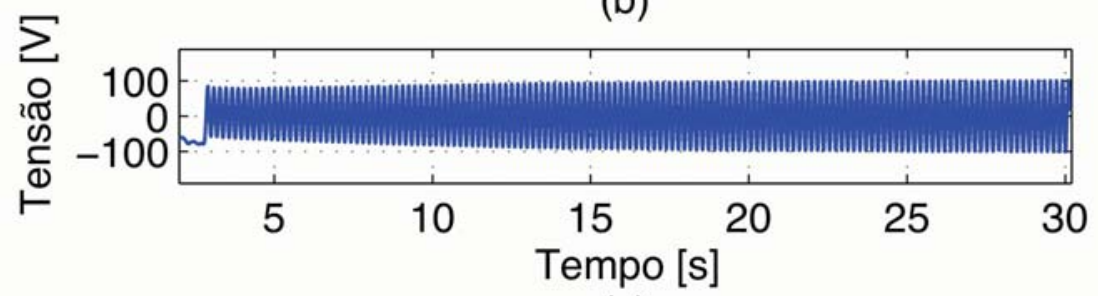

(c)

GRÁFICO 14 - Repostas da Seção Típica, sob velocidade de 10,9 m/s, em circuito aberto: (a) Plunge; (b) Pitch.; (c) Tensão elétrica. 
Após a determinação da velocidade em que LCOs são detectados, verificou-se o desempenho das técnicas SSDS e SSDI na atenuação de oscilações aeroelásticas não lineares.

O Gráfico 15 apresenta o deslocamento plunge, pitch e tensão elétrica, medidos na velocidade de 10,4 m/s, quando a técnica SSDS é utilizada. Um deslocamento inicial de 0,01 $\mathrm{m}$ foi aplicado ao GDL de deslocamento linear como condição inicial. O sistema foi mantido na condição de circuito aberto durante 40 segundos, quando então os materiais piezelétricos foram conectados ao circuito chaveador. Observa-se que o sistema apresenta oscilações persistentes e com amplitudes bem definidas durante os 40 segundos. Após cerca de 8 segundos (48 segundos) as oscilações nos dois GDLs mecânicos, e consequentemente no elétrico, foram suprimidas. Observou-se, também a amplificação da tensão elétrica de um valor de $70 \mathrm{~V}$, para $101 \mathrm{~V}$. Assim como no caso linear, a técnica SSDS é capaz de suprimir oscilações aeroelásticas não lineares de uma seção típica com free play.
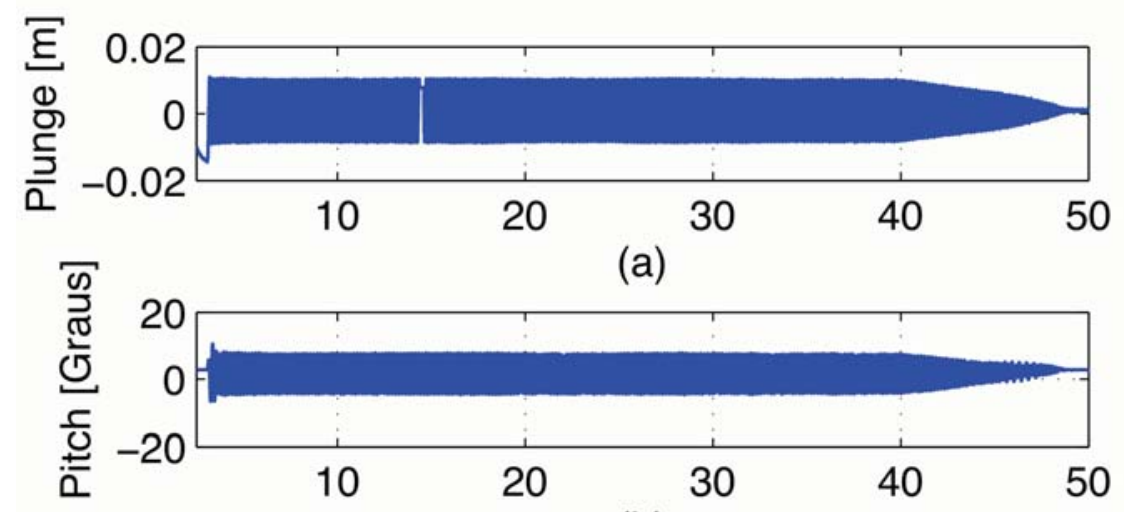

(b)

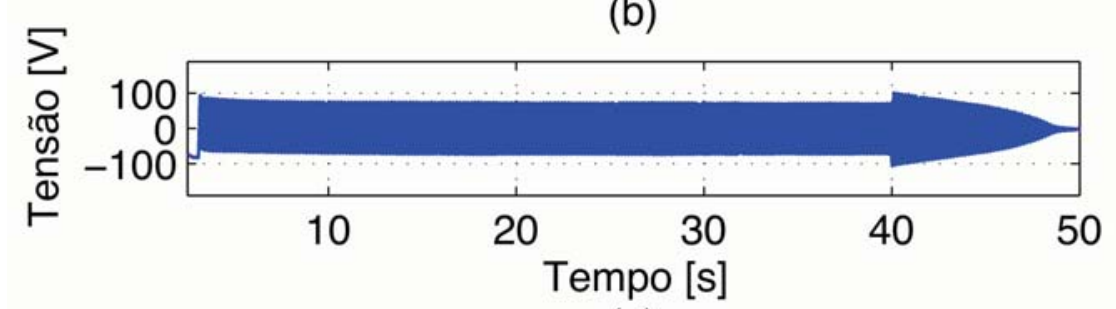

(c)

GRÁFICO 15 - Repostas da Seção Típica, sob velocidade de 10,4 m/s, com acionamento do SSDS, após $\mathrm{t}=40 \mathrm{~s}$ : (a) Plunge; (b) Pitch.; (c) Tensão elétrica.

Posteriormente verificou-se o desempenho da técnica SSDI na atenuação de LCOs. O ensaio foi realizado nas mesmas condições do caso SSDS. O sistema foi mantido em circuito aberto até o tempo de 40 segundos. Novamente, observou-se LCOs bem definidos nos três GDLs até esse momento. Os materiais piezelétricos foram conectados ao circuito 
chaveador no tempo 40 segundos. Rapidamente, após cerca de 6 segundos. As oscilações nos dois GDLs foram suprimidas. Observou-se, também a amplificação da tensão elétrica de um valor de 74V para 125V com o SSDI (Gráfico 16c). Como esperado, o sistema SSDI foi capaz de atenuar oscilações aeroelásticas não lineares em um tempo menor que o sistema SSDS. Vale destacar que um desempenho melhor pode ser obtido com o sistema SSDI caso se consiga reduzir a resistência interna da bobina, utilizada para se obter a indutância requerida, e do circuito chaveador. Neste caso, o coeficiente de inversão seria aumentado, aumentado a dissipação de energia.

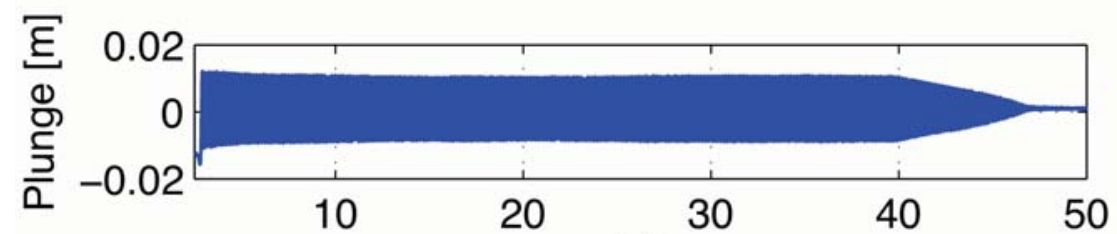

(a)

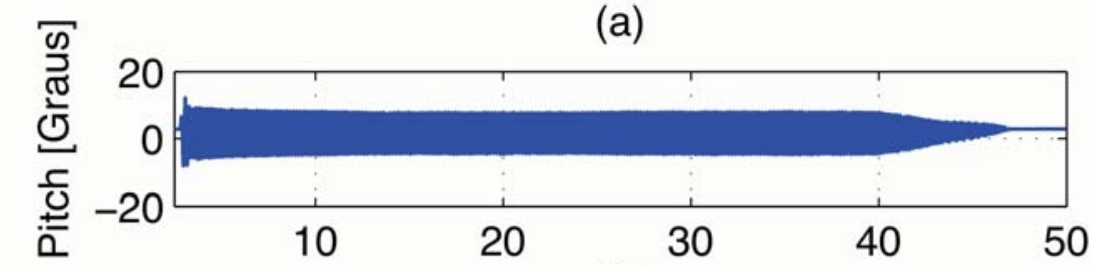

(b)

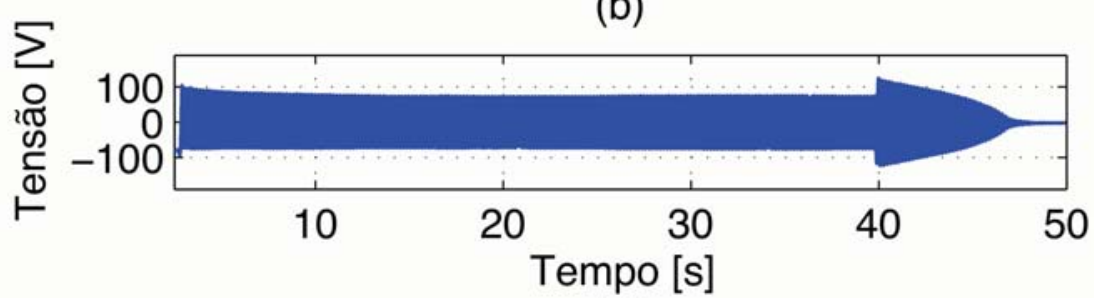

(c)

GRÁFICO 16 - Repostas da Seção Típica, sob velocidade de 10,4 m/s, com acionamento do SSDI, após t = 40s: (a) Plunge; (b) Pitch.; (c) Tensão elétrica.

O Gráfico 17 mostra em detalhe o processo de chaveamento para os casos SSDS e SSDI durante os ensaios aeroelásticos não lineares. Obseva-se o cancelamento da tensão elétrica no caso SSDS (Gráfico 17a) e a inversão para o caso SSDI (Gráfico 17b). Fica claro também, que o processo de inversão é limitado, ou seja, coeficiente de inversão menor que um, devido à resistência interna do circuito chaveador. 


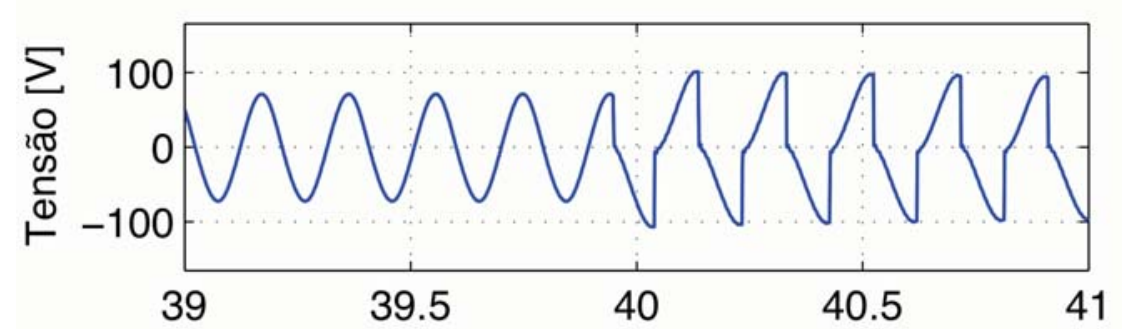

(a)

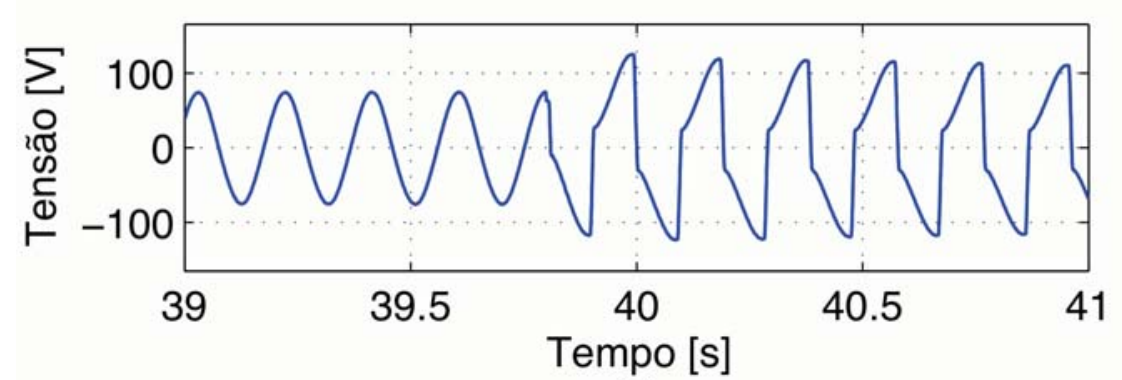

(b)

GRÁFICO 17 - Detalhe do sinal de tensão elétrica, após acionamento do: (a) SSDS; (b) SSDI.

Assim como no caso linear, anteriormente apresentado, foi verificada a capacidade de atenuação das técnicas SSDS e SSDI em velocidades maiores que 10,4 m/s. Para isso, testes foram realizados em velocidades maiores que $10,4 \mathrm{~m} / \mathrm{s}$ e sempre com os materiais piezelétricos conectados ao circuito chaveador. No caso SSDS a seção típica apresenta LCO em $11,2 \mathrm{~m} / \mathrm{s}$, como mostra o Gráfico 18. Notou-se que com o SSDS, a seção típica conseguiu apresentar LCOs com amplitudes aceitáveis até a velocidade de escoamento de 11,4 m/s (Gráfico 19). Os aumentos da velocidade em LCO correspondem à 7\% em relação do valor sem controle. Vale ressaltar que para velocidades abaixo de $11,2 \mathrm{~m} / \mathrm{s}$ as oscilações são suprimidas, para a velocidade de $11,4 \mathrm{~m} / \mathrm{s}$ observam-se LCOs e acima desta velocidade as oscilações são autossustentadas e com amplitudes crescentes. 

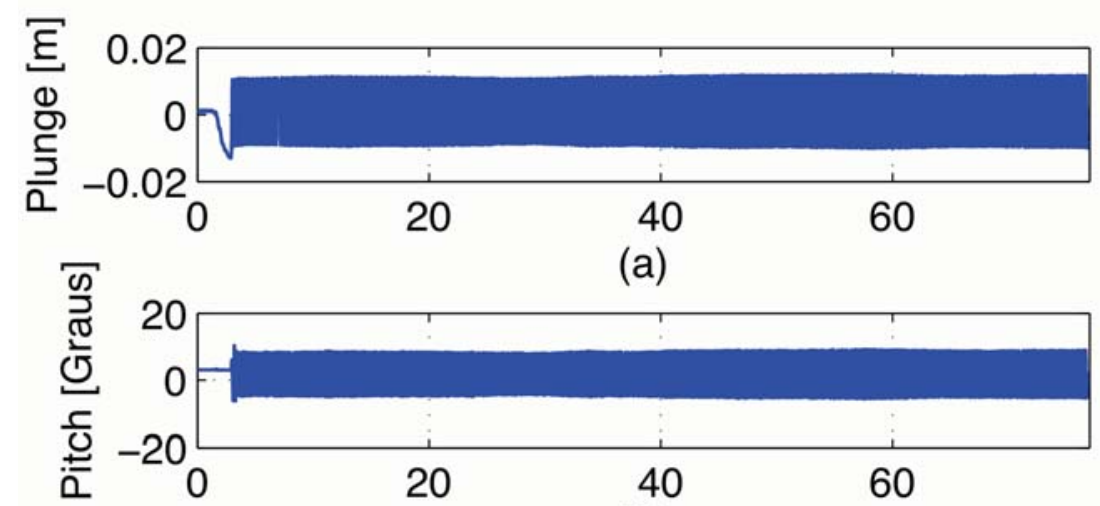

(b)

(c)

GRÁFICO 18 - Repostas da Seção Típica, sob velocidade de 11,2 m/s, com SSDS: (a) Plunge; (b) Pitch.; (c) Tensão elétrica.
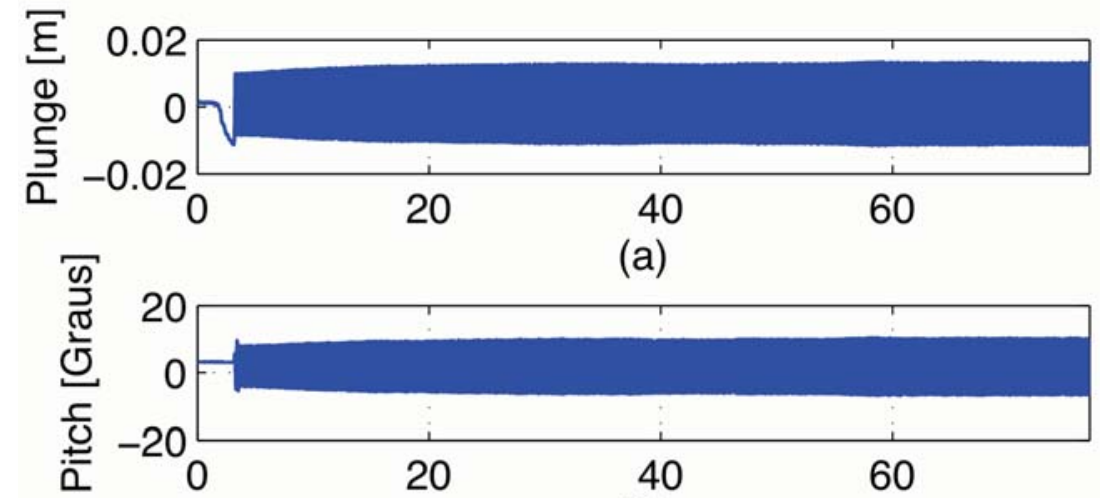

(b)

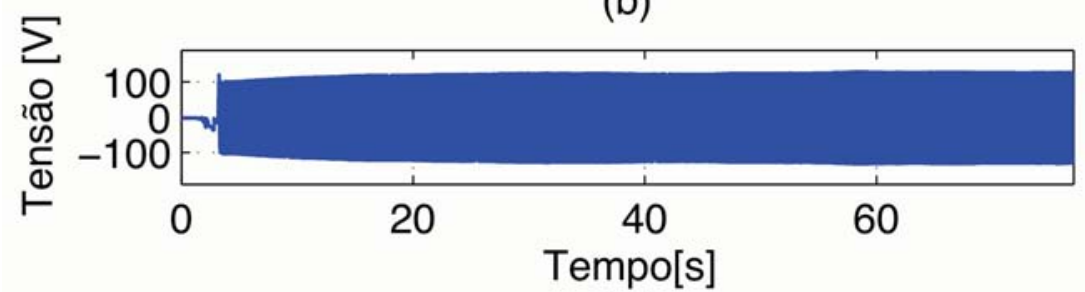

(c)

GRÁFICO 19 - Repostas da Seção Típica, sob velocidade de 11,4 m/s, em circuito aberto: (a) Plunge; (b) Pitch.; (c) Tensão elétrica. 
No caso SSDI, o mesmo ensaio foi realizado e o regime de LCO foi observado até a velocidade de $11,6 \mathrm{~m} / \mathrm{s}$, como mostra o Gráfico 20 . Esse valor representa um aumento de $11,5 \%$ na velocidade em relação ao caso em circuito aberto. No Gráfico 21 , mostra o comportamento do plunge, pitch e tensão elétrica da seção típica sob um escoamento de $11,7 \mathrm{~m} / \mathrm{s}$, e fica claro que apartir da velocidade limite de $11,6 \mathrm{~m} / \mathrm{s}$, as oscilações tornam-se autossustentadas e com amplitudes crescentes.

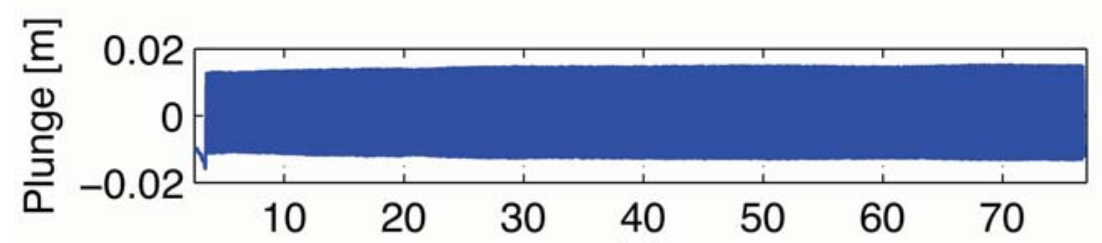

(a)

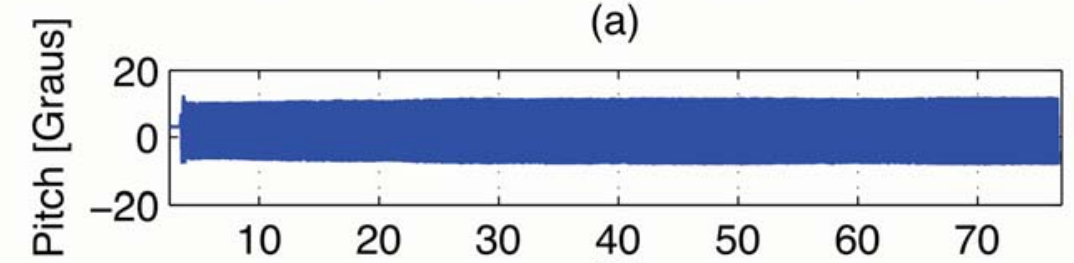

(b)

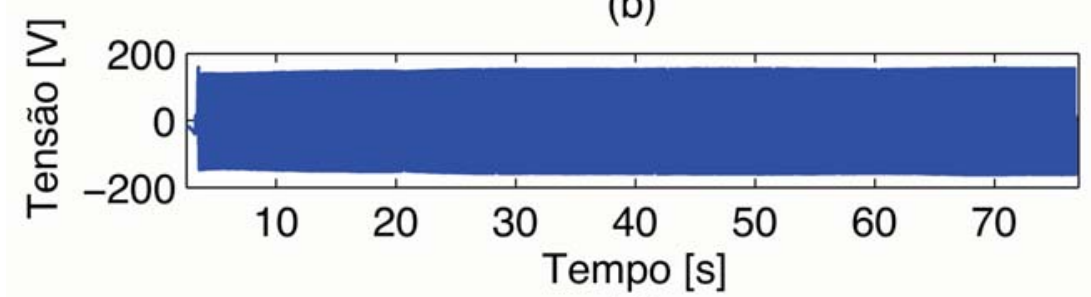

(c)

GRÁFICO 20 - Repostas da Seção Típica, sob velocidade de 11,6 m/s, SSDI: (a) Plunge; (b) Pitch.; (c) Tensão elétrica. 

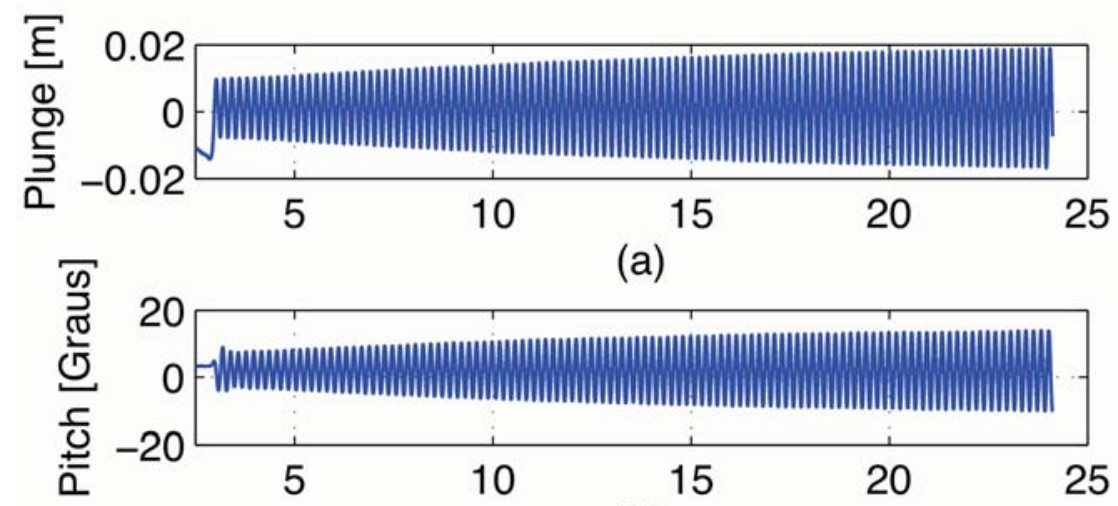

(b)

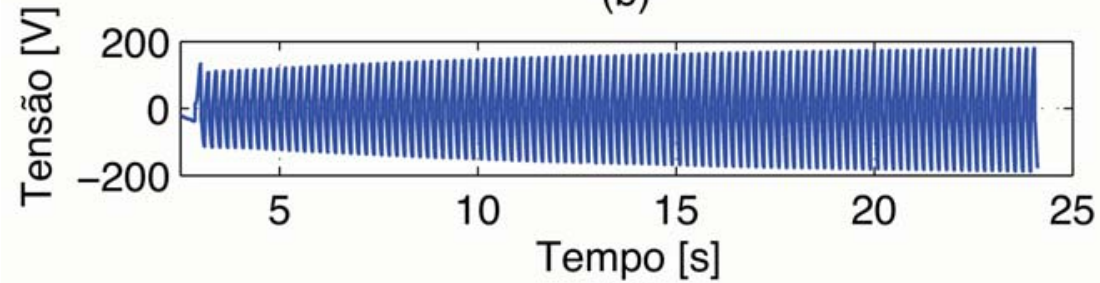

(c)

GRÁFICO 21 - Repostas da Seção Típica, sob velocidade de 11,7 m/s, SSDI: (a) Plunge; (b) Pitch.; (c) Tensão elétrica.

\subsubsection{Ciclo de Trabalho do Sistema Chaveado}

Esta seção apresenta os ciclos de trabalhos das técnicas chaveadas de controle, para o caso linear e caso não linear. O ciclo de trabalho é aqui definido como o produto do acoplamento eletromecânico do sistema $(\theta)$ multiplicado pela tensão elétrica do material piezelétrico versus o deslocamento linear $(h)$.

O Gráfico 22 apresenta o ciclo de trabalho medido para o caso da seção típica linear. A tensão elétrica e deslocamento linear foram medidos na velocidade de $12,9 \mathrm{~m} / \mathrm{s}$, para o SSDS e 13,2 m/s, para o SSDI. Estas velocidades são maiores que a velocidade linear de flutter (sistema em circuito aberto) e foi utilizada no intuito de se ter oscilações persistentes no sistema quando as duas técnicas fossem utilizadas. Portanto, observa-se no Gráfico 22 que a amplitude do deslocamento linear (plunge) aumentando com o tempo, demonstrando que o sistema estava instável. Mesmo assim, é possível observar os efeitos do uso do SSDS e do SSDI para a conversão. 
Observa-se que há a anulação da tensão elétrica no SSDS e a inversão (mesmo que incompleta) no SSDI. A área interna do ciclo representa a energia extraída do sistema, portanto fica clara a razão para o melhor desempenho do sistema SSDI. É importante ressaltar que os dois sinais de referência utilizado na representação do ciclo são de sistemas instáveis, e portanto essa comparação é válida para a região onde o plunge do SSDS e SSDI estão sobrepostos.

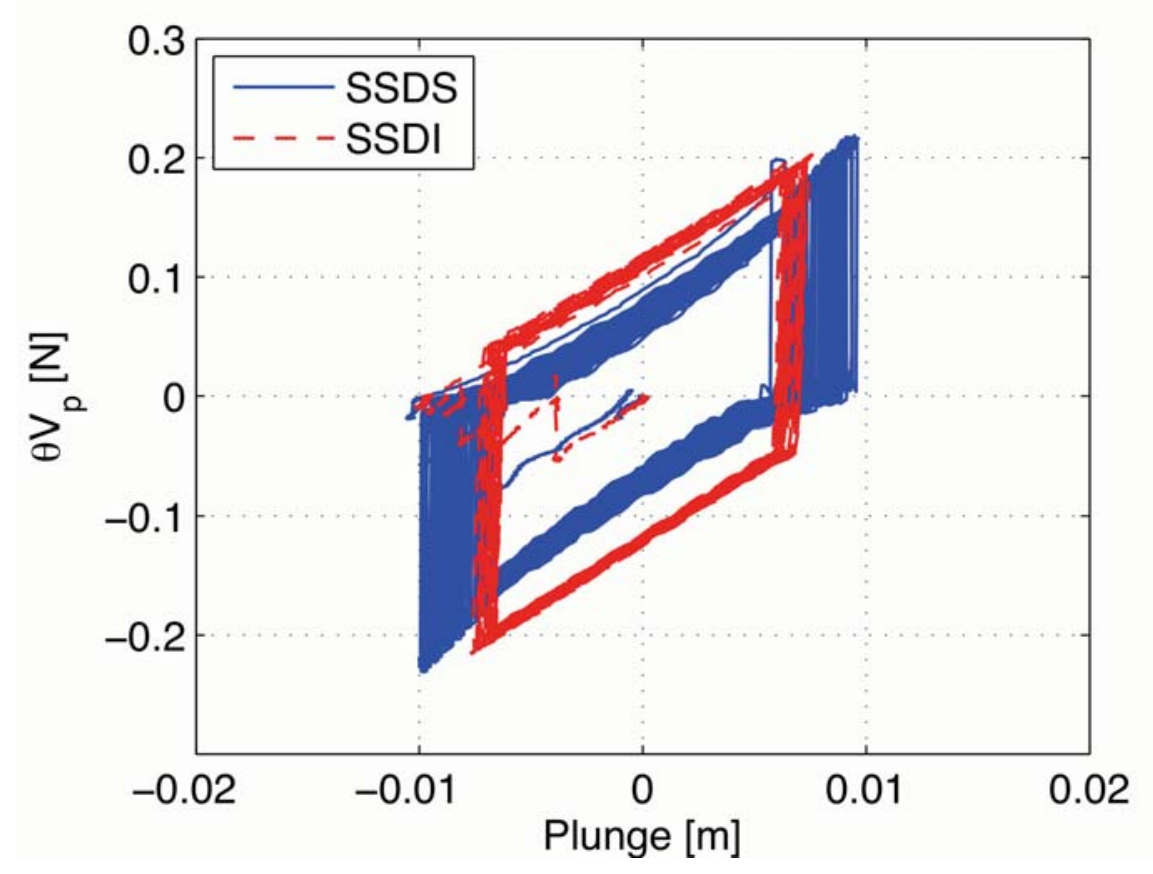

GRÁFICO 22 - Comparação do Ciclo de Trabalho do SSDS com SSDI, para o caso linear.

Os ciclos de trabalho dos casos SSDS e SSDI são apresentados para o caso aeroelástico não linear no Gráfico 23. O caso não linear permitiu medições na velocidade de $11,2 \mathrm{~m} / \mathrm{s}$, para o SSDS e 11,6 m/s, para o SSDI, onde os dois sistemas apresentaram LCOs. Nestes casos, fica também evidente o chaveamento nos pontos de máximo deslocamento, assim como o comportamento da tensão elétrica durante o processo. Fica claro também que a área interna do ciclo no caso SSDI é maior que no caso SSDS, indicando a maior energia extraída do sistema e, consequentemente, maior eficiência no controle de vibrações. 


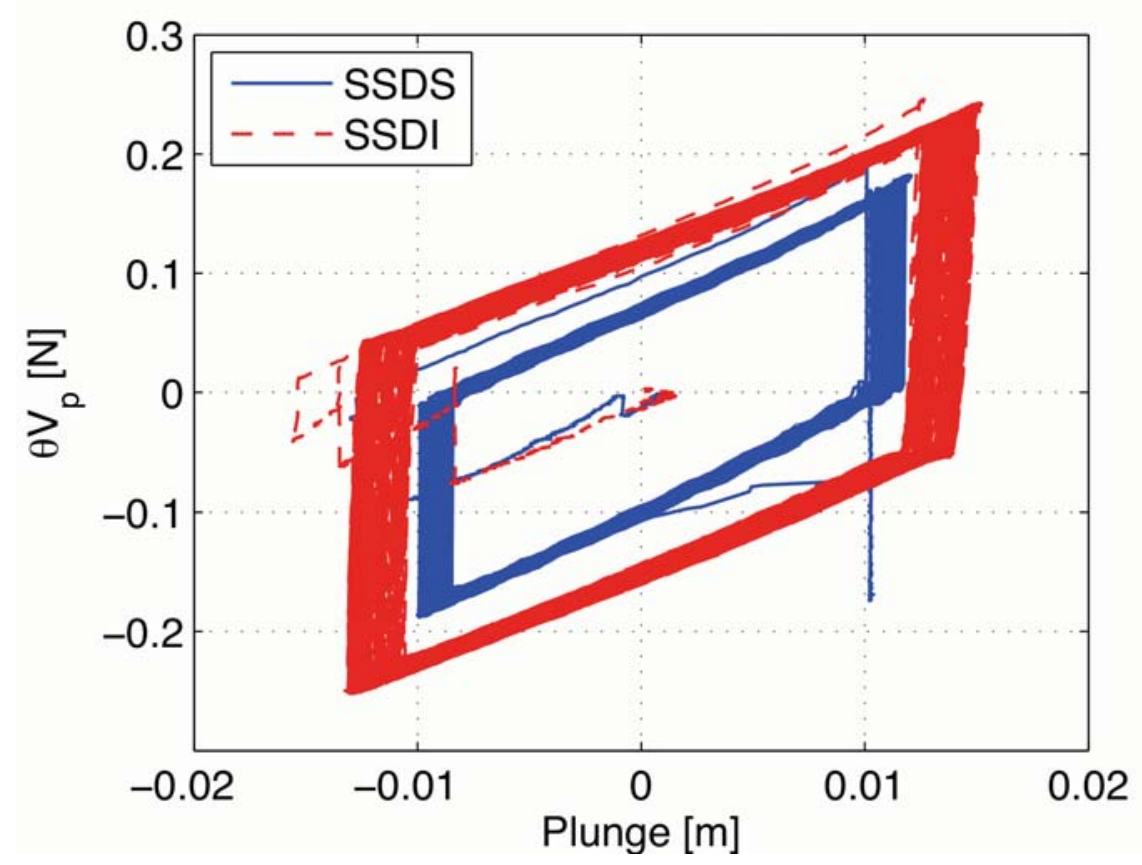

GRÁFICO 23 - Comparação do Ciclo de Trabalho do SSDS com SSDI, para o caso não linear.

\subsection{COLETA PIEZOAEROELÁSTICA DE ENERGIA UTILIZANDO CIRCUITO CHAVEADO}

Os resultados e discussões apresentados na Seção 4.2 mostraram a possibilidade de controle de flutter e de LCOs utilizando as técnicas chaveadas SSDS e SSDI, implementadas com um circuito chaveador autônomo energeticamente. Fica evidente também a ampliação da tensão elétrica nos materiais piezelétricos, assim como a possibilidade de se utilizar o sistema aeroelástico em velocidades maiores que a de flutter (caso linear) ou de LCOs (caso não linear). Tais características possibilitam atingir maiores amplitudes mecânicas e consequentemente, maiores saídas elétricas. Assim sendo, esta seção trata da utilização da seção típica eletromecanicamente acoplada e associada com o circuito chaveador com o intuito de se gerar eletricidade.

São utilizadas três condições diferentes para o circuito elétrico: 1 - materiais piezelétricos conectados a uma ponte retificadora e uma carga resistiva; $2-$ materiais piezelétricos conectados ao circuito chaveador com chaveamento para curto circuito (SSHS) e saída conectada a uma ponte retificadora e carga resistiva; 3 - materiais piezelétricos 
chaveados em um indutor (SSHI) e saída conectada a uma ponte retificadora e carga resistiva. Em todos os casos a carga resistiva é utilizada para se estimar a potência elétrica gerada. $\mathrm{O}$ circuito chaveador modificado para a condição de coleta de energia (com a ponte retificadora) foi apresentado no Capítulo 3.

A ponte retificadora utilizada é composta por 4 diodos e para retificação de onda completa da corrente alternada fornecida pelos materiais piezelétricos. Em paralelo com a saída do sinal retificado, utilizou-se um capacitor filtrando o sinal, de modo a tornar o sinal retificado contínuo.

\subsubsection{Caso Linear}

Os resultados de coleta piezoaeroelástica de energia são apresentados e discutidos nesta seção. Em todos os casos (diferentes domínios elétricos) um conjunto de resistores, variando desde a condição próxima ao curto circuito até próxima ao circuito aberto, foi utilizado. Cada teste em túnel de vento foi realizado na velocidade de flutter do sistema, que varia de acordo com o tipo de chaveamento ou com a carga resistiva considerada.

No primeiro caso investigado os materiais piezelétricos foram conectados à ponte retificadora, e esta a carga resistiva (circuito chaveador não foi utilizado). Esta é a configuração mais básica de um sistema de geração piezelétrica de energia e serviu como referência para as técnicas chaveadas investigadas neste trabalho.

O Gráfico 24 mostra a variação da tensão elétrica retificada com o tempo para quatro valores diferentes de carga resistiva. A tensão elétrica aumenta com o aumento da resistência, exceto para alguns pontos das curvas de $700 \mathrm{k} \Omega$ e $1 \mathrm{M} \Omega$. Para a resistência de valor $100 \Omega$, observa-se o comportamento do sistema em uma condição próxima ao curto circuito. A resistência de $100 \mathrm{k} \Omega$ apresentou um tensão elétrica entre $14 \mathrm{~V}$ e $20 \mathrm{~V}$, considerando a ascendência da curva. $\mathrm{O}$ resistor de $700 \mathrm{k} \Omega$, obteve uma tensão elétrica entre $50 \mathrm{~V}$ e $63 \mathrm{~V}$. Por último, o resistor de $1 \mathrm{M} \Omega$, tensão elétrica entre $55 \mathrm{~V}$ à $63 \mathrm{~V}$. Vale explicar que, no caso aeroelástico linear, é bastante difícil atingir experimentalmente a velocidade linear de flutter. O sistema sempre apresenta características de estabilidade ou instabilidades. Assim, os ensaios são realizados em velocidades tão próximas quanto possível da velocidade linear de flutter, e algumas discrepâncias podem ser obtidas no comportamento dos sinais elétricos. 


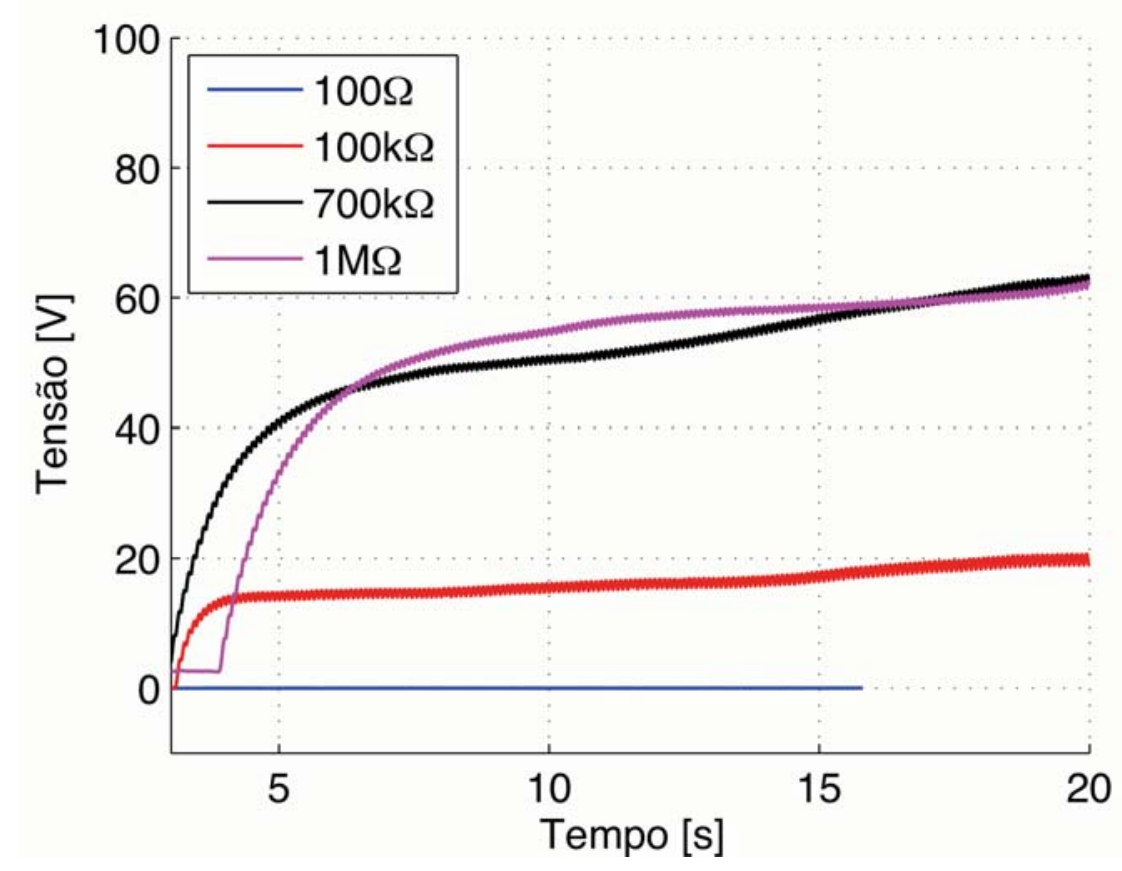

GRÁFICO 24 - Tensão elétrica obtida com o Gerador Básico.

O comportamento da potência elétrica com a variação da carga resistiva é mostrado no Gráfico 25. A potência aumenta com o aumento da resistência desde $100 \Omega$ até $700 \mathrm{k} \Omega$. Quando a resistência é aumentada para $1 \mathrm{M} \Omega$, a potência diminui. Assim, a resistência de $700 \mathrm{k} \Omega$ é a ótima, dentre as verificadas nos experimentos. A potência máxima gerada variou entre $3,5 \mathrm{~mW}$ e $5,5 \mathrm{~mW}$, como mostra o gráfico 25 . 


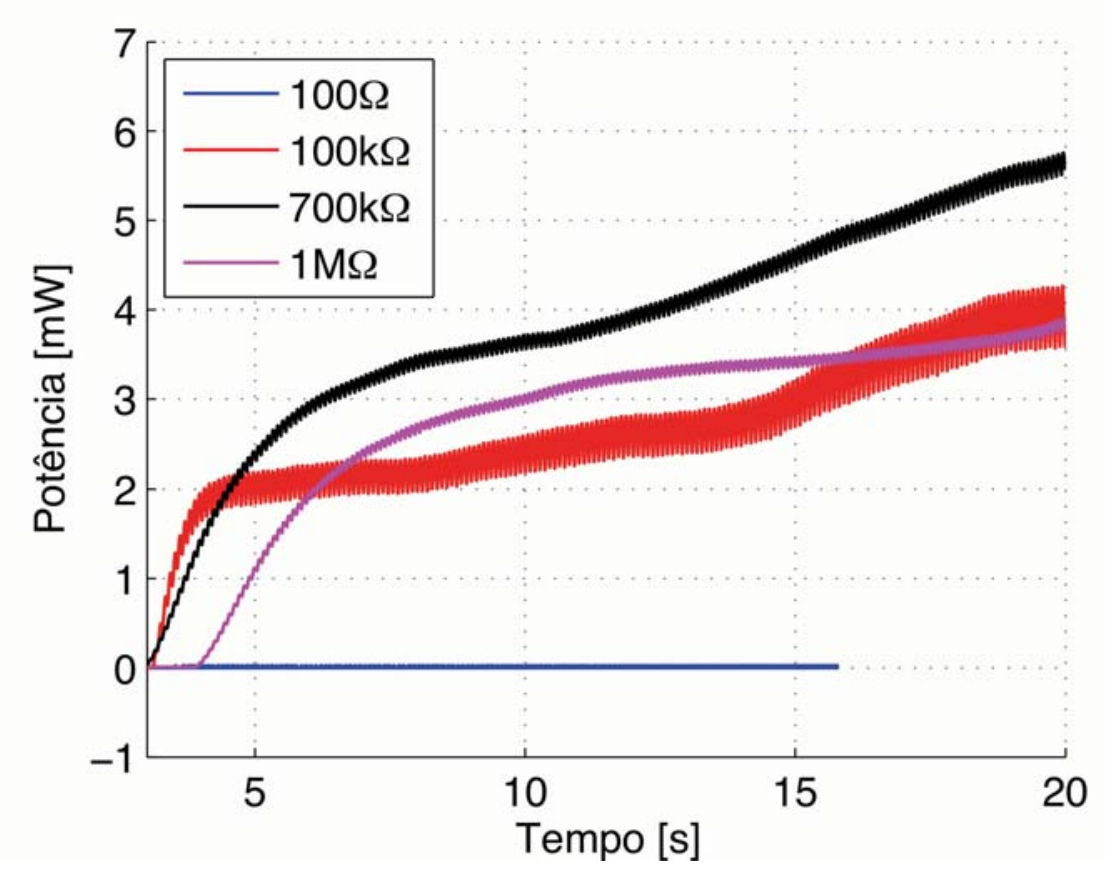

GRÁFICO 25 - Potência obtida com o gerador básico, onde a potência máxima gerada foi de 3,5 mW, fornecida pela resistência de $700 \mathrm{k} \Omega$.

Posteriormente, um procedimento experimental similar foi realizado utilizando-se a técnica SSHS. O Gráfico 26 mostra o aumento da tensão elétrica com o aumento da carga resistiva. A saída elétrica foi medida na velocidade de flutter de cada caso. Como o sistema chaveado tem significativa influência sobre a velocidade de flutter, além de aumentar a conversão (como discutido anteriormente nos casos de controle), amplitudes mecânicas maiores puderam ser atingidas. Consequentemente, observa-se que as voltagens do Gráfico 26, referente ao SSHS, são sempre maiores que do Gráfico 24, do gerador básico (sem circuito chaveador). 


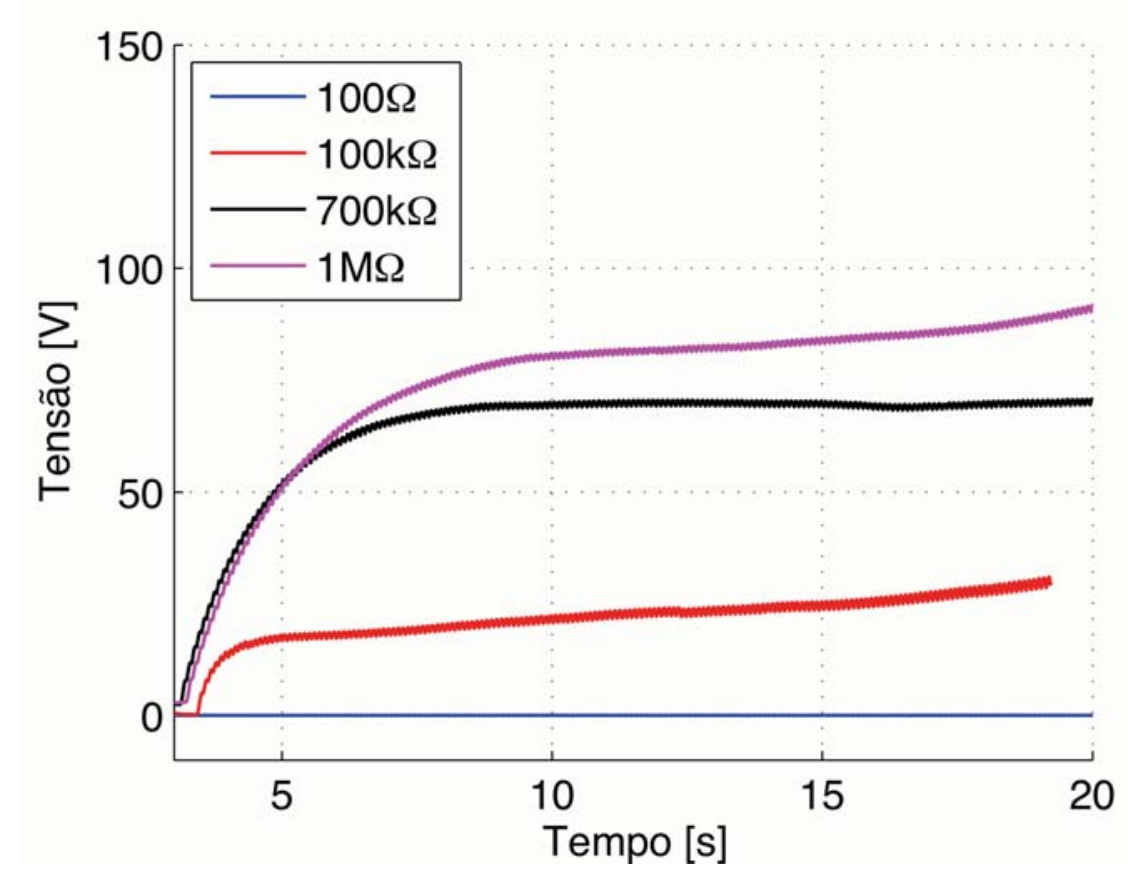

GRÁFICO 26 - Tensão elétrica gerada pelo SSHS.

No gráfico 27, verifica-se que a resistência de $700 \mathrm{k} \Omega$, também fornece a máxima potência (entre as testadas neste caso). Os valores de potência para as resistências de $100 \mathrm{k} \Omega \mathrm{e}$ $1 \mathrm{M} \Omega$ ultrapassaram a potência fornecida pela resistência de $700 \mathrm{k} \Omega$ em alguns pontos. Apesar disso, foi escolhido a resistência de $700 \mathrm{k} \Omega$, como a resistência ótima para o circuito, com potência entre $6,8 \mathrm{~mW}$ à $7 \mathrm{~mW}$. Isso porque, nas regiões que os resistores de $1 \mathrm{M} \Omega \mathrm{e}$ $100 \mathrm{k} \Omega$ forneceram potência maior que o resistor de $700 \mathrm{k} \Omega$, são as regiões onde condições extremas no deslocamento de plunge ocorreram, ou regiões de amplitudes não aceitáveis, que podem danificar o sistema experimental. 


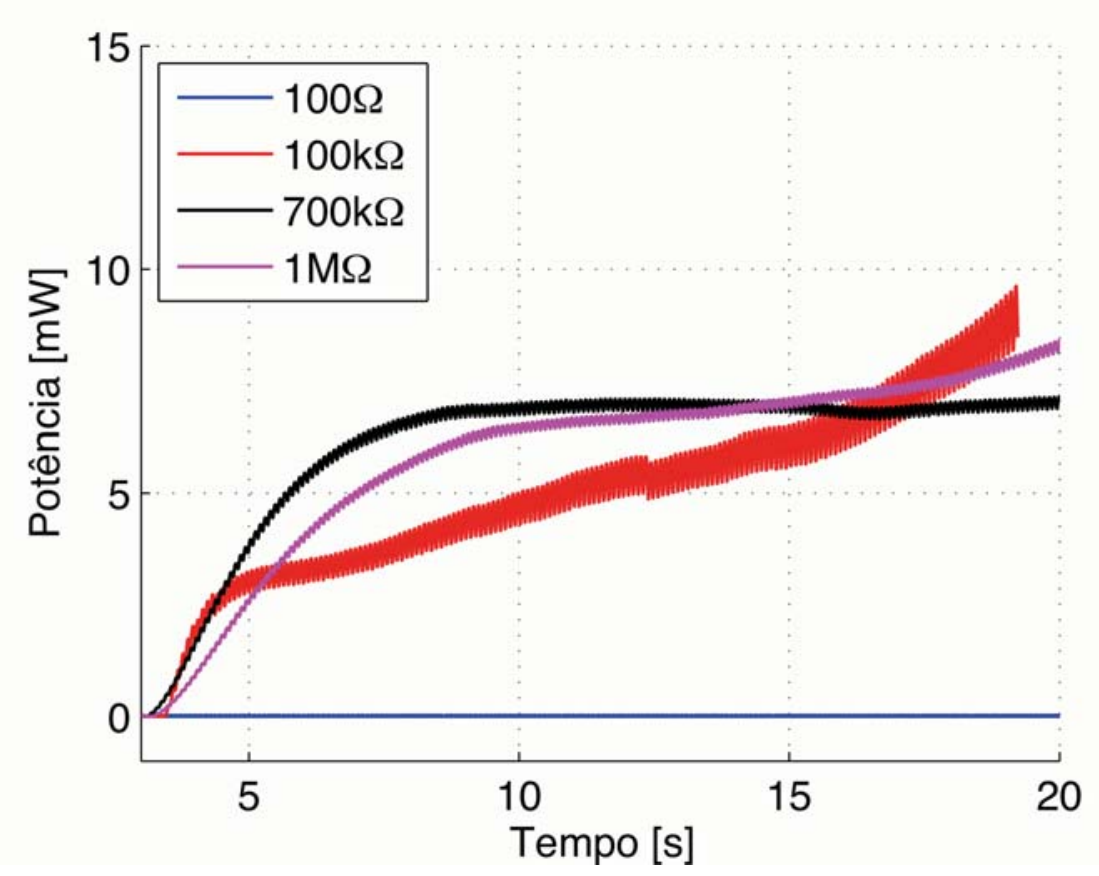

GRÁFICO 27 - Potência obtida com o SSHS, onde a potência máxima gerada foi de $6,8 \mathrm{~mW}$, fornecida pela resistência de $700 \mathrm{k} \Omega$.

Por fim, para o caso linear, investigou-se a geração de energia utilizando a técnica SSHI. Assim como já discutido no caso de controle, o chaveamento no indutor permite um maior incremento na velocidade de flutter e consequentemente maiores amplitudes mecânicas. Assim, neste caso, a tensão elétrica de saída é sempre maior que nos casos anteriores. 


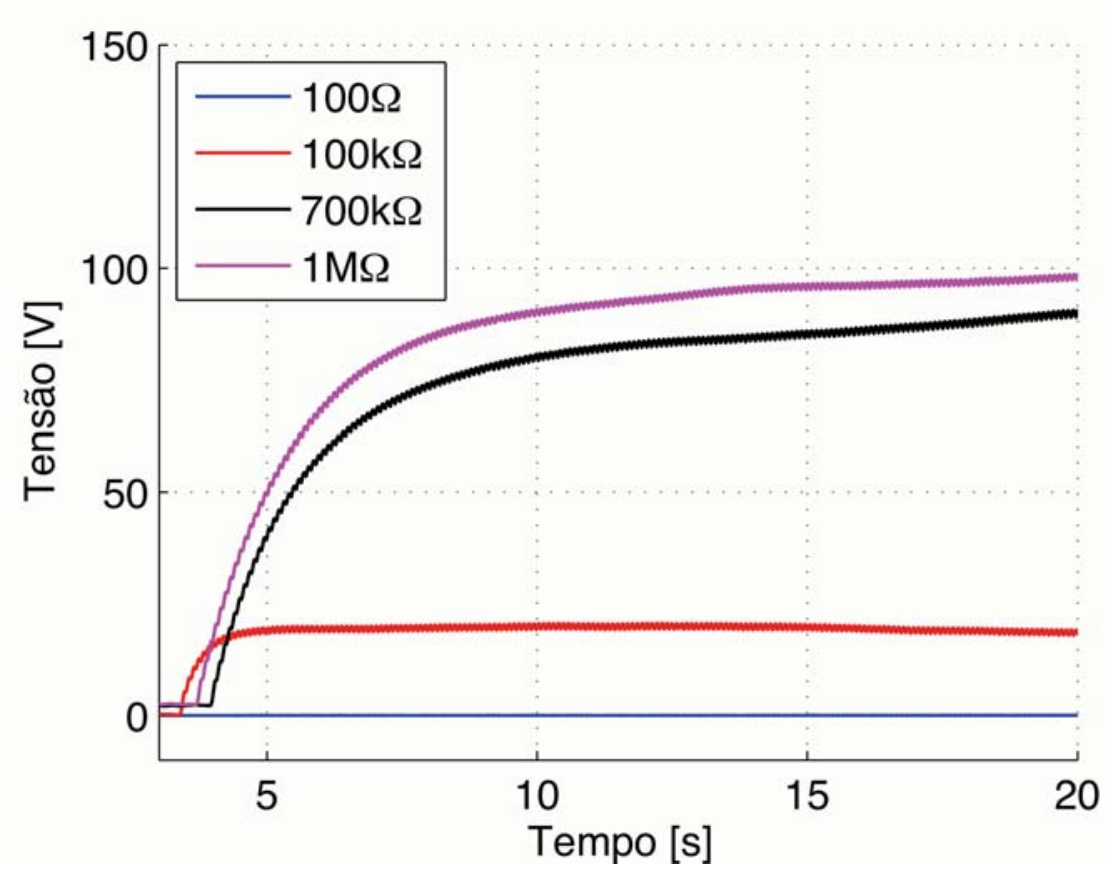

GRÁFICO 28 - Tensão elétrica gerada pelo SSHI.

O comportamento da potência elétrica com a variação da carga resistiva é mostrado no Gráfico 28. Mais uma vez, a resistência de $700 \mathrm{k} \Omega$ fornece a máxima potência, sendo definida como a resistência ótima entre as testadas. A potência gerada com esta resistência variou entre 9,1 mW à 11,5 mW (Gráfico 29).

Tomando-se como base de cálculo os valores iniciais medidos na condição de regime de cada teste, pois representam valores onde as amplitudes de oscilação da seção típicas são aceitáveis, estimou-se o acréscimo de potência gerada pelo circuitos chaveadores. Assim, o uso da técnica SSHS a potência gerada foi, aproximandamente, 94\% maior que em relação à potência gerada apenas com um resistor. A técnica SSHI resultou em potência elétrica $160 \%$ mais elevada que o caso utilizando um resistor. 


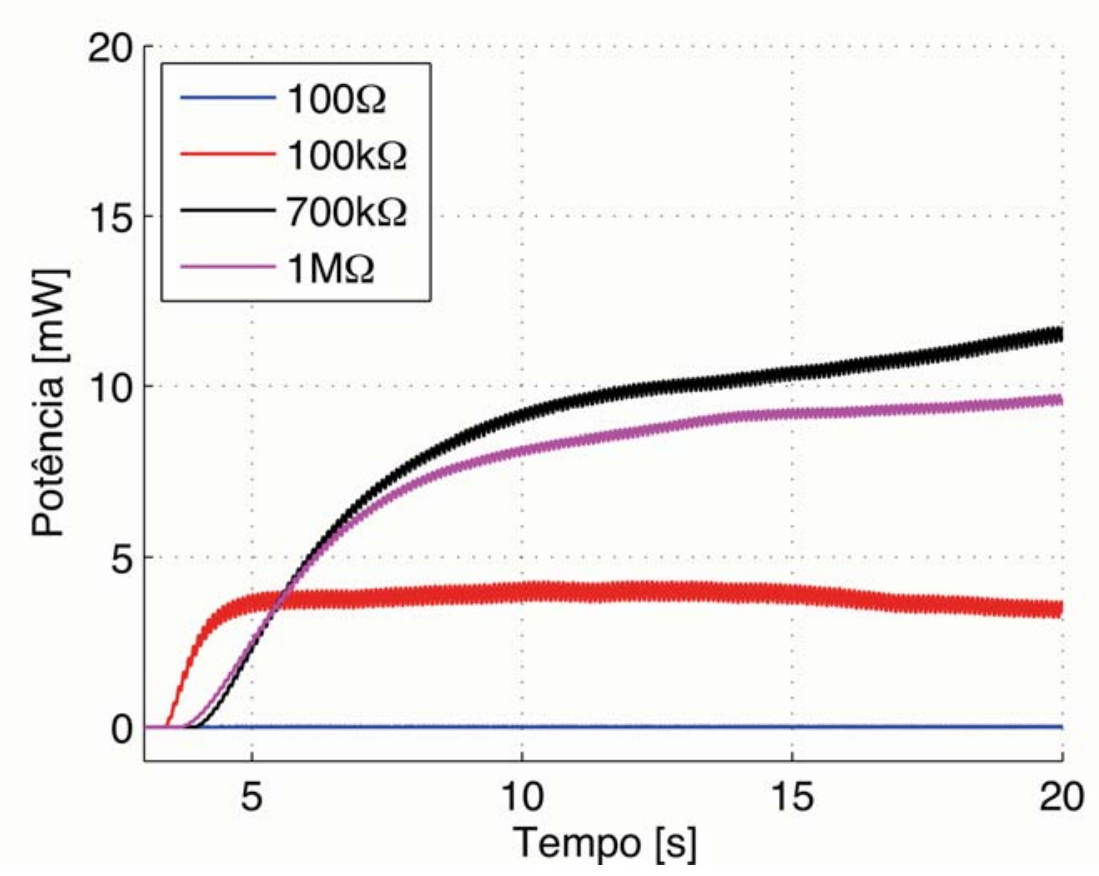

GRÁFICO 29 - Potência obtida com o SSHI, onde a potência máxima gerada foi de 9,1 $\mathrm{mW}$, fornecida pela resistência de $700 \mathrm{k} \Omega$.

Apesar do aumento da potência gerada com o uso dos circuitos chaveadores, o caso linear mostrou-se pouco aplicável, para a geração de energia, já que é difícil alcançar experimentalmente a velocidade crítica de flutter, condição que permitiria uma geração constante.

\subsubsection{Caso Não Linear}

Nesta seção, são apresentados os resultados de coleta de energia a partir de oscilações aeroelásticas não lineares. Novamente, o desempenho das técnicas chaveadas é comparado ao caso básico (carga resistiva). Assim como nos casos de controle, uma folga (free play) foi adicionado ao GDL de deslocamento angular. No caso não linear, foi possível obter LCOs com amplitudes aceitáveis, em velocidades abaixo da velocidade crítica de flutter.

O Gráfico 30 apresenta a variação da tensão elétrica com a carga resistiva. Neste caso, o circuito chaveador não foi utilizado. A tensão elétrica aumenta com o aumento da resistência. Fica claro que, no caso não linear, o sistema permanece em amplitudes fixas (LCOs) ao longo do ensaio. As voltagens obtidas nesse ensaio, são sempre maiores que as 
voltagens do caso equivalente (resistivo) linear. A presença do free play leva o sistema para maiores amplitudes mecânicas e, consequentemente, elétricas.

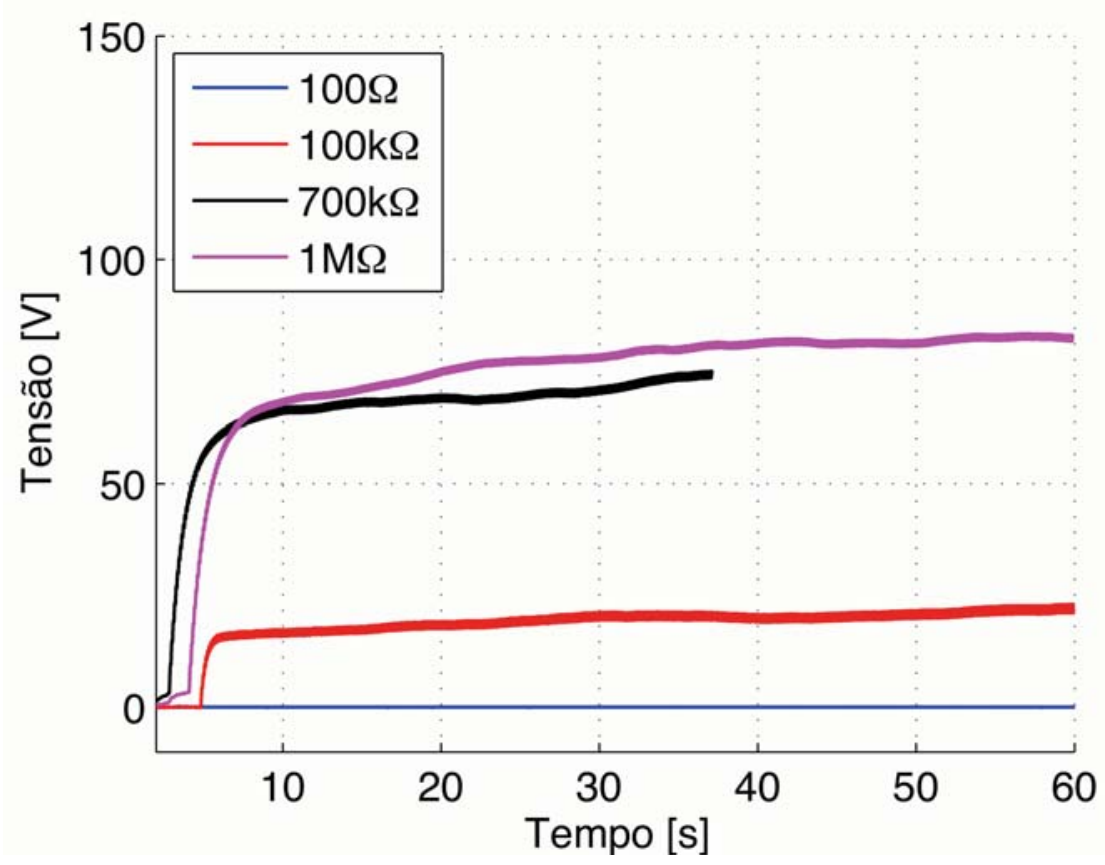

GRÁFICO 30 - Tensão elétrica obtida com o Gerador Básico.

No Gráfico 31, observa-se que a potência aumenta com o aumenta da resistência desde $100 \Omega$ até $700 \mathrm{k} \Omega$. Quando a resistência é aumentada para $1 \mathrm{M} \Omega$ a potência diminui. Assim, potência máxima foi fornecida, novamente, pela resistência de $700 \mathrm{k} \Omega$, com valor de aproximadamente $7,8 \mathrm{~mW}$, maior que a máxima potência obtida para o mesmo circuito quando testado o caso linear. 


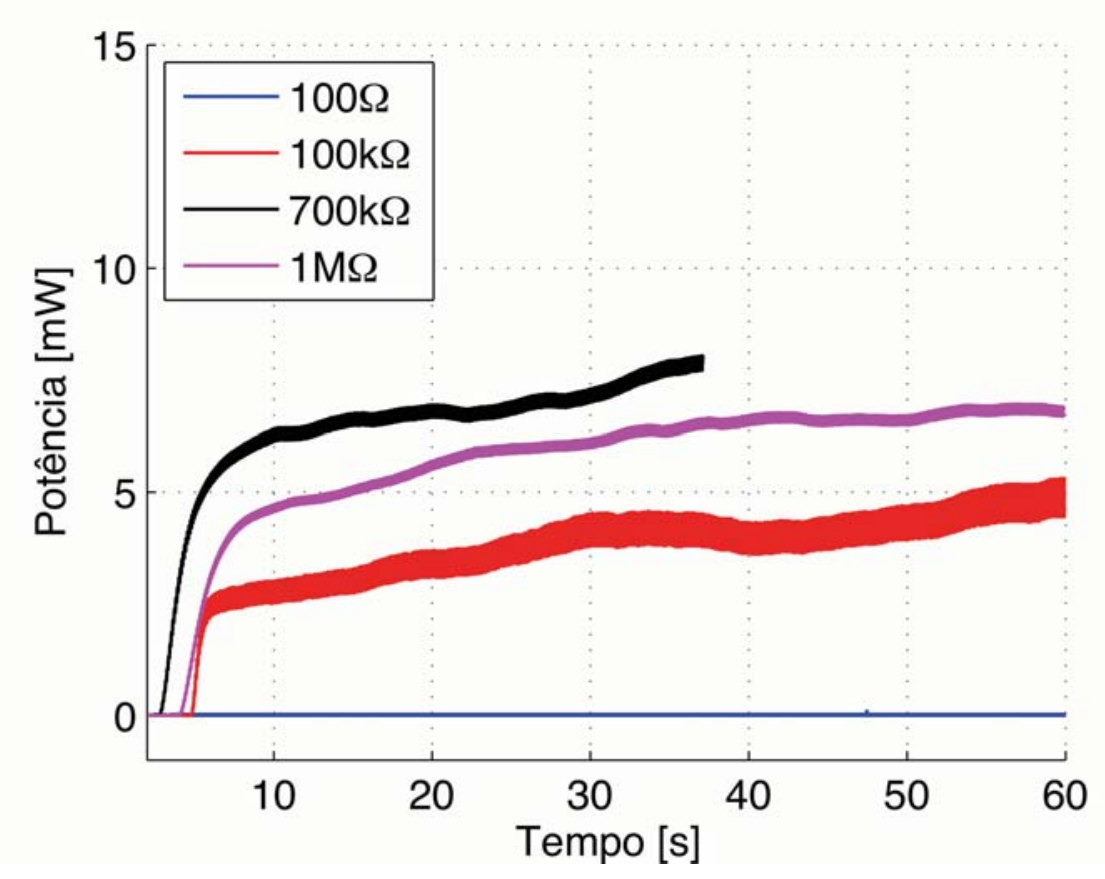

GRÁFICO 31 - Potência obtida com o Gerador Básico, onde a potência máxima gerada foi de 7,8 mW, fornecida pela resistência de $700 \mathrm{k} \Omega$.

Posteriormente, a técnica chaveada SSHS foi utilizada nos experimentos de coleta de energia. O Gráfico 32 mostra que a tensão elétrica aumenta com o aumento da carga resistiva. A tensão elétrica para cada carga considerada é sempre maior que a tensão de cada carga do caso não chaveado. 


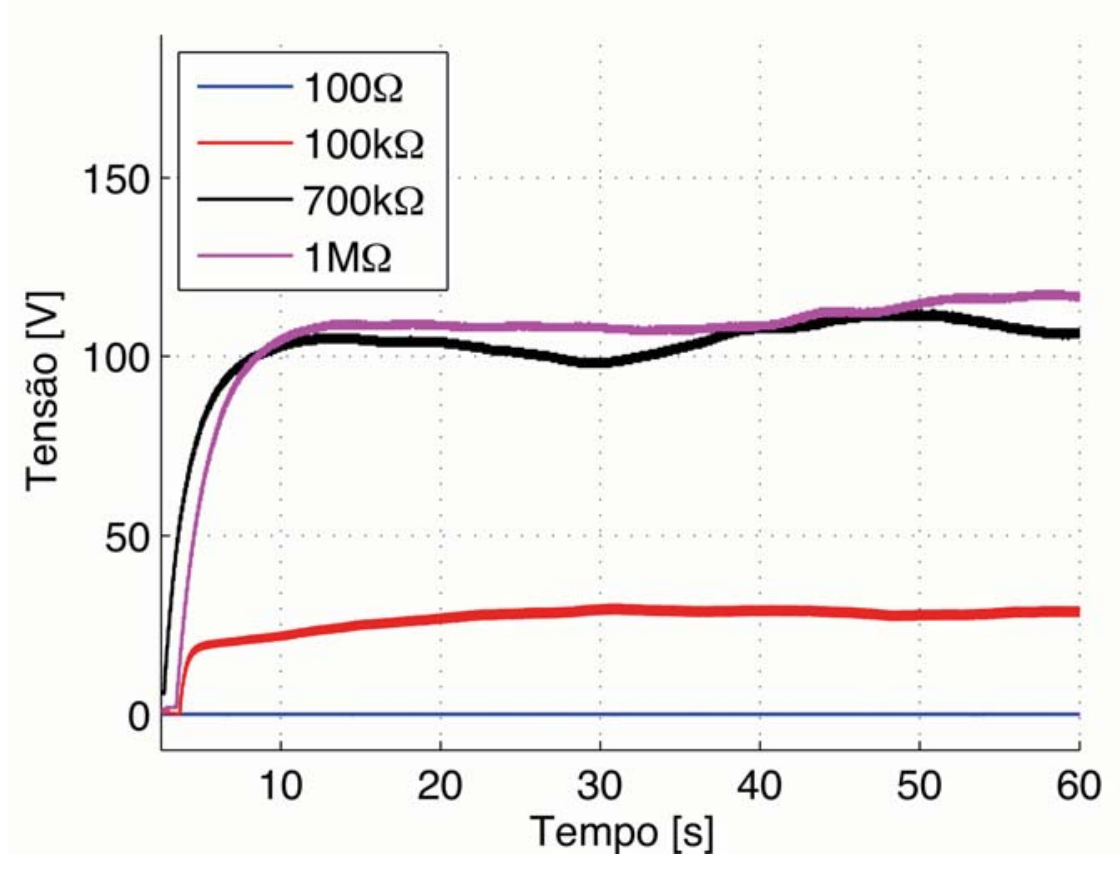

GRÁFICO 32 - Tensão elétrica gerada pelo SSHS.

A variação da potência elétrica é mostrada na Figura 33. Novamente, a máxima potência é fornecida quando a carga resistiva de $700 \mathrm{k} \Omega$ é utilizada. No caso, uma potência média de $15,7 \mathrm{~mW}$ foi gerada, sensivelmente maior que o caso aeroelástico linear $6,8 \mathrm{~mW}$ e o caso puramente resistivo não linear $7,8 \mathrm{~mW}$. 


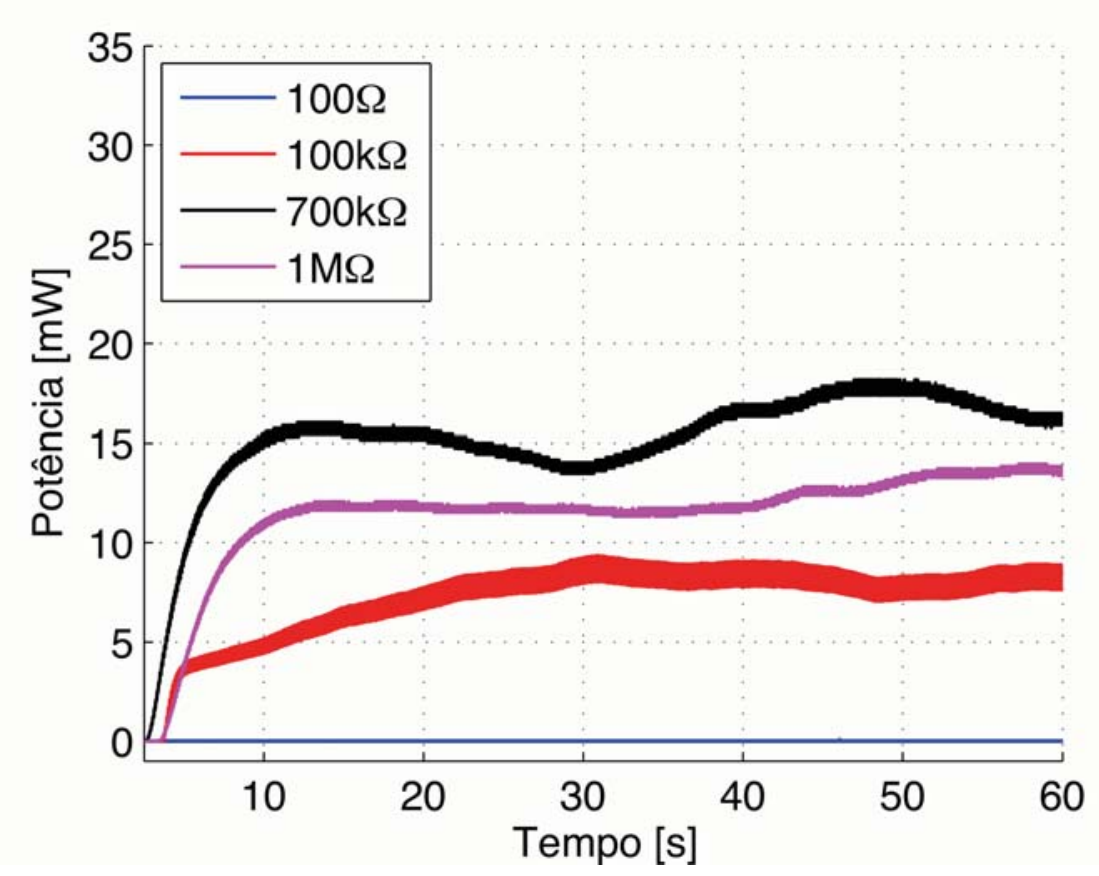

GRÁFICO 33 - Potência obtida com o SSHS, onde a potência máxima gerada foi de $15,7 \mathrm{~mW}$, fornecida pela resistência de $700 \mathrm{k} \Omega$.

O comportamento da tensão elétrica, quando a técnica SSHI foi utilizada, é mostrado no Gráfico 34. A tensão elétrica aumenta com o aumento da resistência. Entretanto, nota-se, que há uma diferença pequena entre as tensão elétrica geradas pelo resistor de $700 \mathrm{k} \Omega$ e 1 $\mathrm{M} \Omega$. Isso pode ser explicado, pelo caráter híbrido do circuito. As duas medidas foram obtidas sob uma mesma velocidade de escoamento e, quanto menor a resistência utilizada em paralelo com o circuito, menor será a eficiência de controle do mesmo. Por isso, nota-se um pequena variação no sinal de tensão elétrica da resistência de $700 \mathrm{k} \Omega$, pois mantem a oscilação no limite da amplitude aceitável. E esse fenômeno, foi observado no SSHS (Gráfico 32) e no SSHI (Gráfico 34). 


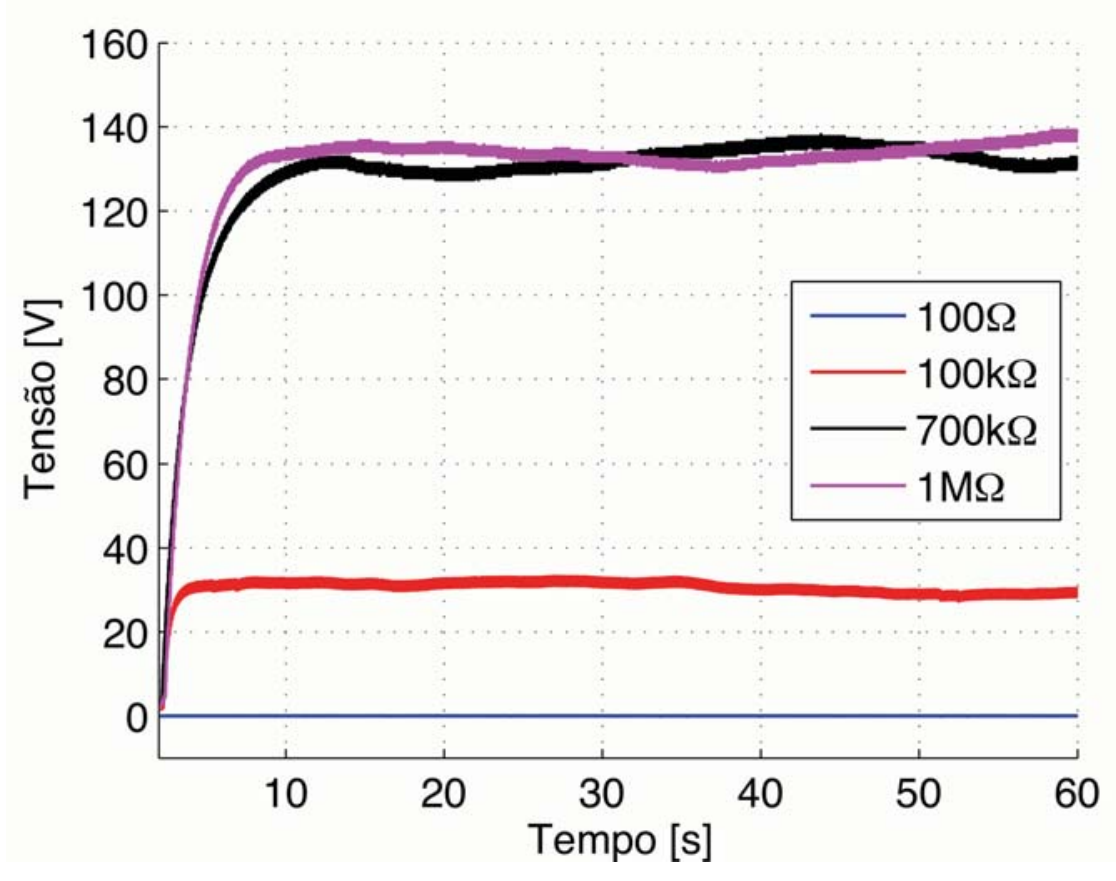

GRÁFICO 34 - Tensão elétrica gerada pelo SSHI.

A variação da potência elétrica com a carga resistiva para o caso SSHI é mostrada no Gráfico 35. A resistência de $700 \mathrm{k} \Omega$ forneceu a máxima potência média de $25,5 \mathrm{~mW}$. Novamente, sensivelmente maior que todos os casos anteriormente apresentados. 


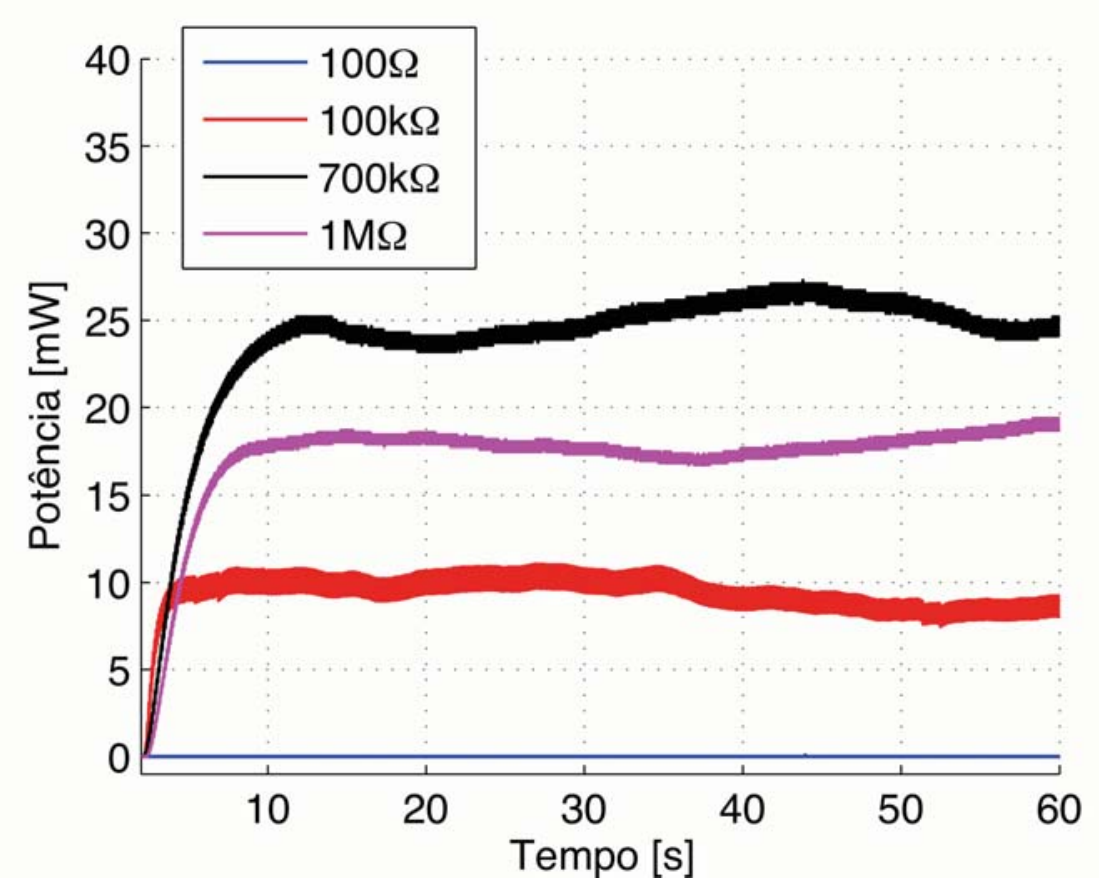

GRÁFICO 35 - Potência obtida com o SSHI, onde a potência máxima gerada foi de $25,5 \mathrm{~mW}$, fornecida pela resistência de $700 \mathrm{k} \Omega$.

Os resultados do caso não linear mostram que a potência gerada, quando a técnica SSHS é utilizada é $101,3 \%$ maior que a obtida com o gerador básico (puramente resistivo). Esse resultado é próximo ao obtido no caso linear. Entretanto com a técnica SSHI, o caso não linear apresentou uma potência $227 \%$ maior que a potência do gerador básico.

A inserção de uma não linearidade ao sistema piezoaeroelástico, favorece oscilações em LCO, amplitudes maiores e, consequentemente, favorece o desempenho de um gerador piezoaeroelástico. A técnica SSHI apresentou o melhor desempenho quanto a conversão de energia, o que já havia sido evidenciado nos ciclos de trabalho, anteriormente discutidos. 


\section{CONCLUSÕES}

Neste trabalho, o controle semi-passivo de vibrações aeroelásticas lineares e não lineares e a coleta pizoaeroelástica de energia foram investigadas experimentalmente. Uma seção típica com 2GDLs e acoplamento eletromecânico no GDL de deslocamento linear foi utilizada. Um circuito chaveador autônomo energeticamente foi desenvolvido e duas técnicas foram investigadas, o SSDS e o SSDI.

O circuito chaveador autônomo desenvolvido foi inicialmente testado para o controle de vibrações de uma viga eletromecanicamente acoplada. A condição de contorno utilizada foi engastado-livre. Esta viga é composta por uma subestrutura metálica, envolvida em sua superfície superior e inferior por camadas de piezocerâmica. Estas piezocerâmicas são polarizadas em direções opostas, possibilitando a ligação em série entre as mesmas. A excitação harmônica de base foi realizada em uma faixa de frequências que incluíam apenas o primeiro modo de vibração. A FRF mecânica foi obtida em três casos: 1 - um resistor ligado aos eletrodos das piezocerâmicas; 2 - utilizando a técnica SSDS e 3 - utilizando a técnica SSDI. Os resultados mostram que o caso SSDI proporcionou a maior redução de vibrações no sistema.

O circuito chaveador desenvolvido foi testado experimentalmente no controle de oscilações aeroelásticas. Inicialmente foram realizados ensaios aeroelásticas lineares. Neste caso, a velocidade linear de flutter em circuito aberto foi definida como $12 \mathrm{~m} / \mathrm{s}$. O chaveamento para curto circuito (SSDS) foi testado, assim como o chaveamento para um indutor (SSDI). Verificou-se que, na velocidade de flutter, as duas técnicas propiciaram a supressão de oscilações. Entretanto, o caso SSDI foi capaz de atenuar as oscilações mais rapidamente. O melhor desempenho da técnica SSDI está relacionada com a inversão do sinal de tensão elétrica, o que proporciona uma força dissipativa no sistema.

Posteriormente, ensaios foram realizados em velocidades maiores que a velocidade linear de flutter. Assim, pôde-se verificar a capacidade de cada uma das técnicas em aumentar a velocidade de flutter, ou expandir o envelope, do sistema. Quando o SSDS foi utilizado, ocorreu um aumento de aproximadamente $8,5 \%$ na velocidade de flutter. No caso SSDI, um incremento de 11,4\% na velocidade linear de flutter. Em ambos os casos, os ciclos de trabalho medidos foram apresentados. Fica claro que a energia extraída do sistema no caso SSDI é maior, explicando o melhor desempenho no controle de vibrações. 
O desempenho das duas técnicas chaveadas, também foi verificado experimentalmente para o caso aeroelástico não linear. Uma folga foi inserida no GDL de deslocamento angular, induzindo uma bilinearidade no sistema. Neste caso, a velocidade, em que oscilações persistentes são observadas, diminui. Assim, LCOs foram medidos na velocidade de 10,4 m/s. Apesar disso, o sistema apresenta instabilidades para velocidades maiores que $10,4 \mathrm{~m} / \mathrm{s}$.

As duas técnicas chaveadas, aqui investigadas, apresentaram bom desempenho também na supressão de LCOs. O caso SSDI, novamente apresentou melhor desempenho. Os ciclos de trabalho apresentados comprovam que o sistema SSDI é capaz de extrair mais energia do sistema. Novamente, verificou-se a capacidade do sistema SSDS e SSDI de suprimir LCOs acima de 10,4 m/s. No primeiro caso (SSDS) ocorreu um aumento de 7\% enquanto no segundo de $11,5 \%$. Assim como no caso linear, além de suprimir oscilações não lineares na velocidade que estas surgem, os controladores semi-passivos autônomos proporcionaram um aumento da velocidade em que amplitudes aceitáveis ocorrem.

Aparentemente, os resultados apresentados neste trabalho são os primeiros publicados na literatura de controle aeroelásticos, com controladores autônomos energeticamente utilizando materiais piezelétricos. Além disso, é importante ressaltar que a utilização da técnica SSDI possibilitou a utilização de um indutor de certa de 8 Henries, pequeno se comparado com o indutor de aproximadamente, $11 \mathrm{kH}$ que deveria ser utilizado no caso de um controlador passivo do tipo resistivo indutivo. Os resultados aqui apresentados resgatam a possibilidade de desenvolvimento de controladores piezelétricos para supressão de flutter, anteriormente criticados por Heeg (1993) e McGowan (1999).

A maior conversão de energia mecânica em elétrica, proporcionada pelos circuitos chaveados, levou a investigação de casos de coleta piezoaeroelástica de energia. No caso, o circuito chaveado foi configurado como gerador de energia, associando-o a uma ponte retificadora e também uma carga resistiva. Foram testados o caso aeroelástico linear e não linear. No caso linear, a máxima potência elétrica obtida foi de $9,1 \mathrm{~mW}$, quando a técnica SSHI foi utilizada. No caso SSHS, uma potência de $6,8 \mathrm{~mW}$ foi obtida. Se comparada com a potência gerada de um gerador básico (materiais piezelétricos ligados diretamente a ponte retificadora e carga resistiva), obteve-se um incremento de $160 \%$, no caso SSHI e $94 \%$ no caso SSHS, em relação a potência máxima fornecida pelo resistor ótimo do caso básico.

No caso não linear, o circuito SSHS forneceu uma potência de $15,7 \mathrm{~mW}, 101,3 \%$ maior que potência máxima fornecida pelo resistor ótimo do gerador básico. Com o circuito 
SSHI foi obtida uma potência de $25,5 \mathrm{~mW}, 227 \%$ maior que a máxima potência fornecida pelo gerador básico, com sua resistência ótima.

A utilização do circuito chaveado possibilitou a utilização do gerador piezoaeroelástico em velocidades maiores que sua velocidade linear de flutter, devido ao maior controle, o que proporciona maior carregamento aerodinâmico e maiores amplitudes mecânicas e, consequentemente, elétricas. Entretanto, as potências obtidas nos casos não lineares são sempre maiores que as potências dos respectivos casos lineares. A presença da folga no GDL de deslocamento angular induz a maiores oscilações, e com isso, maiores saídas elétricas. Assim, a inclusão de não linearidades é benéfica, para o caso de geração piezelétrica de energia.

Como consequência dos resultados obtidos neste trabalho são apresentadas algumas sugestões para trabalhos futuros:

- Buscar diminuir as perdas por resistência interna da técnica SSDI, apresentada neste trabalho;

- Verificação da quantidade mínima de material piezelétricos para um bom desempenho de controle e coleta de energia;

- Investigação de outras técnicas chaveadas, como o SSDV (Synchronized Switch Damping on Voltage), que pode aumentar a efetividade da técnica SSDI;

- Investigar a possibilidade de uma técnica SSDV autônoma, onde o sinal de tensão elétrica para garantir a inversão completa do sinal elétrico do material piezelétrico, seja fornecido pelos próprios materiais piezelétricos. Neste caso, as técnicas de coleta de energia e controle devem ser utilizadas simultaneamente;

- Expansão das técnicas, aqui apresentadas, para o caso multi-modal e utilização para o controle, e coleta de energia, de oscilações aeroelásticas em asas flexíveis;

- Investigação das técnicas de controle, aqui apresentadas, para casos de asas rotativas, tanto para casos de materiais piezelétricos distribuídos ao longa de uma pá de um helicóptero (ou gerador eólico), quanto para o caso redução de vibrações em sistemas de comando. 


\section{REFERÊNCIAS}

ABDELKEFI, A.; NAYFEH, A. H.; HAJJ, M. R. Modeling and analysis of piezoaeroelastic energy harvesters. Nonlinear Dynamics, v. 67, n. 2, p. 925-939, 2011.

AGNENI, A.; MASTRODDI, F.; POLLI, G. M. Shunted piezoelectric patches in elastic and aeroelastic vibrations. Computers \& Structures, v. 81, n. 2, p. 91-105, 2003.

AKAYDIN, H. D.; ELVIN, N.; ANDREOPOULOS, Y. Energy Harvesting from Highly Unsteady Fluid Flows using Piezoelectric Materials. Journal of Intelligent Material Systems and Structures, v. 21, n. 13, p. 1263-1278, 2010.

ALLEN, J. J.; SMITS, A. J. ENERGY HARVESTING EEL. Journal of Fluids and Structures, v. 15, n. 3-4, p. 629-640, 2001.

ANTON, S. R.; SODANO, H. A. A review of power harvesting using piezoelectric materials (2003-2006). Smart Materials and Structures, v. 16, n. 3, p. R1-R21, 2007.

BADEL, A.; GUYOMAR, D.; LEFEUVRE, E.; RICHARD, C. Piezoelectric Energy Harvesting using a Synchronized Switch Technique. Journal of Intelligent Material Systems and Structures, v. 17, n. 8-9, p. 831-839, 2006.

BADEL, A.; SEBALD, G.; GUYOMAR, D. et al. Piezoelectric vibration control by synchronized switching on adaptive voltage sources: Towards wideband semi-active damping. The Journal of the Acoustical Society of America, v. 119, n. 5, p. 2815-2825, 2006.

BEEBY, S. P.; TUDOR, M. J.; WHITE, N. M. Energy harvesting vibration sources for microsystems applications. Measurement Science and Technology, v. 17, n. 12, p. R175R195, 2006.

BIBO, A.; LI, G.; DAQAQ, M. F. Electromechanical Modeling and Normal Form Analysis of an Aeroelastic Micro-Power Generator. Journal of Intelligent Material Systems and Structures, v. 22, n. 6, p. 577-592, 2011.

BRYANT, M.; GARCIA, E. Modeling and Testing of a Novel Aeroelastic Flutter Energy Harvester. Journal of Vibration and Acoustics, v. 133, n. 1, p. 011010, 2011.

CHEN, G.; CHEN, CHAOQIANG. Semiactive Control of the 20-Story Benchmark Building with Piezoelectric Friction Dampers. Journal of Engineering Mechanics, v. 130, n. 4, p. 393-400, 2004. 
CHEN, S.; WANG, G.; CHIEN, M. Analytical modeling of piezoelectric vibration-induced micro power generator. Mechatronics, v. 16, n. 7, p. 379-387, 2006.

CHEN, Y.-Y.; VASIC, D.; COSTA, F.; WU, W.-J.; LEE, C.-K. A self-powered switching circuit for piezoelectric energy harvesting with velocity control. The European Physical Journal Applied Physics, v. 57, n. 3, p. 30903, 2012.

CHEN, YU-YIN; VASIC, DEJAN; COSTA, FRANÇOIS; LEE, CHIH-KUNG; WU, WENJONG. Self-powered semi-passive piezoelectric structural damping based on zero-velocity crossing detection. Smart Materials and Structures, v. 22, n. 2, p. 025029, 2013.

CLARK, W. W. Semi-active vibration control with piezoelectric materials as variable stiffness actuators. Proceedings of SPIE - The International Society for Optical Engineering. v. 3672, p.123-130, 1999.

CLARK, W. W. Vibration Control with State-Switched Piezoelectric Materials. Journal of Intelligent Material Systems and Structures, v. 11, n. 4, p. 263-271, 2000.

COOK-CHENNAUlT, K. A; THAMBI, N.; SASTRY, A M. Powering MEMS portable devices - a review of non-regenerative and regenerative power supply systems with special emphasis on piezoelectric energy harvesting systems. Smart Materials and Structures, v. 17, n. 4, p. 043001, 2008.

CRAWLEY, E F; LAZARUS, K B. Induced strain actuation of isotropic and anisotropic plates. AIAA journal, v. 29, n. 6, p. 944-951, 1991.

CRAWLEY, EDWARD F; LUIS, J. DE. USE OF PIEZOELECTRIC ACTUATORS AS ELEMENTS OF INTELLIGENT STRUCTURES. AIAA journal, v. 25, n. 10, p. 13731385, 1987.

DELL ISOLA, F.; MAURINI, C.; PORFIRI, M. Passive damping of beam vibrations through distributed electric networks and piezoelectric transducers: prototype design and experimental validation. Smart Materials and Structures, v. 13, n. 2, p. 299-308, 2004.

DELPERO, T.; LILlO, LUIGI DI; BERGAMINI, A.; ERMANNI, P.; LILLO, L DI. Piezoelectric vibration damping using autonomous synchronized switching on inductance. ASME 2011 Conference on Smart Materials, Adaptive Structures and Intelligent Systems, SMASIS 2011. v. 2, p.427-433, 2011. Scottsdale, AZ, United states.

DOSCH, J. J.; INMAN, DANIEL J; GARCIA, EPHRAHIM. Self-sensing piezoelectric actuator for collocated control. Journal of Intelligent Material Systems and Structures, v. 3, n. 1, p. 165-185, 1992. 
DOWELL, E.; EDWARDS, J.; STRGANAC, T. Nonlinear aeroelasticity. Journal of Aircraft, v. 40, n. 5, p. 857-874, 2003.

DUCARNE, J.; THOMAS, O.; DEU, J. F. Structural Vibration Reduction by Switch Shunting of Piezoelectric Elements: Modeling and Optimization. Journal of Intelligent Material Systems and Structures, v. 21, n. 8, p. 797-816, 2010.

DUNNMON, J. A.; STANTON, S. C.; MANN, B. P.; DOWELL, E. H. Power extraction from aeroelastic limit cycle oscillations. Journal of Fluids and Structures, v. 27, n. 8, p. 1182-1198, 2011. Elsevier.

DUTOIT, N. E.; WARDLE, B. L. Performance of Microfabricated Piezoelectric Vibration Energy Harvesters. Integrated Ferroelectrics, v. 83, n. 1, p. 13-32, 2006.

DUTOIT, N. E.; WARDLE, B. L.; KIM, S.-G. Design Considerations for Mems-Scale Piezoelectric Mechanical Vibration Energy Harvesters. Integrated Ferroelectrics, v. 71, n. 1, p. 121-160, 2005.

DÜRR, J. Integration of piezoceramic actuators in fiber-reinforced structures for aerospace applications. Journal of Intelligent Material Systems and Structures, v. 3326, p. 81-92, 1998.

EDBERG, D. L.; BICOS, A. S.; FULLER, C. M.; TRACY, J. J. Theoretical and experimental studies of a truss incorporating active members. Journal of Intelligent Material Systems and Structures, v. 3, n. 2, p. 333-347, 1992.

ERTURK, A.; INMAN, D. J. A Distributed Parameter Electromechanical Model for Cantilevered Piezoelectric Energy Harvesters. Journal of Vibration and Acoustics, v. 130, n. 4, p. 041002, 2008.

ERTURK, A.; BILGEN, O.; FONTENILLE, M.; INMAN, D. J. Piezoelectric Energy Harvesting from Macro-Fiber Composites with an Application to Morphing-Wing Aircrafts. Proceedings of the 19th International Conference of Adaptive Structures and Technologies, 2008.

ERTURK, A.; INMAN, D. An experimentally validated bimorph cantilever model for piezoelectric energy harvesting from base excitations. Smart Materials and Structures, v. 18, n. 2, p. $025009,2009$.

ERTURK, A.; VIEIRA, W. G. R.; MARQUI, C. DE; INMAN, D. J. On the energy harvesting potential of piezoaeroelastic systems. Applied Physics Letters, v. 96, n. 18, p. 184103, 2010. ERTURK, ALPER; INMAN, DANIEL J. Piezoelectric energy harvesting. 1st ed. Chischester: John Wiley \& Sons Ltda, 2011. 
FLEMING, A J; MOHEIMANI, S O R. Adaptive piezoelectric shunt damping. Smart Materials and Structures, v. 12, n. 1, p. 36-48, 2003.

FLEMING, A.J.; BEHRENS, S.; MOHEIMANI, S.O.R. Synthetic impedance for implementation of piezoelectric shunt-damping circuits. Electronics Letters, v. 36, n. 18, p. $1525,2000$.

FORWARD, R. L. Electronic damping of vibrations in optical structures. Applied Optics, v. 18, n. 5, p. 690, 1979.

FULLER, C. C.; ELLIOTT, S.; NELSON, P. A. Active control of vibration. 1st editio ed. San Diego, CA: Academic Press, 1996.

GIURGIUTIU, V. Review of Smart-Materials Actuation Solutions for Aeroelastic and Vibration Control. Journal of Intelligent Material Systems and Structures, v. 11, n. 7, p. $525-544,2000$.

GUYOMAR, D.; BADEL, ADRIEN; LEFEUVRE, ELIE; RICHARD, CLAUDE. Toward energy harvesting using active materials and conversion improvement by nonlinear processing. IEEE Transactions on Ultrasonics, Ferroelectrics and Frequency Control, v. 52, n. 4, p. 584-595, 2005.

GUYOMAR, D.; LALLART, M.; MONNIER, T. Stiffness Tuning Using a Low-Cost Semiactive Nonlinear Technique. IEEE/ASME Transactions on Mechatronics, v. 13, n. 5, p. 604-607, 2008.

GUYOMAR, D.; RICHARD, C.; MOHAMMADI, S. Semi-passive random vibration control based on statistics. Journal of Sound and Vibration, v. 307, n. 3-5, p. 818-833, 2007.

HAGOOD, N.W.; FLOTOW, A. VON. Damping of structural vibrations with piezoelectric materials and passive electrical networks. Journal of Sound and Vibration, v. 146, n. 2, p. 243-268, 1991.

HAGOOD, NESBITT W; CHUNG, W. H.; FLOTOW, ANDREAS VON. Modelling of piezoelectric actuator dynamics for active structural control. Collection of Technical Papers AIAA/ASME/ASCE/AHS/ASC Structures, Structural Dynamics and Materials Conference. p.2242-2256, 1990.

HASSAN, M.; DUBAY, R.; LI, C.; WANG, R. Active vibration control of a flexible one-link manipulator using a multivariable predictive controller. Mechatronics, v. 17, n. 6, p. 311$323,2007$.

HEEG, J. Analytical and Experimental Investigation of Flutter Suppression by Piezoelectric Actuation. NASA Technical Paper 3241, 1993. 
HOLLKAMP, J. J. Multimodal Passive Vibration Suppression with Piezoelectric Materials and Resonant Shunts. Journal of Intelligent Material Systems and Structures, v. 5, n. 1, p. 49-57, 1994.

HOLLKAMP, J. J.; STARCHVILlE, T. F. A Self-Tuning Piezoelectric Vibration Absorber. Journal of Intelligent Material Systems and Structures, v. 5, n. 4, p. 559-566, 1994.

HOPKINS, M. A.; HENDERSON, D. A.; MOSES, R. W. et al. Active vibration-suppression systems applied to twin-tail buffeting. In: J. M. Sater (Ed.); SPIE. v. 3326, p.27-33, 1998. San Diego, CA.

HOUSNER, G. W.; BERGMAN, L. A.; CAUGHEY, T. K. et al. Structural Control: Past, Present, and Future. Journal of Engineering Mechanics, v. 123, n. 9, p. 897-971, 1997.

JI, H.; QIU, J.; BADEL, A.; CHEN, Y.; ZHU, K. Semi-active vibration control of a composite beam by adaptive synchronized switching on voltage sources based on LMS algorithm. Journal of Intelligent Material Systems and Structures, v. 20, n. 8, p. 939-947, 2009a.

JI, H.; QIU, J.; BADEL, A.; ZHU, K. Semi-active Vibration Control of a Composite Beam using an Adaptive SSDV Approach. Journal of Intelligent Material Systems and Structures, v. 20, n. 4, p. 401-412, 2009b.

JI, H.; QIU, J.; ZHU, K.; BADEL, A. Two-mode vibration control of a beam using nonlinear synchronized switching damping based on the maximization of converted energy. Journal of Sound and Vibration, v. 329, n. 14, p. 2751-2767, 2010. Elsevier.

JI, HONGLI; QIU, JINHAO; CHENG, J.; INMAN, DANIEL. Application of a negative capacitance circuit in synchronized switch damping techniques for vibration suppression. In: M. N. Ghasemi-Nejhad (Ed.); Proceedings of SPIE - The International Society for Optical Engineering. v. 7643, p.76432V-76432V-12, 2010.

KHODAYARI, A.; AHMADI, A.; MOHAMMADI, SABER. On physical realization of the wireless semi active real time vibration control based on signal statistical behavior. Sensors and Actuators A: Physical, v. 167, n. 1, p. 102-109, 2011.

KWON, S.-D. A T-shaped piezoelectric cantilever for fluid energy harvesting. Applied Physics Letters, v. 97, n. 16, p. 164102, 2010.

LALLART, M.; BADEL, A.; GUYOMAR, D. Nonlinear Semi-active Damping using Constant or Adaptive Voltage Sources: A Stability Analysis. Journal of Intelligent Material Systems and Structures, v. 19, n. 10, p. 1131-1142, 2007. 
LALLART, M.; GUYOMAR, DANIEL; JAYET, Y. et al. Synchronized switch harvesting applied to selfpowered smart systems: Piezoactive microgenerators for autonomous wireless transmitters. Sensors and Actuators A: Physical, v. 138, n. 1, p. 263-272, $2008 \mathrm{~b}$.

LALLART, M.; LEFEUVRE, É.; RICHARD, C.; GUYOMAR, D. Self-powered circuit for broadband, multimodal piezoelectric vibration control. Sensors and Actuators A: Physical, v. 143 , n. 2, p. 377-382, 2008a.

LARSON, G. D.; ROGERS, P. H. State switched acoustic source. The Journal of the Acoustical Society of America, v. 96, n. 5, p. 3317, 1994.

LARSON, G. D.; ROGERS, P. H.; MUNK, W. State switched transducers: A new approach to high-power, low-frequency, underwater projectors. The Journal of the Acoustical Society of America, v. 103, n. 3, p. 1428-1441, 1998.

LAZARUS, KENNETH B; CRAWLEY, EDWARD F; LIN, C. Y. Fundamental mechanisms of aeroelastic control with control surface and strain actuation. Journal of Guidance, Control, and Dynamics, v. 18, n. 1, p. 10-17, 1995.

LAZARUS, KENNETH B; LUNDSTROM, M. E.; MOORE, J. W.; CRAWLEY, EDWARD F. Packaged strain actuator. ,1997.

LEFEUVRE, E. Semi-passive Piezoelectric Structural Damping by Synchronized Switching on Voltage Sources. Journal of Intelligent Material Systems and Structures, v. 17, n. 8-9, p. 653-660, 2006.

LIANG, J.; LIAO, W. Improved Design and Analysis of Self-Powered Synchronized Switch Interface Circuit for Piezoelectric Energy Harvesting Systems. IEEE Transactions on Industrial Electronics, v. 59, n. 4, p. 1950-1960, 2012.

LU, F.; LEE, H. P.; LIM, S. P. Modeling and analysis of micro piezoelectric power generators for micro-electromechanical-systems applications. Smart Materials and Structures, v. 13, n. 1, p. 57-63, 2004.

MARNEFFE, B. DE; PREUMONT, A. Vibration damping with negative capacitance shunts: theory and experiment. Smart Materials and Structures, v. 17, n. 3, p. 035015, 2008.

MARQUI, C. DE; ERTURK, A.; INMAN, D. J. Piezoaeroelastic Modeling and Analysis of a Generator Wing with Continuous and Segmented Electrodes. Journal of Intelligent Material Systems and Structures, v. 21, n. 10, p. 983-993, 2010.

MARQUI, C. DE; VIEIRA, W. G. R.; ERTURK, A.; INMAN, D. J. Modeling and Analysis of Piezoelectric Energy Harvesting From Aeroelastic Vibrations Using the Doublet-Lattice Method. Journal of Vibration and Acoustics, v. 133, n. 1, p. 011003, 2011. 
MCGOWAN, A. M. R. An examination of applying shunted piezoelectrics to reduce aeroelastic response. CEAS/AIAA/ICASE/NASA Langley International Forum on Aeroelasticity and Structural Dynamics 1999. p.553-572, 1999.

MCGOWAN, A.; WILKIE, W. K.; MOSES, R. W. et al. Aeroservoelastic and structural dynamics research on smart structures conducted at NASA Langley Research Center. Proceedings of SPIE - The International Society for Optical Engineering. v. 3326, p.188-201, 1998.

MOHAMMADI, SABER. Semi-passive vibration control using shunted piezoelectric materials, 2008. Department of Electrical Engineering, Institut National des Sciences Appliquées de Lyon.

MOKRANI, B.; RODRIGUES, G.; IOAN, B.; BASTAITS, R.; PREUMONT, A. Synchronized switch damping on inductor and negative capacitance. Journal of Intelligent Material Systems and Structures, v. 23, n. 18, p. 2065-2075, 2012.

MOSES, R. W. Vertical-tail-buffeting alleviation using piezoelectric actuators: some results of the actively controlled response of buffet-affected tails (ACROBAT) program. Proceedings of SPIE - The International Society for Optical Engineering. v. 3044, p.87-98, 1997.

MOSES, R. W. Contributions to active buffeting alleviation programs by the NASA Langley Research Center. Collection of Technical Papers - AIAA/ASME/ASCE/AHS/ASC Structures, Structural Dynamics and Materials Conference. v. 2, p.1034-1042, 1999.

MYERS, R.; VICKERS, M.; KIM, H.; PRIYA, S. Small scale windmill. Applied Physics Letters, v. 90, n. 5, p. 054106, 2007.

NIEDERBERGER, D.; MORARI, M. An autonomous shunt circuit for vibration damping. Smart Materials and Structures, v. 15, n. 2, p. 359-364, 2006.

OGATA, K. System Dynamics. Upper Saddle River: Pearson/Prentice Hall, 2004.

PETERS, D. A. TOWARD A UNIFIED LIFT MODEL FOR USE IN ROTOR BLADE STABILITY ANALYSES. Journal of the American Helicopter Society, v. 30, n. 3, p. 3242, 1985.

POBERING, S.; SCHWESINGER, N. A novel hydropower harvesting device. Proceedings. 2004 International Conference on MEMS, NANO and Smart Systems, 2004. ICMENS 2004. p.431-436, 2004. IEEE.

PRIYA, S.; CHEN, C.; FYE, D.; ZAHND, J. Piezoelectric Windmill: A Novel Solution to Remote Sensing. Japanese Journal of Applied Physics, v. 44, n. 3, p. L104-L107, 2005. 
RANCOURT, D.; TABESH, A.; FRÉCHETTE, L. Evaluation of Centimeter-Scale Micro Wind Mills: Aerodynamics and Electromagnetic Power Generation. Proceedings of PowerMEMS 2007. p.93-96, 2007.

RICHARD, C.; GUYOMAR, D.; LEFEUVRE, E. Self-powered electronic breaker with automatic switching by detecting maxima or minima of potential difference between its power electrodes. Patent \# PCT/FR2005/003000, Publication number: WO/2007/063194, 2007.

RICHARD, CLAUDE; GUYOMAR, DANIEL; AUDIGIER, D.; BASSALER, H. Enhanced semi passive damping using continuous switching of a piezoelectric device on an inductor. In: V. V. Varadan; N. M. Wereley; Richard O. Claus; et al. (Eds.); Proceedings of SPIE - The International Society for Optical Engineering. v. 3989, p.288-299, 2000.

RICHARD, CLAUDE; GUYOMAR, DANIEL; AUDIGIER, D.; CHING, G. Semi-passive damping using continuous switching of a piezoelectric device. (V. V. Varadan, N. M. Wereley, Y. Bar-Cohen, et al., Eds.)Proceedings of SPIE - The International Society for Optical Engineering, v. 3672, n. March, p. 104-111, 1999. Newport Beach, CA, USA.

RIORDAN, R. H. S. Simulated inductors using differential amplifiers. Electronics Letters, v. 3, n. 2, p. 50, 1967.

ROUNDY, S.; WRIGHT, P. K.; RABAEY, J. A study of low level vibrations as a power source for wireless sensor nodes. Computer Communications, v. 26, n. 11, p. 1131-1144, 2003.

SCHMIDT, V. H. Piezoelectric energy conversion in windmills. IEEE 1992 Ultrasonics Symposium Proceedings. p.897-904, 1992. IEEE.

SHETA, E. F.; MOSES, R. W.; HUTTSELL, L. J. Active smart material control system for buffet alleviation. Journal of Sound and Vibration, v. 292, n. 3-5, p. 854-868, 2006.

SIROHI, J.; MAHADIK, R. Piezoelectric wind energy harvester for low-power sensors. Journal of Intelligent Material Systems and Structures, v. 22, n. 18, p. 2215-2228, 2011.

SODANO, H. A.; PARK, G.; INMAN, D. J. Estimation of Electric Charge Output for Piezoelectric Energy Harvesting. Strain, v. 40, n. 2, p. 49-58, 2004.

SOUSA, V. C.; M ANICÉZIO, M. DE; MARQUI JR, C DE; ERTURK, A. Enhanced aeroelastic energy harvesting by exploiting combined nonlinearities: theory and experiment. Smart Materials and Structures, v. 20, n. 9, p. 094007, 2011.

SOUSA, VAGNER CANDIDO DE; MARQUI JR., CARLOS DE. MODELING AND ANALYSIS OF A BROADBAND PIEZOAEROELASTIC ENERGY HARVESTER. 
Proceedings of COBEM - Brazilian Congress of Mechanical Engineering, 2011. Natal, RN, Brazil.

SUN, J. Q.; JOLLY, M. R.; NORRIS, M. A. Passive, adaptive and active tuned vibration absorbers - a survey. Journal of Mechanical Design, Transactions of the ASME, v. 117 B, p. 234-242, 1995.

TANG, D.; DOWELL, E. H.; VIRGIN, L. N. LIMIT CYCLE BEHAVIOR OF AN AIRFOIL WITH A CONTROL SURFACE. Journal of Fluids and Structures, v. 12, n. 7, p. 839-858, 1998.

TANG, L.; PAÏDOUSSIS, M. P.; JIANG, J. Cantilevered flexible plates in axial flow: Energy transfer and the concept of flutter-mill. Journal of Sound and Vibration, v. 326, n. 1-2, p. 263-276, 2009.

TAYLOR, G. W.; BURNS, J. R.; KAMMANN, S. A.; POWERS, W. B.; WELSH, T. R. The Energy Harvesting Eel: a small subsurface ocean/river power generator. IEEE Journal of Oceanic Engineering, v. 26, n. 4, p. 539-547, 2001.

THEODORSEN, T. General theory of aerodynamics instability and the maechanism of flutter. n. 496, 1935.

UCHINO, K.; ISHII, T. Mechanical damper using piezoelectric ceramics. Nippon Seramikkusu Kyokai Gakujutsu Ronbunshi/Journal of the Ceramic Society of Japan, v. 96, n. 8, p. 863-867, 1988.

VIANA, F. A. C. AMORTECIMENTO DE VIBRAÇÕES USANDO PASTILHAS PIEZELÉTRICAS E CIRCUITOS SHUNT RESSONANTES, 2005. Faculdade de Eng. Mecânica - Universidade Federal de Uberlândia.

WU, S. Piezoeleciric shunts with a parallel R-L circuit for structural damping and vibration control. Smart Structures and Materials 1996: Passive Damping and Isolation. v. 27201259, p.259-269, 1996.

XU, F. J.; YUAN, F. G.; HU, J. Z.; QIU, Y. P. Design of a miniature wind turbine for powering wireless sensors. Proceedings of SPIE 7646. v. 7647, p.764741-764741-9, 2010.

YI, F.; DYKE, S. J. Performance of smart structures. Proceedings of SPIE - The International Society for Optical Engineering. v. 3988, p.94-104, 2000.

YI, F.; DYKE, SHIRLEY J.; CAICEDO, J. M.; CARLSON, J. D. Experimental Verification of Multiinput Seismic Control Strategies for Smart Dampers. Journal of Engineering Mechanics, v. 127, n. 11, p. 1152-1164, 2001. 
ZHAO, Y. Vibration Suppression of a Quadrilateral Plate Using Hybrid Piezoelectric Circuits. Journal of Vibration and Control, v. 16, n. 5, p. 701-720, 2010.

ZHU, L.; CHEN, R.; LIU, X. Theoretical analyses of the electronic breaker switching method for nonlinear energy harvesting interfaces. Journal of Intelligent Material Systems and Structures, v. 23, n. 4, p. 441-451, 2012. 
